\title{
Extractant Impregnated Resins for the Recovery of Aldehydes and Chiral Resolution
}


Graduation committee:

Rector Magnificus, chairman

Prof. dr. ir. A. B. de Haan, promoter

Dr. ir. A. G. J. van der Ham, assistant-promoter

Prof. dr. ing. J. L. Cortina

Prof. dr. ing. H.-J. Bart

Prof. dr. ir. P. J. A. M. Kerkhof

Prof. dr. ir. J. W. M. Nordermeer

Dr. ir. M. van Sint Annaland

\author{
Universiteit Twente \\ Technische Universiteit Eindhoven \\ Universiteit Twente \\ Universidad Politecnica Barcelona \\ Universität Kaiserslautern \\ Technische Universiteit Eindhoven \\ Universiteit Twente \\ Universiteit Twente
}

Publisher:

Gildeprint, Enschede, The Netherlands

Copyright (C) 2008 by K. Babić

All rights reserved. No part of this book may be reproduced or transmitted in any form, or by any means, including, but not limited to electronic, mechanical, photocopying, recording, or otherwise, without the prior permission of the author.

ISBN 978-90-365-2647-0

Author email: katarina.babicegmail.com 


\title{
EXTRACTANT IMPREGNATED RESINS FOR THE RECOVERY OF ALDEHYDES AND CHIRAL RESOLUTION
}

\author{
DISSERTATION
}

to obtain

the doctor's degree at the University of Twente, on the authority of the rector magnificus, prof. dr. W. H. M. Zijm,

on account of the decision of the graduation committee, to be publicly defended on Thursday April 10th 2008 at 15.00 by

\section{Katarina Babić}

born on 17 May 1979

in Belgrade, Serbia 
This dissertation is approved by the promoter:

Prof. dr. ir. A. B. de Haan

and the assistant-promoter

Dr. ir. A. G. J. van der Ham 



\section{Foreword}

\section{Sonnet: To Science}

by Edgar Allan Poe

Science! true daughter of Old Time thou art!

Who alterest all things with thy peering eyes.

Why preyest thou thus upon the poet's heart,

Vulture, whose wings are dull realities?

How should he love thee? or how deem thee wise,

Who wouldst not leave him in his wandering

To seek for treasure in the jewelled skies,

Albeit he soared with an undaunted wing?

Hast thou not dragged Diana from her car?

And driven the Hamadryad from the wood

To seek a shelter in some happier star?

Hast thou not torn the Naiad from her flood, The Elfin from the green grass, and from me

The summer dream beneath the tamarind tree?

My deepest gratitude goes to all the people who contributed to the research presented in the pages to follow: my scientific guides André de Haan and Louis van der Ham, my daily "shoulders for crying” Daleen Venter, Renze Wijntje and Željko Kotanjac, my students (Marko Zubić, Francisco Rodríguez Ropero, Marc Arderiu Girame, Gé Driessen), colleagues and dear friends from the former Separation Technology Group, my family. Thank you for lighting the flame inside me.

Enschede,

K. Babić

April 2008 



\section{Summary}

Many industrial processes result in a number of aqueous streams containing low concentrations of various organics. Sometimes these species are very valuable or they are either contaminants to the environment or reaction poisons. Either way, it is required that they are recovered from these streams, which is difficult to achieve with conventional separation techniques such as extraction or adsorption. In this research the possibilities for the application of Extractant Impregnated Resins (EIRs) to separate polar organic substances from aqueous streams are explored. EIR technology synergistically combines the advantages of both extraction and adsorption. The concept of EIRs is based on the incorporation of a selective extractive reagent into a porous particle by physical impregnation. When contacted with an aqueous solution the reagent forms a complex with a solute. Both reagent and the formed complex remain in the resin phase as they are insoluble in the aqueous phase. The research focuses on separation of aldehydes, which are very frequently processed compounds in chemical and pharmaceutical industry and on the chiral resolution of amino-alcohols, which are important chiral intermediates.

\section{Recovery of aldehydes}

The applicability of Extractant Impregnated Resin (EIR) technology for recovery of aldehydes from aqueous solutions was demonstrated by designing an EIR for the recovery of benzaldehyde. Afterwards, the study was extended to various other aldehydes.

The extraction capabilities of various structurally different aliphatic and aromatic primary amines towards benzaldehyde were tested in liquid-liquid equilibrium experiments and compared. Aliphatic amines showed high affinity. As the most promising extractant, a C18-20 branched aliphatic amine, Primene ${ }^{\circledast} \mathrm{JM}-\mathrm{T}$, was identified. Afterwards, the extraction capability of Primene ${ }^{\circledast}$ JM-T towards several aldehydes with different molecular structure, ranging from straight chain or branched, saturated or unsaturated aliphatic to aromatic and heterocyclic is investigated. The influence of process parameters such as initial concentration of both amine and aldehydes as well as the effect of temperature on the extraction equilibrium are investigated. In addi- 


\section{iv $\|$ Summary}

tion, a simple model incorporating both physical and chemical equilibrium is developed to describe the experimentally observed behaviour. It is noticed that higher initial concentration of the amine results in a higher overall distribution ratio, while for a higher initial concentration of aldehyde, the distribution ratio is lower. The overall extraction performance of the Primene ${ }^{\circledast} \mathrm{JM}$-T depends highly on the molecular structure of the aldehyde. It decreases in the following order: pentanal $>3$-methylbutanal $>$ benzaldehyde $>$ furfural $>2$-methyl-2-butenal. It is observed that the temperature effect on the distribution coefficient is highly dependent on the system studied.

The reactive sorption equilibrium of aldehydes of different molecular structure with polymeric resins impregnated with Primene ${ }^{\circledast}$ JM-T was investigated afterwards. As solid support, commercially available macroporous adsorbents Amberlite XAD-16 and XAD-4 (polystyrene - divinyl benzene), MPP (macroporous polypropylene) and Stamypor (macroporous polyethylene), were used and their performances compared. Their capacities for removal of aldehydes were compared with the non-impregnated resin and the resin impregnated with the non-reactive solvent. It was shown that the addition of a reactive extractant can increase the adsorption capacity of an otherwise poor adsorbent by several orders of magnitude. The increase in amine loading of the particle results in an increase in sorption capacity for aldehydes. Particles with the highest porosity can retain the highest amount of amine, resulting in the highest capacity for the aldehyde recovery. It was observed that the polymeric support material does not significantly influence the sorption of pentanal, 3-methylbutanal and furfural but has a large influence on the sorption of benzaldehyde, most likely due to the additional adsorption on the particle surface. The molecular structure of the aldehyde influences the complexation with the amine and thus has a large influence on the overall sorption capacity, which decreases in following order: pentanal $>3$ methylbutanal $>$ benzaldehyde $>$ furfural. The temperature has an opposite effect on the sorption of pentanal and benzaldehyde. With temperature increase the overall sorption capacity for pentanal decreases, while for benzaldehyde it increases. A simple mathematical model, based on the known liquid-liquid equilibrium behaviour is proposed to explain the experimentally obtained data. The model appeared to successfully predict the equilibrium behaviour for all the aldehydes investigated, while resulting in considerable underestimation for benzaldehyde due to additional adsorption. An attempt to correct the model by including the simple Freundlich isotherm demonstrated that the development of a more detailed approach is needed.

Further development of EIRs for the removal of aldehydes from aqueous solutions required investigation of the sorption kinetics. It was studied for Amberlite XAD-16 and MPP particles impregnated with Primene ${ }^{\circledast}$ JM-T. Initially, the modified shrinking core model was used to determine the rate controlling step and it was shown that this sorption is most likely controlled by both chemical reaction and diffusion in the particle. Afterwards a model, accounting for the simultaneous mass transfer and chemical 
reaction, is developed to describe the process. It is based on the analogy to the diffusion and reaction in a stagnant liquid sphere, but corrected for the porosity and particle properties influencing the diffusion. The developed model describes the kinetic behaviour of the process in the low concentration region rather well. However, in the high concentration region, larger discrepancies are observed. Initially, the influence of the flow rate was investigated to eliminate the effect of the external mass transfer. The influence of the particle morphology was investigated for both physical and reactive sorption. Physical sorption experiments were used to determine the tortuosity $\tau$ that accounts for the particle properties influencing diffusion. It was shown that the diffusion is faster in XAD-16 than in MPP impregnated systems. The reaction rate constant $k_{x}$ was determined by fitting the model to the experimental data. Sorption of benzaldehyde appears to be significantly slower $\left(k_{x} \sim 10^{-4} 1 / \mathrm{mol} \mathrm{s}\right)$ than the sorption of pentanal ( $\left.k_{x} \sim 10^{-3} \mathrm{l} / \mathrm{mol} \mathrm{s}\right)$ due to the slower chemical reaction. The influence of the particle size was investigated for the sorption of pentanal with XAD-16. It was observed that the particle size does influence the diffusion term, but does not have an effect on the reaction rate. On the other hand, the extractant loading influences the reaction rate slightly in the low concentration region, whereas the initial concentration of the solute has a more pronounced effect.

Stability of EIRs regarding the loss of the extractant due to the leakage in water was studied by comparing the solubility of Primene ${ }^{\circledast} \mathrm{JM}-\mathrm{T}$ in water before and after the immobilization. It was shown that immobilization reduces the extractant's solubility in water considerably.

\section{Chiral separation of amino-alcohols}

The applicability of Extractant Impregnated Resin (EIR) technology for chiral separation of amino-alcohols has been evaluated taking phenylglycinol as an archetype model enantiomer. Azophenolic crown ether was used as a versatile enantioselective extractant and 1-phenyloctane was selected as a suitable solvent for this application because of its very low solubility in water. The extraction system was first evaluated by liquid-liquid equilibrium experiments. It was shown that the crown ether dissolved in 1-phenyloctane has an intrinsic selectivity of 11.5. However, due to very low solubility of phenylglycinol in 1-phenyloctane, the overall capacity of the crown ether solution in 1-phenyloctane is limited. The extractant solution was immobilized in macroporous polypropylene particles. Competitive sorption isotherms were obtained from batch experiments and successfully described with a predictive model based on the complexation constants and partitioning ratios, either obtained from literature or from independent experiments. The equilibrium selectivity of these EIRs approaches the intrinsic selectivity for low phenylglycinol concentrations. The $\boldsymbol{d y}$ namic behaviour and stability of the system were examined in column experiments. 


\section{vi $\|$ Summary}

Breakthrough profiles as well as the elution curves of the R enantiomer are less sharp than those of the $\mathrm{S}$ enantiomer proving that the R enantiomer is more strongly retained on the column. Separation of phenylglycinol enantiomers is favoured by using lower feed flow rates. Water containing only atmospheric carbon dioxide proved sufficient to regenerate the column. During multiple cycles the breakthrough profiles remain unchanged indicating that these EIRs will be sufficiently stable. 


\section{Samenvatting}

In een groot aantal industriële processen komen waterige (afval)stromen met lage concentraties organische stoffen voor. Soms zijn deze componenten zeer waardevol, soms zijn ze schadelijk voor het milieu of kunnen ze een katalysator deactiveren. In ieder geval moeten deze componenten verwijderd worden, hetgeen moeilijk is met conventionele scheidingstechnieken zoals extractie of adsorptie. In dit onderzoek is de mogelijkheid van het inzetten van Extractant Geïmpregneerde Deeltjes (EIRs) voor de verwijdering van polaire organische componenten uit waterige stromen onderzocht. EIR technologie combineert de voordelen van zowel extractie als adsorptie. Het concept is gebaseerd op het inbrengen van een selectieve extractant in een poreus deeltje door middel van fysische impregnatie. Wordt de extractant nu in contact gebracht met een waterige oplossing dan vormt de extractant een complex met het solute (de te verwijderen component). Zowel de extractant als het gevormde complex blijven in het deeltje omdat ze niet oplosbaar zijn in water. Het onderzoek richt zich op de scheiding van aldehyden, een belangrijke component in de chemische en farmaceutische industrie en op de chirale scheiding van amino-alcoholen, belangrijke chirale tussenprodukten.

\section{Terugwinning van aldehyden}

De toepasbaarheid van Extractant Geïmpregneerde Deeltjes (EIRs) technologie voor de terugwinning van aldehyden uit waterige stromen is aangetoond door een EIR te ontwerpen voor de terugwinning van benzaldehyde. Daarna is het onderzoek uitgebreid naar andere aldehyden.

Het extractievermogen van verschillende alifatische en aromatische primaire amines voor benzaldehyde is onderzocht met vloeistof-vloeistofevenwichtsexperimenten. Alifatische amines tonen een hoge affiniteit. Als meest veelbelovende extractant is een C18-C20 vertakte alifatische amine, Primene ${ }^{\circledR} \mathrm{JM}-\mathrm{T}$, geïdentificeerd. Hierna is dit amine nader onderzocht op geschiktheid voor de verwijdering van andere aldehyden met verschillende moleculaire structuren. Hierbij zijn rechte en vertakte ketens, verzadigde en onverzadigde alifatische, aromatische en heterocyclische verbindingen onderzocht. De invloed van procesparameters zoals de initiële concentratie van zowel 


\section{viii || Samenvatting}

het amine en het aldehyde alsmede de temperatuur op het extractie-evenwicht is onderzocht. Aanvullend hierop is een eenvoudig model ontwikkeld op basis van fysische en chemische reactie-evenwichten voor het beschrijven van de experimentele resultaten. Deze resultaten laten zien dat een hogere initiële concentratie van het amine tot een hogere overall verdelingscoëfficiënt leidt. Daarentegen leidt een hogere aldehyde concentratie tot een verlaging van de verdelingscoëfficiënt. De algehele prestatie van de extractant Primene ${ }^{\circledast}$ JM-T wordt sterk bepaald door de moleculaire structuur van het aldehyde. Deze neemt af in de volgorde: pentanal $>3$-methylbutanal $>$ benzaldehyde $>$ furfural $>2$-methyl-2-butenal. Resultaten laten zien dat het effect van de temperatuur op de verdelingscoëfficiënt sterk afhangt van het onderzochte systeem.

Het vervolgonderzoek richtte zich op de reactieve sorptie-evenwichten van verschillende aldehyden met Primene ${ }^{\circledast} \mathrm{JM}-\mathrm{T}$ dat door impregnatie is ingebracht in polymere deeltjes. Als dragermateriaal is gekozen voor commercieel beschikbare hoog poreuze adsorbentia zoals Amberlite XAD-16 en XAD-4 (op basis van polystyreendivinylbenzeen), MPP (macroporeus polypropyleen) en Stamypor (macroporeus polyethyleen). Deze zijn onderzocht en hun prestaties onderling vergeleken. Hun extractiecapaciteit is vergeleken met die van niet geïmpregneerde deeltjes en met deeltjes geïmpregneerd met het niet reactieve oplosmiddel. Hiermee is aangetoond dat de toevoeging van een reactieve extractant aan een normaliter slecht adsorberend poreus deeltje de adsorptiecapaciteit kan verhogen met verscheidene orde groottes. Een toename van de hoeveelheid amine in het deeltje resulteert in een hogere sorptie capaciteit voor aldehyden. Deeltjes met de hoogste porositeit kunnen de grootste hoeveelheid amine bevatten wat resulteert in de hoogste capaciteit voor aldehyde verwijdering. Resultaten laten zien dat het polymere dragermateriaal van de deeltjes het sorptiegedrag van de aldehyden pentanal, 3-methylbutanal en furfural niet significant beïnvloed, dit in tegenstelling tot de sorptie van benzaldehyde, wat waarschijnlijk komt door additionele adsorptie van benzaldehyde aan het oppervlak van de deeltjes. De moleculaire structuur van het aldehyde heeft een grote invloed op de complexatie met het amine en daarom ook op de sorptiecapaciteit van het geïmpregneerde deeltje, die afneemt in de volgorde pentanal $>3$-methylbutanal $>$ benzaldehyde $>$ furfural. Het effect van de temperatuur op het sorptie-evenwicht is tegengesteld voor pentanal en benzaldehyde. Voor pentanal neemt de sorptiecapaciteit af met een temperatuurstijging, voor benzaldehyde neemt die toe. Een eenvoudig wiskundig model gebaseerd op het bekende vloeistof-vloeistof evenwichtsgedrag is voorgesteld om het experimentele gedrag te verklaren. Dit model geeft een goede beschrijving van het sorptie-evenwicht van de onderzochte aldehyden, echter voor benzaldehyde geeft het model een veel te lage waarde voor de capaciteit, waarschijnlijk omdat er een extra adsorptiebijdrage is van het dragermateriaal zelf. Een poging om het model hiervoor te corrigeren met behulp van de Freundlich isotherm liet zien dat een meer gedetailleerde aanpak vereist is. 
Voor de verdere ontwikkeling van EIRs voor de verwijdering van aldehyden uit waterige systemen is ook kennis vereist van de sorptiekinetiek. Dit is onderzocht voor Amberlite XAD-16 en MPP deeltjes geïmpregneerd met Primene ${ }^{\circledast}$ JM-T. Initieel is gebruik gemaakt van het 'modified shrinking core' model om de snelheidsbepalende stap te bepalen. Resultaten laten zien dat de sorptiesnelheid zeer waarschijnlijk zowel door de chemische reactie, alsmede door de diffusie van het solute in het deeltje wordt gelimiteerd. Hierna is een model opgesteld gebaseerd op de gelijktijdige stofoverdracht en chemische reactie om het process te beschrijven. Het is gebaseerd op de analogie met diffusie en chemische reactie in een stagnante druppel, echter gecorrigeerd voor de porositeit en andere eigenschappen van het deeltje. Dit model geeft een goede beschrijving van de sorptiesnelheid in het lage concentratiegebied. Echter, in het hoge concentratiegebied is het verschil tussen het model en de experimentele resultaten groter. Eerst is het effect van de vloeistofsnelheid op de sorptiesnelheid onderzocht om het effect van externe stofoverdracht te elimineren. De invloed van de deeltjesmorfologie is onderzocht voor zowel fysische als reactive sorptie. Fysische sorptie experimenten zijn gebruikt om de tortuositeit $\tau$ vast te stellen, om de deeltjeseigenschappen van invloed op de diffusie in acht te nemen. Resultaten laten zien dat de diffusie in XAD-16 sneller is dan in MPP geïmpregneerde systemen. De reactiesnelheidsconstante $k_{x}$ is bepaald door het model te fitten aan de experimentele data. De sorptiesnelheid van benzaldehyde is aanzienlijk langzamer $\left(k_{x} \sim 10^{-4} \mathrm{l} / \mathrm{mol}\right.$ s) dan die van pentanal $\left(k_{x} \sim 10^{-3} \mathrm{l} / \mathrm{mol} \mathrm{s}\right)$ door een veel langzamere chemische reactie. Het effect van de deeltjesdiameter van XAD-16 is onderzocht voor de sorptie van pentanal. Resultaten laten zien dat de deeltjesdiameter wel invloed heeft op de diffusietransportterm, maar niet op de reactiesnelheid. Aan de andere kant, in het lage concentratiegebied heeft de extractantbelading van het deeltje een klein effect op de reactiesnelheid terwijl de initiële concentratie van het solute een sterker effect heeft.

De stabiliteit van EIRs ten aanzien van extractant verliezen aan het water is ook nader onderzocht door de oplosbaarheid van Primene ${ }^{\circledast} \mathrm{JM}-\mathrm{T}$ in water te bepalen voor en na immobilisatie in het deeltje. De resultaten tonen aan dat immobilisatie de oplosbaarheid van de extractant aanzienlijk heeft verlaagd.

\section{Chirale scheiding van amino-alcoholen}

De toepassing van Extractant Geimpregneerde Deeltjes (EIRs) technologie voor chirale scheiding van amino-alcoholen is onderzocht voor het modelenantiomeer fenylglycinol. Hiervoor is een azofenol kroonether geselecteerd als enantiomeerselectieve extractant en is 1-fenyloctaan gekozen als geschikt oplosmiddel voor deze toepassing, omdat het een zeer lage water oplosbaarheid heeft. Dit extractiesysteem is eerst geëvalueerd door middel van vloeistof-vloeistofevenwichtsexperimenten. Resultaten tonen dat de kroonether opgelost in 1-fenyloctaan een intrinsieke selectiviteit heeft 


\section{x $\quad \mid \quad$ Samenvatting}

van 11,5. Echter, door de erg lage oplosbaarheid van fenylglycinol in 1-fenyloctaan, is de overall capaciteit van het systeem beperkt. Het extractiemengsel is vervolgens geïmmobiliseerd in macroporeuze polypropyleendeeltjes. Competitieve sorptie-isothermen zijn verkregen met batch experimenten en deze resultaten zijn succesvol beschreven met een voorspellend model, gebaseerd op complexatieconstanten en partitiecoëfficiënten afkomstig uit de literatuur of van onafhankelijke experimenten. De evenwichtsselectiviteit van deze EIRs benadert die van de intrinsieke selectiviteit voor lage fenylglycinol concentraties. Het dynamisch gedrag en stabiliteit van dit systeem zijn onderzocht doormiddel van kolomexperimenten. Zowel de doorbraakcurves als de elutiecurves van het R-enantiomeer zijn minder scherp dan die van het S-enantiomeer, waarmee is aangetoond dat het R-enantiomeer sterker aan de kolom wordt gebonden dan het S-enantiomeer. De scheiding van de fenylglycinol enantiomeren wordt beter bij lage vloeistofsnelheden. Voor de regeneratie bleek water verzadigd met atmosferisch $\mathrm{CO}_{2}$ voldoende effectief. Gedurende meerdere cycli bleven de doorbraakcurves onveranderd, hetgeen aangeeft dat de EIRs voldoende stabiel zullen zijn. 


\section{Contents}

1 Extractant Impregnated Resins 1

1.1 Recovery of low concentration organics from aqueous streams . . . . . . 3

1.2 Extractant Impregnated Resins (EIRs) . . . . . . . . . . . . . . . . 3

1.3 Development history and application potential . . . . . . . . . 5

1.4 Objectives and scope of this research $\ldots \ldots \ldots \ldots$

References .......................... 8

2 Recovery of benzaldehyde using EIRs 13

2.1 Introduction . . . . . . . . . . . . . . . 15

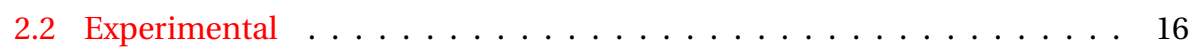

2.3 Results and discussion . . . . . . . . . . . . . . . . . . 19

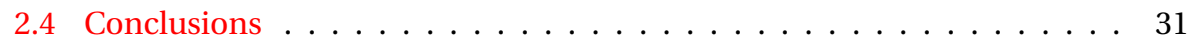

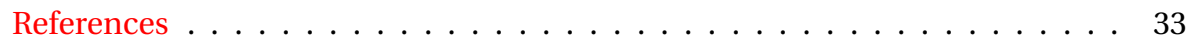

3 Reactive extraction of aldehydes 37

3.1 Introduction . . . . . . . . . . . . . . . . 39

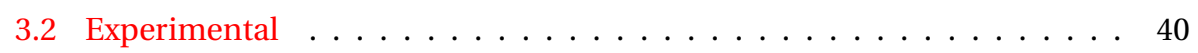

3.3 Model .......................... 41

3.4 Results and discussion . . . . . . . . . . . . . . . . 43

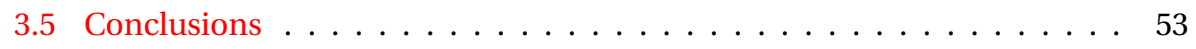

References ....................... 54

4 Sorption equilibrium $\quad 57$

4.1 Introduction . . . . . . . . . . . . . . . . 59 


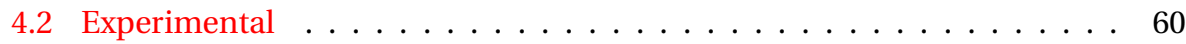

4.3 Mathematical model . . . . . . . . . . . . . . . . . . . 61

4.4 Results and discussion . . . . . . . . . . . . . . . . . 63

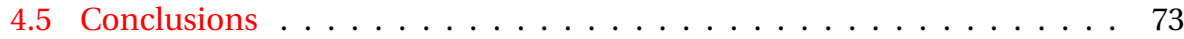

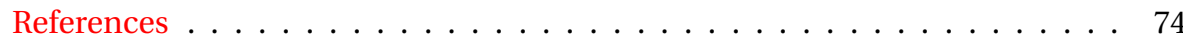

5 Sorption kinetics $\quad 77$

5.1 Introduction . . . . . . . . . . . . . . . . 79

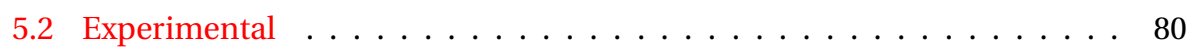

5.3 Results and discussion . . . . . . . . . . . . . . . 86

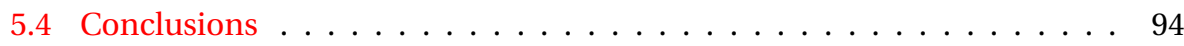

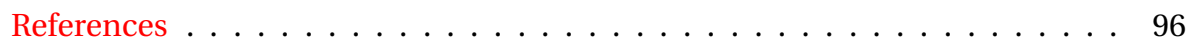

6 Chiral separation of amino-alcohols $\quad 99$

6.1 Introduction . . . . . . . . . . . . . . . . . . . . . 101

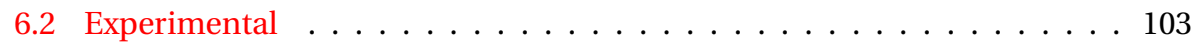

6.3 Results and discussion . . . . . . . . . . . . . . . . . . 106

6.4 Conclusions . . . . . . . . . . . . . . . . . . . . . . 117

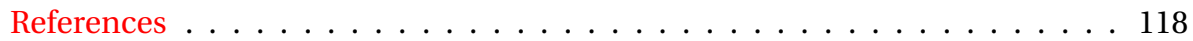

7 Conclusions and recommendations 123

7.1 Conclusions . . . . . . . . . . . . . . . . . . . . . 125

7.2 Recommendations for future work . . . . . . . . . . . . . 126

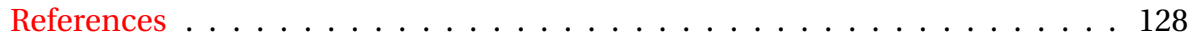

List of publications and conference contributions $\quad 131$

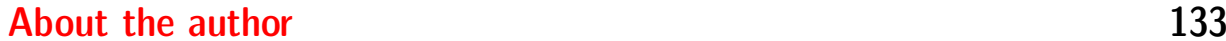




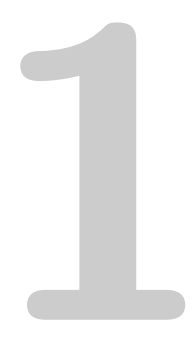

\section{Extractant Impregnated Resins}

Many industrial processes result in a number of aqueous streams containing low concentrations of various species. Sometimes these species are very valuable or they are either contaminants to the environment or poisons for the reaction. Either way, it is required that they are recovered from these streams, which is difficult to achieve with conventional separation techniques such as extraction or adsorption. Despite their limitations, both technologies have distinct advantages which are desirable for a potential process. In Extractant Impregnated Resins (EIRs) these advantages are synergistically combined. This chapter first explains the drawbacks and advantages of the conventional separation techniques that led to the development of EIRs and then motivates the research presented in this thesis. 



\subsection{Recovery of low concentration organics from aqueous streams}

$\mathrm{T}$ HE CURRENT LEGISLATIONS are more and more decreasing the allowed concentrations of contaminants in plant effluents. Due to increasingly tight regulations concerning minimization of the environmental damage, nowadays chemical industry is pushed towards development of "closed cycle" processes, where all waste streams are recycled [1]. Besides the ecological concern, imposed by the statutory requirements, the ultimate driving force for the industry is the reduction of the production costs, resulting in higher profits. Waste streams reused in the process bring additional cost benefits encouraging the investments in the development of suitable technologies. Contaminants are usually present in small quantities in the industrial effluents, resulting in rather high costs for their removal. Furthermore, modern industrial tendencies are shifting the production of chemicals towards the use of renewable and reusable resources. As a result fermentation has been recognized as a leading technology in that direction [2]. However, the recovery of chemicals from the fermentation broth presents a challenge due to the broad range of species present and in addition, fermentation effluents are largely diluted.

\subsection{Extractant Impregnated Resins (EIRs)}

The application of classical separation techniques such as distillation and extraction for processing very dilute solutions is rather unfeasible due to high costs and very low yields. Techniques such as reactive extraction and adsorption have been investigated and used for this type of separations, but also suffer from significant drawbacks. Reactive extraction usually has problems with phase separation due to the emulsion formation. To increase the contact area it is necessary to vigorously mix the phases, which leads to the loss of reagent. In addition, reactive extraction is not very feasible for the recovery of species present in low concentration due to the high excess of solvent/reactant required and not very suitable for recovering species from viscous solutions. Concerning adsorption, nonfunctionalized resins tend to have low capacity and/or low selectivity. Better performing chelating, ion exchange or enantioselective resins are very expensive due to their difficult and time consuming preparation. Therefore the need exists for the development of a new technique able to fulfill the targeted requirements. The suitable technique should avoid the mentioned disadvantages of the conventional techniques but maintain their advantages. For instance, adsorption is rather suitable for processing dilute solutions, the used equipment is relatively simple and easy to operate and there is no problem of liquid/solid phase separation. On the other hand, reactive extractants have high capacity and selectivity 


\section{4 || Chapter 1}

towards the targeted compounds and usually offer high mass transfer rates. Additionally, a reagent in a "free solution" is much cheaper than chemically functionalized adsorbents.

A possible solution was proposed by Warshawsky [3], Grinstead [4] and Kroebel and Meyer [5]. They developed solvent/extractant impregnated resins (SIRs or EIRs) as a synergistic combination of adsorption and reactive extraction. The extractant impregnated resin concept is based on the physical impregnation of a selective extractant in a porous adsorbent. In order to apply this technology for removal of components from water it is necessary to fill the pores with a water-insoluble organic phase. This would give sufficient capacity and selectivity to remove apolar organics such as hydrocarbons from water. However, polar organics do not show a strong tendency to transfer from an aqueous to an organic phase. To improve their affinity for the organic phase it is enriched with a complexing agent capable of reacting with the targeted molecules and forming a complex which remains in the organic phase (Figure 1.1). This reaction should be reversible but sufficiently strong to increase the solute's affinity for the organic phase by several orders of magnitude to obtain an economically feasible process.

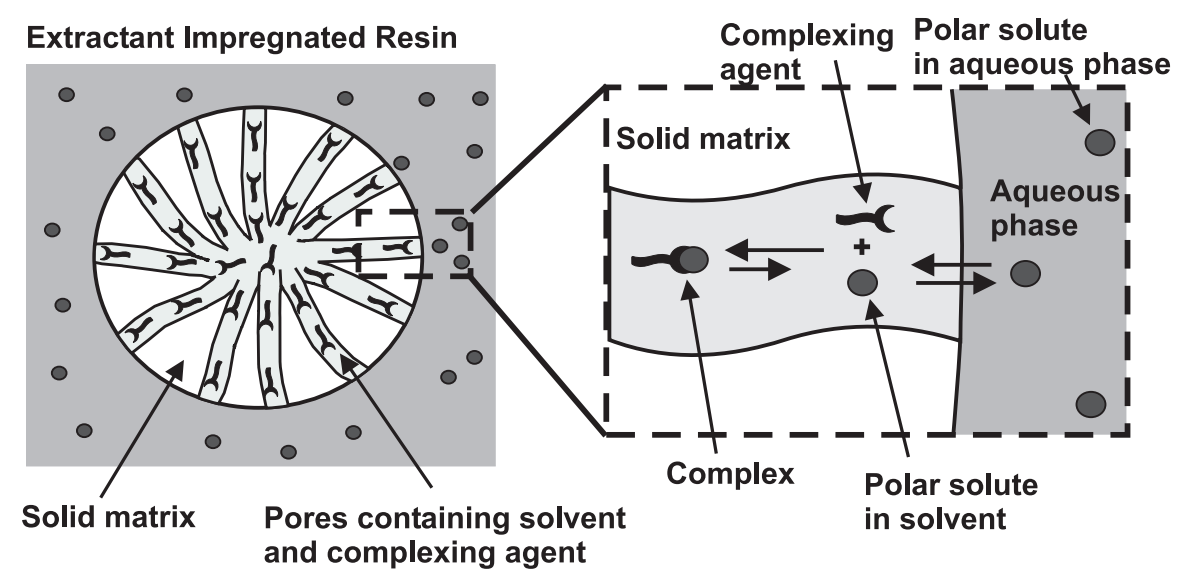

Figure 1.1: Extractant impregnated resins

A very important feature of EIR technology is its flexibility. For classical adsorbents functional groups need to be introduced chemically for each specific application, thus it is rater difficult to vary the type and the amount of functional groups. In the case of EIRs, the introduction of the complexing agent is done by physical impregnation, usually by soaking the polymeric particle in an organic solution containing the complexing agent. Thus the preparation procedure is much simpler and more flexible. Furthermore, a large number of extractants is already known from solvent extraction 
studies, allowing straightforward implementation of data from liquid-liquid studies. This poses a significant advantage over related membrane techniques, for instance solvent-polymeric membranes or liquid membranes, where the permeation selectivity is very much dependent on the permeation rate of the species inside the membrane and not on the distribution coefficient, i.e. phase equilibrium. Additionally, in comparison with classical adsorbents, EIRs should be able to have a higher capacity because the whole pore volume instead of only the pore surface is utilized. The impregnated extractants have a strong affinity towards the polymeric support, but keep the extracting properties (capacity and selectivity) as in the liquid state [6-8].

\subsection{Development history and application potential}

Extractant Impregnated Resins were first developed in the early seventies of the last century for the removal of traces of metals from aqueous streams. There are numerous papers published on this topic, which were extensively reviewed by Cortina and Warshawsky [9]. However, a major drawback of this technique, the loss of the extractant by partitioning into the aqueous medium, hampered its larger commercial application. Even though the solubility of the extractant in water is usually very low (typically a few ppm) and even reduced by immobilization [10], it eventually results in the loss of capacity. Therefore, the application of impregnated resins might be feasible only for the recovery of high value species such as precious and radioactive metals [11, 12]. To make this technique also interesting for low-priced species an additional effort has to be made to reduce the extractant losses below ppb level [8]. Several techniques were explored for the stabilization of these resins like "wet drying" and post-impregnation encapsulation or coating the resin beads with a semi-permeable polymer layer [1315].

As pointed out by Warshawsky in 1981 [8], the work in some related techniques such as solvent-polymeric membranes $[16,17]$ suggested the potentially interesting application of impregnated resins in the field of separation of organics.

The first commercial application of EIRs for organics recovery was for the treatment of effluent water of a natural gas plant contaminated with hydrocarbons, developed by Akzo Nobel, the Netherlands in 1992 [18]. The success of a pilot plant study in Harlingen (the Netherlands) led to commercialization of this technique under the name of Macro Porous Polymer Extraction (MPPE). In this case, the polymer particles are filled with a non-reactive organic solvent. When the effluent water passed through the column filled with these MPPE particles all hydrocarbons with relatively high affinity for the organic solvent are removed. Periodically, particles are regenerated with low pressure steam. Volatized hydrocarbons are condensed, separated by gravity and then sold as a product, whereas the water phase is recycled to the system. 


\section{$6 \quad$ Chapter 1}

Besides treatment of process water, MPPE was also applied for groundwater remediation [19]. It proved to be very efficient for the removal of wide varieties of aliphatic, aromatic and halogenated hydrocarbons.

For the more challenging separation of polar organics from aqueous solutions, a simple non-reactive solvent immobilized in a particle would not give a satisfactory performance. Thus a reactive agent has to be introduced. In that case, the EIR technique can also be applied for the removal of polar water contaminants such as phenols [20] and aldehydes [10] and potentially many others.

Besides environmental applications, EIRs are very suitable for the in-situ removal of products from a reaction medium, typically from fermentation broths. This is very often vital if reaction inhibitors are formed or if a shift of the reaction in the desired direction is needed. Moreover, in certain cases when the extractant is toxic to the reaction environment it is beneficial to immobilize it in a particle and in that way minimize the influence on the environment. It was shown that phenols can successfully be removed from the fermentation broth with EIRs which also strongly enhanced the productivity [21]. Addition of the impregnated particles to the fermentation broth resulted in a fourfold increase in the amount of phenol produced. In addition, for the same reason the EIRs described for the recovery of aldehydes like benzaldehyde and furfural [22] can be used. This application is especially interesting in the production of ethanol by fermentation during which furfural is produced as a by-product. Since it strongly inhibits the fermenting micro-organisms, it needs to be removed from the reaction broth [23].

Recovery of carboxylic and amino acids, typically produced by fermentation, from aqueous solutions with EIRs presents another potential application. This subject was extensively studied by several authors. As extractants for the carboxylic acids tertiary amines (like TOA) [24-26] or organophosphorus extractants (like TBP) [27] are often used. Amino acids are often recovered with resins impregnated with quaternary ammonium salts (like TOMAC or TCMAC) [28, 29]. As a solid support macroporous nonfunctionalized polystyrene-divinylbenzene resins are typically used.

On the other hand, amino acids are typically found as racemic mixtures. The resolution of racemic mixtures is a rather challenging separation problem. This separation is usually done by chromatography, which requires specific enantioselective adsorbents. These adsorbents are however very expensive due to a time consuming preparation and besides, very often suffer from very low capacity [30]. The research published for some related separation techniques like supported liquid membranes [31-33] and ligand exchange chromatography [34] pointed out an interesting possibility of using EIRs for the separation of enantiomers. To achieve this separation, particles have to be impregnated with an optically active reagent. 


\subsection{Objectives and scope of this research}

The goal of this research is to explore the possibilities for the application of Extractant Impregnated Resins for the separation of polar organic substances from aqueous streams. The polar organics need to be recovered from these streams either to prevent contamination of the environment or the reaction medium or to obtain a valuable product. In this light, the research focuses on separation of aldehydes, which are very frequently processed compounds in chemical and pharmaceutical industry and on the chiral resolution of amino-alcohols, which are important chiral intermediates. To achieve the set goal the following major topics should be addressed:

- Identification of a suitable extractant/solvent system

- Equilibrium and kinetic performance of impregnated resins

- Resin stability

Chapter 2 presents a proof of principle study for the recovery of benzaldehyde from aqueous streams using EIRs. First an extractant suitable for this application, based on both physical properties and reactivity towards benzaldehyde, is selected. Subsequently its performance is evaluated in both liquid-liquid and impregnated resin systems. In addition, the stability of such impregnated resins is investigated by studying the influence of the polymeric support on the solubility of the extractant in water.

In Chapter 3 the extraction capability of the previously selected extractant was tested towards several aldehydes with different molecular structure, ranging from straight chain or branched, saturated or unsaturated aliphatic to aromatic and heterocyclic. The equilibrium isotherms in a liquid-liquid system are determined. The influence of the process parameters such as initial concentration of both extractant and aldehydes as well as the effect of temperature on the extraction equilibrium are investigated.

Chapters 4 and 5 present the study of the equilibrium and kinetic performance of impregnated resins for the recovery of aldehydes from aqueous solutions. Several different macroporous supports are tested and their influence on the sorption investigated. Based on an analogy with the liquid-liquid extraction a predictive description of the sorption is developed.

In Chapter 6 the field of potential applications of extractant impregnated resins is extended towards separation of chiral molecules. A proof of principle study is presented for the separation of the enantiomers of phenylglycinol. Even though a suitable chiral selector could be found in literature, the extraction system had to be adjusted for the use in this technique by selection of an appropriate diluent that should have 


\section{8 || Chapter 1}

desirable physical properties but should not hamper the enantioselectivity of the chiral reagent. A potentially applicable system is tested first through liquid-liquid experiments, after which the competitive sorption isotherms of phenylglycinol enantiomers on the established EIRs are determined. The dynamic behaviour and the stability of the system are investigated in column experiments.

The last chapter of this thesis (Chapter 7) summarizes the main conclusions following from the presented research and proposes future research steps towards a successful industrial application.

\section{References}

[1] S. Kentish and G. Stevens. Innovations in separations technology for the recycling and re-use of liquid waste streams. Chemical Engineering Journal, 84, 149-159 (2001). 1.1

[2] A. S. Kertes and C. J. King. Extraction chemistry of fermentation product carboxylic acids. Biotechnology and Bioengineering, 28, 269-282 (1986). 1.1

[3] A. Warshawsky. South African Patent Application 71/5637 (1971). 1.2

[4] R. Ginstead. Final report by the Dow Chemical Co. on contract No. 14-12-808 to the Water Quality Office of U.S. Environmental Protection Administration (1971). 1.2

[5] R. Kroebel and A. Meyer. Production of absorbents, West German Patent Application 2,162,951 (1971). 1.2

[6] J. Cortina, N. Miralles, A. Sastre, M. Aguilar, A. Profumo and M. Pesavento. Solvent impregnated resins containing di(2,44-trimethylpentyl)phosphinic acid. I. Comparative study of di(2,44-trimethylpentyl)phosphinic acid adsorbed on Amberlite XAD-2 and dissolved in toluene. Reactive Polymers, 21, 89-101 (1993). 1.2

[7] J. Cortina, N. Miralles, A. Sastre, M. Aguilar, A. Profumo and M. Pesavento. Solvent impregnated resins containing di(2,44-trimethylpentyl)phosphinic acid. II. Study of the distribution equilibria of $\mathrm{Zn}, \mathrm{Cu}$ and Cd. Reactive Polymers, 21, 103116 (1993). 1.2

[8] A. Warshawsky. Extraction with Solvent-Impregnated Resins, volume 8 of Ion Exchange and Solvent Extraction, pages 229-310. Marcel-Dekker, New York (1981). $1.2,1.3$

[9] J. L. Cortina and A. Warshawsky. Ion Exchange and Solvent Extraction, volume 13 of Ion Exchange and Solvent Extraction, chapter Developments in solid-liquid extraction by Solvent Impregnated Resins, pages 195-293. Dekker, New York (1997). 1.3 
[10] K. Babić, L. van der Ham and A. de Haan. Recovery of benzaldehyde from aqueous streams using extractant impregnated resins. Reactive and Functional Polymers, 66(12), 1494-1505 (2006). 1.3

[11] J. Cortina, E. Meinhardt, O. Roijals and V. Marti. Modification and preparation of polymeric adsorbents for precious-metal extraction in hydrometallurgical processes. Reactive and Functional Polymers, 32(2), 149-165 (1998). 1.3

[12] S. El-Dessouky and E. Borai. Extraction chromatography of thorium ion by solid phase impregnated resins containing bi-functional organic extractants. Journal of Radioanalitycal and Nuclear Chemistry, 268(2), 247-254 (2006). 1.3

[13] D. Muraviev, L. Ghantous and M. Valiente. Stabilization of solvent-impregnated resin capacities by different techniques. Reactive and Functional Polymers, 38, 259-268 (1998). 1.3

[14] S. Alexandratos and K. Ripperger. Synthesis and characterization of high-stability solvent-impregnated resins. Industrial and Engineering Chemistry Research, 37, 4756-4760 (1998). 1.3

[15] A. Trochimczuk, N. Kabay, M. Arda and M. Streat. Stabilization of solvent impregnated resins (SIRs) by coating with water soluble polymers and chemical crosslinking. Reactive and Functional Polymers, 59, 1-7 (2004). 1.3

[16] I. Cabasso, J. Jagur-Grodzinski and D. Vofsi. Polymeric alloys of polyphosphonates and acetyl cellulose. I. Sorption and diffusion of benzene and cyclohexane. Journal of Applied Polymer Science, 18, 2117-2136 (1974). 1.3

[17] I. Cabasso, J. Jagur-Grodzinski and D. Vofsi. A study of permeation of organic solvents through polymeric membranes based on polymeric alloys of polyphosphonates and acetyl cellulose. II. Separation of benzene, cyclohexene and cyclohexane. Journal of Applied Polymer Science, 18, 2137-2147 (1974). 1.3

[18] H. Pars and D. Meijer. Removal of dissolved hydrocarbons from poduction water by Macro Porous Polymer Extraction (MPPE), SPE 46577. In SPE International Conference on Health, Safety and Environment in Oil and Gas Exploration and Production, held in Caracas (1998). 1.3

[19] D. Billet. MPPE technology for the elimination of organic components dispersed and dissolved in groundwater. In Third international symposium on water, held in Cannes (2001). 1.3

[20] H. Gao and Y. Su. Solvent extraction and adsorption by extracting resins of phenol. Huadong Huagong Xueyuan Xuebao, 17(3), 249-254 (1991). 1.3

[21] C. van den Berg, J. Vente, J. de Bont, D. Verdoes and L. van der Wielen. In-situ product removal with solvent-impregnated resins enhances the phenol production by fermentation. In SPICA 2006, Innsbruck, Austria, Book of Abstracts (2006). 1.3 


\section{$10 \quad$ Chapter 1}

[22] K. Babić, A. van der Ham and A. B. de Haan. Sorption equilibrium for the removal of aldehydes from aqueous streams with Primene ${ }^{\circledR}$ JM-T impregnated resins. Manuscript in preparation. 1.3

[23] J. R. Weil, B. Dien, R. Bothast, R. Hendrickson, N. S. Mosier and M. R. Ladisch. Removal of fermentation inhibitors formed during pretreatment of biomass by polymeric adsorbents. Industrial and Engineering Chemistry Research, 41, 61326138 (2002). 1.3

[24] M. Traving and H.-J. Bart. Recovery of organic acids using ion-exchangerimpregnated resins. Chemical Engineering Technology, 5(10), 997-1003 (2002). 1.3

[25] R.-S. Juang and H.-L. Chang. Distribution equilibrium of citric acid between aqueous solutions and tri-n-octylamine-impregnated macroporous resins. Industrial and Engineering Chemistry Research, 34, 1294-1301 (1995). 1.3

[26] R.-S. Juang and T.-C. Chou. Sorption of citric acid from aqueous solutions by macroporous esins containing a tertiary amine - Equilibria. Separation Science and Technology, 31(10), 1409-1425 (1996). 1.3

[27] M. O. Ruiz, J. L. Cabezas, I. Escudero, J. R. Alvarez and J. Coca. Valeric acid extraction with tri-N-butyl phosphate impregnated in a macroporous resin. I. Equilibrium and mass transfer rates. Separation Science and Technology, 39(1), 77-95 (2004). 1.3

[28] M. O. Ruiz, J. L. Cabezas, I. Escudero, J. R. Alvarez and J. Coca. $\alpha$-Phenylglycine extraction with a trialkylmethylammonium chloride-impregnated macroporous resin. 1. Equilibrium. Trans IChemE, 40(A), 529-536 (2002). 1.3

[29] A. Kostova and H.-J. Bart. Equilibrium study of amino acid reactive sorption with solvent impregnated resins, Part I. Solvent Extraction and Ion Exchange, 25, 109126 (2007). 1.3

[30] E. Francotte. Enantioselective chromatography as a powerful alternative for the preparation of drug enantiomers. Journal of Chromatography A, 906, 379-397 (2001). 1.3

[31] T. Shinbo, T. Yamaguchi, H. Yanagishita, K. Sakaki, D. Kitamoto and M. Sugiura. Supported liquid membranes for enantioselective transport of amino acid mediated by chiral crown ether - Effect of membrane solvent on transport rate and membrane stability. Journal of Membrane Science, 84, 241-248 (1993). 1.3

[32] M. Pietraszkiewicz, M. Kozbial and O. Pietraszkiewicz. Chiral discrimination of amino acids and their potassium or sodium salts by optically active crown ether derived from D-mannose. Journal of Membrane Science, 138, 109-113 (1998). 1.3

[33] M. Kozbial, M. Pietraszkiewicz and O. Pietraszkiewicz. Chiral discrimination of amino acids by an optically active crown ether studied by HPLC, extraction and 
liquid membrane transport experiments. Journal of Inclusion Phenomena and Molecular Recognition in Chemistry, 30, 69-77 (1998). 1.3

[34] V. Davankov. Chiral selectors with chelating properties in liquid chromatography: fundamental reflections and selective review of recent developments. Journal of Chromatography A, 666, 55-76 (1994). 1.3 



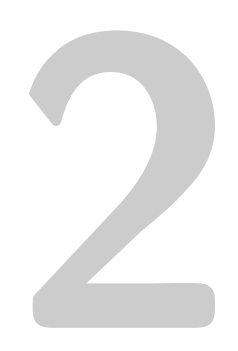

\title{
Recovery of benzaldehyde from aqueous streams using Extractant Impregnated Resins
}

\begin{abstract}
The performance of Extractant Impregnated Resin (EIR) technology for extraction of aldehydes from aqueous solutions has been investigated. The extraction capabilities of several different aliphatic and aromatic primary amines towards aldehydes were tested and compared. Aliphatic amines showed high affinity. The most promising extractant, Primene $^{\circledast} J M-T$, was immobilized in a porous particle. As a solid support three different macroporous adsorbents were tested, XAD-16, MPP and Stamypor. Their capacities for removal of aldehydes were compared with the non-impregnated resin and the resin impregnated with the non-reactive solvent. It was shown that the addition of a reactive extractant can increase the adsorption capacity of an otherwise poor adsorbent by several orders of magnitude. Capacity for removal of aldehydes was increased with the increase of amine loading on the particle. Temperature influence on the sorption of benzaldehyde on fully impregnated MPP was studied. It was shown that with temperature increase sorption capacity is increased. Stability of EIRs regarding the loss of the extractant due to the leakage in water, was also studied. It was shown that the immobilization reduces extractant's solubility in water. Sorption kinetics was investigated for fully impregnated XAD-16 and MPP. The modified shrinking core model was used to determine the rate controlling step and it was shown that this sorption is most likely controlled by both chemical reaction and diffusion in the particle.
\end{abstract}





\subsection{Introduction}

A QUEOUS SOLUTIONS containing components present in low concentrations are result of many industrial processes. Very often it is necessary to recover them from these streams, either to obtain a valuable product or to prevent contamination of the environment. Therefore it is desirable to reduce their presence in water to very low concentrations (ppb-level), rendering conventional reactive extraction unfeasible due to the high excess of solvent/reactant required. On the other hand, adsorption is very often not selective enough, has very low capacity or is very expensive when resins containing functional groups are used.

As a process that can overcome these disadvantages, but maintain the advantages of both mentioned separation techniques, Extractant Impregnated Resin (EIR) technology is proposed [1]. It is a synergistic combination of adsorption and reactive extraction that combines a high capacity and selectivity with relatively simple equipment and operation. Already a lot of research has been done in this field for removal of traces of metals from aqueous streams [2-4]. Lately, the EIR technology has been extended for recovery of organic compounds, like phenols [5], flavonoids [6], carboxylic acids [7-10] and amino acids [11, 12], and antibiotics (spiramycin [13]). In the present research we investigate the removal of aldehydes from diluted aqueous streams using EIR technology, which has, according to our knowledge, not been done so far. Aldehydes are compounds very often used in chemical and pharmaceutical industry as raw materials and intermediates [14].

The concept of EIRs is based on the incorporation of a selective extractive reagent into a porous particle by physical impregnation. In order to apply this technology for removal of components from water it is necessary to fill the pores with a waterinsoluble organic phase. However, aldehydes do not show a strong tendency to transfer from an aqueous to an organic phase. To improve their affinity for the organic phase it is functionalised with a complexing agent capable of forming a complex with aldehydes, which remains in the organic phase. This reaction should be reversible but sufficiently strong to increase the aldehyde's affinity for the organic phase by several orders of magnitude to obtain an economically feasible process. As complexing agents primary amines can be used because they form stable imines (Schiff bases) in reaction with aldehydes (Figure 2.1) [15]. By choosing an amine with a large apolar organic tail it can be assured that it is insoluble in water, thus prevent potential loss of the extractant.

According to the mentioned criteria some commercially available aliphatic and aromatic amines were selected and experimentally tested by liquid-liquid experiments for their affinity towards benzaldehyde. Benzaldehyde was chosen to represent aldehydes due to its commercial and industrial significance, especially as a building block for specialty chemical production [14, 16]. The performance of three different poly- 


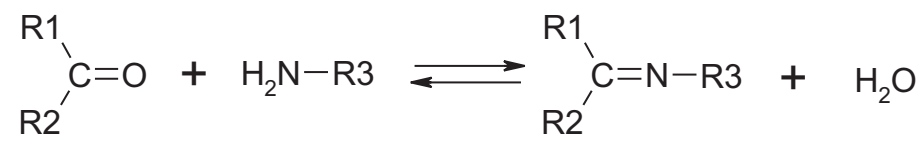

Figure 2.1: Reaction between aldehyde and primary amine

meric resins, Amberlite XAD-16 (polystyrene-co-divinylbenzene), MPP (macroporous polypropylene) and Stamypor (macroporous polyethylene) was investigated.

Temperature effects on the sorption process were investigated to explore the feasibility of temperature shift for the regeneration of these EIRs. Stability of EIRs, regarding the loss of the extractant due to the leakage in water, was also studied. Finally, the kinetics of the EIR process was investigated. In order to determine the rate controlling step, the modified shrinking core model was applied.

\subsection{Experimental}

\subsubsection{Reagents}

Benzaldehyde (99\%), 1-phenyldodecane (1-PD, $98 \%)$, squalene (SQ, $99 \%$ ), dodecylamine (DDA, $98 \%$ ), octadecylamine (ODA, $98 \%)$, n-hexane (99\%), ethanol (99\%) and acetone (98\%) were purchased from Merck, Germany. 4,4'-Methylenebis-(2,6diisopropylaniline) (MBDIPA, $98 \%$ ), 4,4'-Methylenebis(2-isopropyl-6-methylaniline) (MBIPMA, $98 \%$ ) and dibenzofuran (98\%)were purchased from Acros, Belgium. Figure 2.2 shows the chemical structures of these compounds. All chemicals were used as received. A sample of primary amine Primene ${ }^{\circledast} \mathrm{JM}-\mathrm{T}$ was received from Rohm and Haas, Europe. Amberlite XAD-16 was purchased from Sigma Aldrich. Macroporous polypropylene (MPP) particles were donated by Akzo Nobel, the Netherlands. Macroporous polyethylene (Stamypor) particles were donated by Sabic, the Netherlands. The properties of particles used in this research are listed in Table 2.1.

\subsubsection{Liquid-liquid equilibria}

Liquid-liquid equilibrium experiments were conducted on a fully automated workstation, described by Kuzmanović et al. [17]. The extraction was done in closed 2-ml glass vials that were agitated for $24 \mathrm{~h}$ at $25^{\circ} \mathrm{C}$ to ensure equilibrium. After agitation, the vials were transferred into thermostated $\left(25^{\circ} \mathrm{C}\right)$ trays, and a settling time of at least $2 \mathrm{~h}$ was allowed and shown to be sufficient. After settling, $70 \mu \mathrm{l}$ samples of the aqueous phase were taken and diluted with $255 \mu$ l of ethanol to prevent phase separation and the evaporation of benzaldehyde. Finally, $25 \mu \mathrm{l}$ of an internal standard 


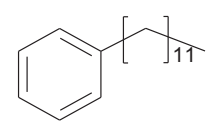

1-phenyldodecane $1-\mathrm{PD}$<smiles>CC(C)c1cc(Cc2cc(C(C)C)c(N)c(C(C)C)c2)cc(C(C)C)c1N</smiles>

4,4'-methylenebis(2,6-diisopropylaniline) MBDIPA<smiles>C/C=C(\C)CCC/C(C)=C/CC/C(C)=C/CC/C(C)=C/CC/C(C)=C/CC/C=C(\C)CCC=C(C)C</smiles>

squalene

SQ<smiles>CC(C)(C)CN</smiles>

octadecylamine

ODA<smiles>CC(C)(C)CCN</smiles>

dodecylamine

DDA

MBIPMA

Figure 2.2: Structures of selected extractants

Table 2.1: Properties of different resins used in this research

\begin{tabular}{lccc}
\hline Property & XAD-16 & MPP & Stamypor \\
\hline material & pSty-DVB & polypropylene & polyethylene \\
particle size (mm) & $0.5-0.71^{a}$ & $0.8-1.85(95 \%)$ & $>1.18(79 \%)$ \\
& & $0.71-0.8(2.5 \%)^{b}$ & $0.8-1.18(19 \%)^{b}$ \\
maximum swelling & & & \\
with 1-PD or JMT & $25-30$ vol\% $^{c}$ & not observed & not observed \\
porosity & $0.6^{a}$ & $0.55^{d}$ & $0.65^{d}$ \\
pore size $(\mathrm{nm})$ & $20-25^{a}$ & $500-1000^{e}$ & n.a. \\
surface area $\left(\mathrm{m}^{2} / \mathrm{g}\right)$ & $764.62^{f}$ & $11.51^{f}$ & $7.17^{f}$ \\
\hline
\end{tabular}

${ }^{a}$ Data obtained from the manufacturer

${ }^{b}$ Data obtained by sieving the particles

${ }^{c}$ Calculation based on the increase of the particle size (measured by sieving) of $8-10 \%$ after impregnation

$d$ Estimation according to the amount of Primene ${ }^{\circledR} \mathrm{JM}$-T retained in the pores

${ }^{e}$ Estimation from the SEM image

${ }^{f}$ Data obtained by BET measurement

solution (dibenzofuran in ethanol, $0.025 \mathrm{M}$ for high concentrations and $0.0025 \mathrm{M}$ for low concentrations of benzaldehyde) was added to the vial and quantitative analysis was done using a gas chromatograph, Varian CP-3800 system equipped with a capillary VF- $5 \mathrm{~ms}$ column $(30 \mathrm{~m}, 0.25 \mathrm{~mm} ; 0.50 \mu \mathrm{m}$ packing) and a FID detector. Samples 


\section{8 || Chapter 2}

of known concentration of benzaldehyde were used for calibration. Accuracy of the analytical method was determined to hold within $2.5 \%$.

The distribution ratio of benzaldehyde was calculated as the ratio of its concentration in the organic phase over its concentration in the aqueous phase. The concentration of benzaldehyde in the organic phase was calculated from the mass balance.

\subsubsection{Impregnation procedure}

The impregnation procedure is based on the procedure published by Juang et al. [8] Amberlite XAD-16 was first cleaned with acetone and n-hexane and then dried under vacuum at $60^{\circ} \mathrm{C}$, while MPP and Stamypor were cleaned only with acetone. Dry resin was then contacted with a mixture of n-hexane and amine or 1-PD. Dilution of the amine and 1-PD in n-hexane was done only to assure a homogeneous loading of the particles. After a contact time of at least 3 hours [7], n-hexane was removed by drying under vacuum at $60^{\circ} \mathrm{C}$. The loading of the resin with extractant was determined by measuring the increase of the mass. EIRs were also characterised by density, measured with helium pycnometer (AccuPyc 1330, Micromeritics).

\subsubsection{Sorption equilibria}

Batch adsorption experiments were used to determine the capacity of the EIRs. In each experiment equal volumes of EIR $(0.5 \mathrm{ml}$; determined by measuring mass and density) and equal volume of $0.03 \mathrm{M}$ aqueous solution of benzaldehyde $(15 \mathrm{ml})$ were placed in a $50 \mathrm{ml}$ glass-stoppered flask and shaken at $200 \mathrm{rpm}$ and appropriate temperature for at least $24 \mathrm{~h}$ using the thermostated shaking bath (Julabo Shake Temp SW23), which was determined to be sufficient to reach equilibrium. All the volumes were determined by measuring mass and density. Finally, a 2-ml sample of the aqueous phase was removed using a 2-ml syringe fitted with a filter (Schleicher\&Schuel, Spartan 30/0.45 RC), and transferred to a 2-ml amber vial. Preparation and analysis of the samples were in parallel with the liquid-liquid experiments. The amount of benzaldehyde in the EIR particles was calculated from the mass balance.

\subsubsection{Bleeding experiments}

For determination of Primene ${ }^{\circledR}$ JM-T solubility in water two phases were contacted, the equilibrium was reached and phase settling was allowed. Sample of the aqueous phase was taken with a syringe fitted with a filter (Schleicher\&Schuel, Spartan 30/0.45 $\mathrm{RC}$ ). To determine loss of the extractant from impregnated particles due to the solubility in water, similar experiments as for sorption equilibria were performed. EIRs 
were contacted with the same amount of water (instead of aqueous solution of benzaldehyde). The presence and concentration of Primene ${ }^{\circledast} \mathrm{JM}-\mathrm{T}$ in the aqueous phase was determined using a gas chromatograph, Varian CP-3800 system equipped with a capillary VF-5ms column ( $30 \mathrm{~m}, 0.25 \mathrm{~mm} ; 0.50 \mu \mathrm{m}$ packing) and a FID detector. Prior to analysis, samples were preconcentrated in $\mathrm{n}$-heptane. Calibration was done using the solutions of Primene ${ }^{\circledast} \mathrm{JM}-\mathrm{T}$ in n-heptane of a known concentration. As an internal standard 0.0036 M solution of 1-phenyloctane in n-heptane was used. Since Primene ${ }^{\circledR}$ JM-T is a mixture of amines, it appears on a chromatogram as a cloud of peaks and therefore, for the quantification, a forced peak had to be introduced. Standard deviation of such analytical method was determined to be lower than $10 \%$, which was accepted for the purpose of this research.

\subsubsection{Kinetic experiments}

Kinetics was investigated in a stirred vessel. $50 \mathrm{~cm}^{3}$ of aqueous solution of benzaldehyde was placed in the vessel. Initial concentration of the solution was $0.03 \mathrm{M}$. At the time zero $0.816 \mathrm{~cm}^{3}$ of impregnated resin was introduced to the reaction vessel. A $150 \mu \mathrm{l}$ of the solution phase was collected at various time intervals. Total number of samples was chosen to satisfy the criteria that total volume can be considered constant (difference in volume is less than $2.5 \%$ ). Initial experiments were done to determine the optimal stirring speed, regarding to the problem of mechanical damage of the particles or extractant loss. Additionally, if the intraparticle diffusion coefficients need to be estimated it is necessary that the liquid film resistance is negligible. Resulting, the optimal stirring speed was found to be $600 \mathrm{rpm}$, which was in agreement with literature data [7].

\subsection{Results and discussion}

\subsubsection{Extractant screening}

Different amines were tested in order to find the most suitable extractant for further use in EIR technology. Selection was based on amine affinity for benzaldehyde recovery, but also on certain physical properties that can assure its successful application in EIR technology. The most important features were (non) solubility in water and fluidity at room conditions. Most of the amines with a large organic tail are, however, solid at room conditions. Therefore it was necessary to dissolve them in a solvent. The solvent should be insoluble in water, but able to dissolve these amines. Figure 2.3 shows the results of the extractant screening experiments for benzaldehyde. An aqueous solution of benzaldehyde was contacted with nearly saturated solutions of amines 


\section{0 || Chapter 2}

in organic solvent. Corresponding concentrations are listed in Table 2.2. For comparison, the distribution ratio is defined as the ratio of benzaldehyde concentration in organic phase over its concentration in the aqueous phase in equilibrium.

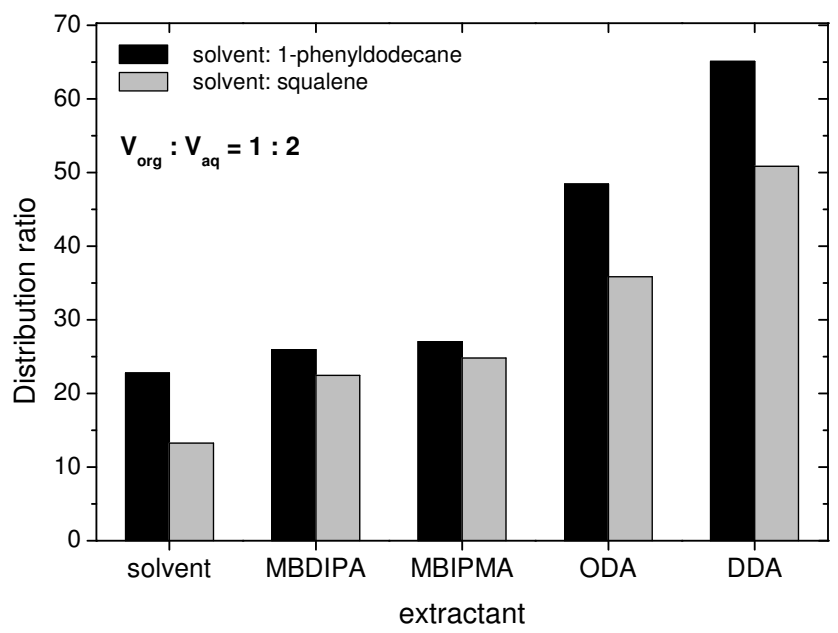

Figure 2.3: Distribution ratio of benzaldehyde for different solvents and extractants

Table 2.2: Concentration of saturated solutions of different amines in organic solvents

\begin{tabular}{llc}
\hline Amine & Solvent & $\begin{array}{c}\text { Saturation } \\
\text { concentration (mol/l) }\end{array}$ \\
\hline MBDIPA & 1-phenyldodecane & 0.368 \\
& squalene & 0.489 \\
MBIPMA & 1-phenyldodecane & 0.181 \\
& squalene & 0.211 \\
ODA & 1-phenyldodecane & 0.024 \\
& squalene & 0.022 \\
DDA & 1-phenyldodecane & 0.068 \\
& squalene & 0.040 \\
\hline
\end{tabular}

The first two selected extractants, MBDIPA and MBIPMA are aromatic amines with two amino groups. As shown in Figure 2.3 they do not give a significant increase in distribution ratio compared to the pure solvent. The aromatic ring stabilizes the amino 
groups through the delocalization of the unshared electron pair of the nitrogen over the ortho and para positions of the ring [15]. Additionally, there might be some steric hindrances as well. Consecutively, it becomes much less reactive. On the other hand, aliphatic amines (ODA, DDA) show a significant increase in distribution ratio towards benzaldehyde, although their saturation concentrations are much lower those of aromatic amines. The difference between DDA and ODA is due to the difference in concentration. Although trends are the same, squalene shows lower capacities in all cases.

It can be concluded that for this application the extractant should be an aliphatic amine, insoluble in water, and, for a feasible process, should be present in high concentrations. Primene ${ }^{\circledast} \mathrm{JM}-\mathrm{T}$ fulfills these criteria. It is a mixture of isomeric primary aliphatic amines in the $\mathrm{C}$ 18-22 range, with a highly branched alkyl chain in which the amino nitrogen atom is linked to a tertiary carbon. It is a not very viscous liquid (viscosity is reported to be $13.9 \times 10^{-6} \mathrm{~m}^{2} \cdot \mathrm{s}^{-1}$ at $22.8^{\circ} \mathrm{C}$ [18]) and therefore it does not require an additional solvent. In Figure 2.4 distribution ratios are presented as a function of Primene ${ }^{\circledast}$ JM-T concentration in n-hexane. The last point represents distribution ratio obtained with pure amine. Results show an increase of the distribution ratio with the increase of the amine concentration. This proves the necessity to use high amine concentrations or if possible pure amine. The obtained experimental data can be satisfactorily described with a simple equilibrium model presented with equations 2.1-2.6 and Figure 2.5. Since the scope of this work was the exploration of the applicability of EIR technique rather than detailed (extensive) thermodynamic modelling, the equilibrium was described with as few parameters as possible. Therefore, it was assumed that activities could be replaced with concentrations.

The reaction equilibrium constant is defined with eq. 2.1. $C$ represents the concentration in mol/l. Subscripts Ald and Am stand for aldehyde and amine, respectively, while AldAm stands for the complex formed by aldehyde and amine (Schiff base). Superscripts org and $a q$ indicate organic and aqueous phase, respectively. It was assumed that the concentration of water is constant and therefore can be incorporated in the equilibrium constant.

$$
K_{r}=\frac{C_{\text {AldAm }}^{\text {org }}}{C_{A l d}^{\text {org }} \cdot C_{A m}^{\text {org }}}
$$

The physical partitioning ratio of aldehyde is given by eq. 2.2. It was assumed that it remains constant throughout the whole range of concentrations used in this work.

$$
P=\frac{C_{\text {Ald }}^{\text {org }}}{C_{\text {Ald }}^{a q}}
$$

The overall equilibrium, as a consequence of physical and reaction equilibria, is expressed with the overall distribution ratio of the aldehyde (eq. 2.3). 


\section{2 || Chapter 2}

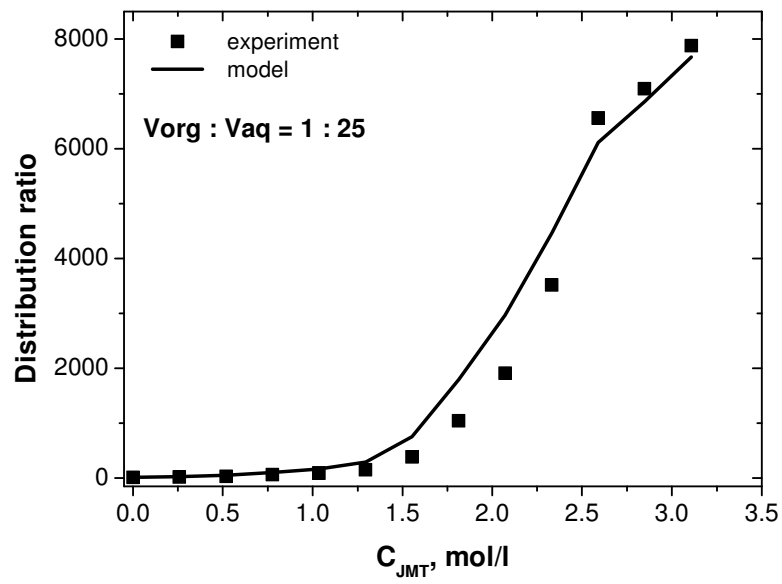

Figure 2.4: Distribution ratio of benzaldehyde as a function of Primene ${ }^{\circledast} J M-T$ concentration in n-hexane at $25^{\circ} \mathrm{C}$

$$
D=\frac{C_{\text {Ald }}^{\text {org }}+C_{\text {AldAm }}^{\text {org }}}{C_{\text {Ald }}^{\text {aq }}}
$$

To solve this model, mass balances for all the species present in the system are applied (eqs 2.4 and 2.5).

$$
\left(C_{\text {Ald, } 0}^{a q}-C_{\text {Ald }}^{a q}\right) \cdot V^{a q}=\left(C_{\text {Ald }}^{\text {org }}+C_{\text {AldAm }}^{\text {org }}\right) \cdot V^{\text {org }}
$$

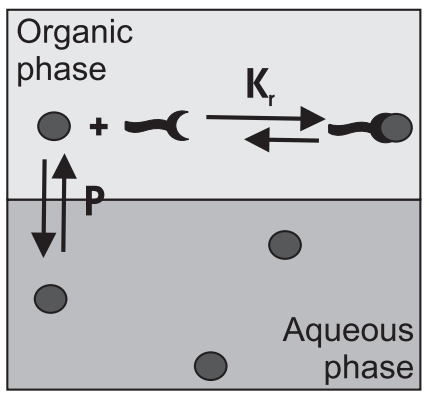

Figure 2.5: Schematic representation of the reactive liquid-liquid equilibria 


$$
C_{A m, 0}^{\text {org }}=C_{A m}^{\text {org }}+C_{\text {AldAm }}^{\text {org }}
$$

By combining equations 2.1-2.5, the overall distribution coefficient of aldehyde in the system is obtained as an implicit function of the system parameters $\left(K_{r}, P, V^{\text {org }}\right.$, $V^{a q}$ ) and the initial concentrations of amine in the organic phase and aldehyde in the aqueous phase (eq. 2.6).

$$
D=P \cdot\left[1+\frac{C_{A m, 0}^{o r g} \cdot\left(1+\frac{V^{o r g}}{V^{a q}} \cdot D\right)}{1+\frac{V^{o r g}}{V^{a q}} \cdot D+K_{r} \cdot P \cdot C_{A l d, 0}^{a q}}\right]
$$

Eq. 2.6 was used to fit the experimental data by minimizing the sum of squares of the deviations between the fitting curve and experimental points. The unknown equilibrium constant $K_{r}$ was used as fitting parameter and an optimal value of $168 \pm 12$ $1 \mathrm{~mol}^{-1}$ was obtained. Physical partitioning ratio of benzaldehyde between $n$-hexane and water, $P$, was obtained from an independent experiment The value obtained is $14.8 \pm 1.5$.

\subsubsection{EIR performance}

The most promising extractant, Primene ${ }^{\circledast}$ JM-T, was immobilized. Resins impregnated with the amine were compared with non-impregnated resins and resins impregnated with a non-reactive solvent. Results are presented in Figure 2.6 and corresponding extractant loadings given in Table 2.3. For comparison of different EIRs, the distribution ratio was defined as the ratio of benzaldehyde concentration in the EIR particle over its concentration in the aqueous phase (eq. 2.7). The concentration in the EIR phase was calculated according to the mass balance defined by eq. 2.8. Equal volumes of EIR $(0.5 \mathrm{ml})$ were compared. The EIR volume was defined as the total volume of particles.

$$
\begin{gathered}
D=\frac{C_{\text {Ald }}^{E I R}+C_{\text {AldAm }}^{E I R}}{C_{\text {Ald }}^{a q}} \\
\left(C_{\text {Ald }, 0}^{a q}-C_{\text {Ald }}^{a q}\right) \cdot V^{a q}=\left(C_{\text {Ald }}^{E I R}+C_{\text {AldAm }}^{E I R}\right) \cdot V^{E I R}
\end{gathered}
$$

The affinity of unimpregnated MPP towards benzaldehyde is very poor. As can be seen from Figure 2.6, by adding only a non-reactive solvent, in this case 1-phenyldodecane, the distribution ratio is increased seven times. If, instead, the reactive amine Primene ${ }^{\circledast} \mathrm{JM}-\mathrm{T}$ is added the capacity improvement is much higher. The distribution ratio can be increased up to 440 times compared to the unimpregnated MPP to a level of 1400 for a fully impregnated particle $\left(3.71 \mathrm{~mol}_{\mathrm{JMT}} / \mathrm{kg}_{\mathrm{MPP}}\right.$, or $\left.1.85 \mathrm{~mol}_{\mathrm{JMT}} / \mathrm{l}_{\mathrm{EIR}}\right)$. 


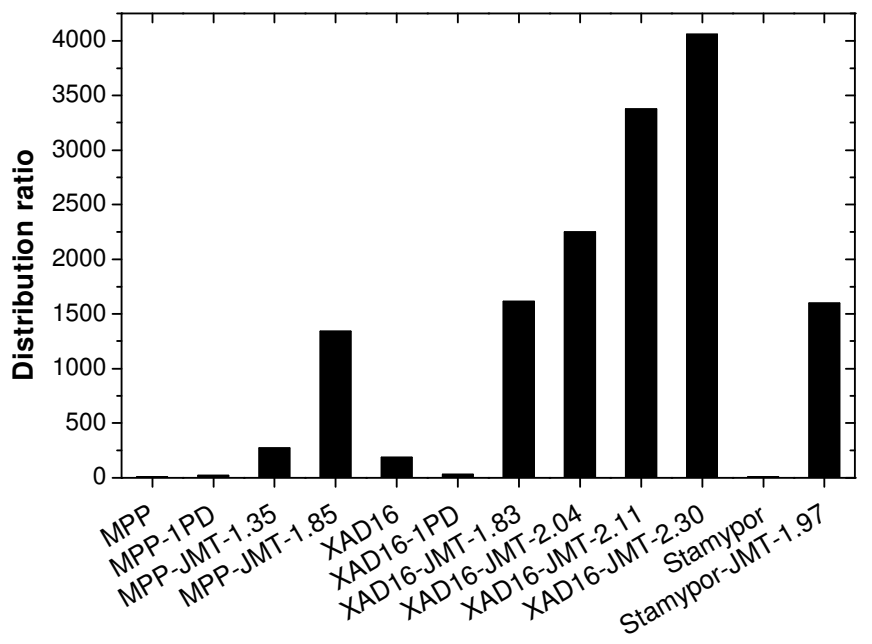

Figure 2.6: Distribution ratio of different EIRs for removal of benzaldehyde at $25^{\circ} \mathrm{C}$

Table 2.3: Loading of extractants

\begin{tabular}{ccc}
\hline resin & extractant & loading, mol/1 EIR \\
\hline MPP & - & n.a. \\
& 1-PD & 2.02 \\
& JM-T & 1.35 \\
& JM-T & 1.85 \\
XAD-16 & - & n.a. \\
& 1-PD & 2.51 \\
& JM-T & 1.83 \\
& JM-T & 2.04 \\
& JM-T & 2.11 \\
& JM-T & 2.30 \\
Stamypor & - & n.a. \\
& JM-T & 1.97 \\
\hline
\end{tabular}


Unimpregnated Stamypor exhibits the same behaviour towards benzaldehyde as MPP. Being more porous it can hold a higher amount of extractant. Therefore distribution ratio for fully impregnated Stamypor is higher than the one of fully impregnated MPP.

Amberlite XAD-16 is a polystyrene-divinylbenzene particle, thus being aromatic it has some affinity towards aromatic compounds like benzaldehyde. Impregnation with a non-reactive solvent, such as 1-phenyldodecane, results in a decrease of its capacity. Possibly all the adsorption sites are blocked with 1-phenyldodecane and the solvent can not compensate this loss. Simple physical solubility of benzaldehyde in 1-phenyldodecane is not sufficient enough. On the other hand, if XAD-16 is impregnated with Primene ${ }^{\circledR}$ JM-T, its capacity is increased significantly up to a distribution ratio of 4000 for a fully loaded particle.

If the MPP and XAD-16 with similar loading of extractant are compared, it can be seen that the distribution ratios are almost equal. Actually, the distribution ratio of XAD-16 impregnated with Primene ${ }^{\circledast}$ JM-T is slightly higher than that of MPP. Probably $\mathrm{XAD}-16$ is not fully impregnated and some active adsorption sites are left. Since they show affinity towards benzaldehyde they can increase the capacity.

With the increase of the amine loading on the particle the distribution ratio is increased, which is shown for all tested polymeric supports. Therefore, it is desirable to have as much amine inside the particle as possible to increase the distribution ratio. Thus, better performance will be expected from a more porous particle.

\subsubsection{Temperature influence}

The reaction between primary amine and aldehyde is influenced by temperature, as shown by Kuzmanović et al. [19]. Therefore it was expected that resins impregnated with Primene ${ }^{\circledast} \mathrm{JM}-\mathrm{T}$ could be regenerated by a temperature shift. Experiments were conducted at $25^{\circ} \mathrm{C}, 50^{\circ} \mathrm{C}$ and $70^{\circ} \mathrm{C}$ and corresponding isotherms are shown in Figure 2.7. Sorption capacity $q$ is defined as the amount of benzaldehyde retained per unit volume of EIR (eq. 2.9).

$$
q=\frac{n_{\text {Ald }}^{E I R}+n_{\text {AldAm }}^{E I R}}{V^{E I R}}
$$

From the results in the low concentration region it is clear that the reaction between benzaldehyde and Primene ${ }^{\circledR} \mathrm{JM}-\mathrm{T}$ is almost not influenced by temperature. In the higher benzaldehyde concentration region (higher than $0.005 \mathrm{~mol} / \mathrm{l}$ ), where the sorption is mainly influenced by the physical solubility, it can be seen that with temperature increase the sorption capacity is also increased. Possible explanation might be the fact that solubility of water in amine decreases significantly with the increase 


\section{Chapter 2}

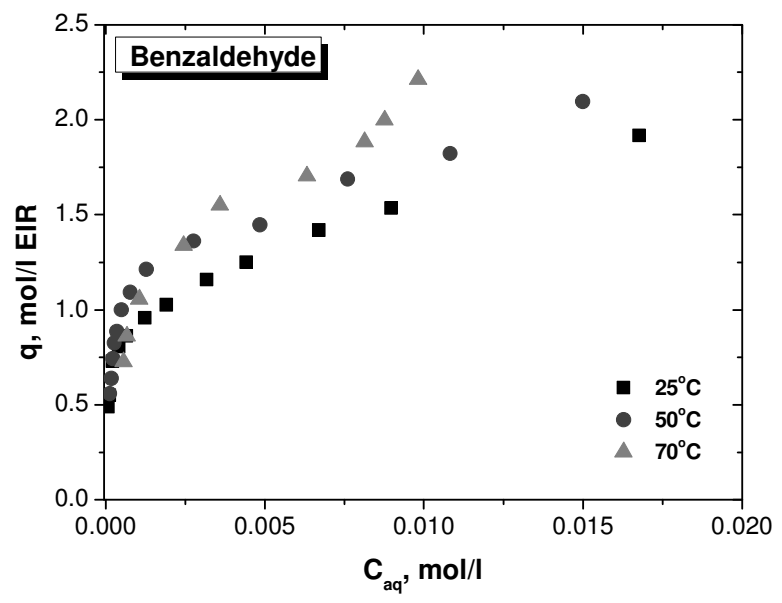

Figure 2.7: Sorption capacities of fully impregnated MPP $\left(1.85 \mathrm{~mol}_{\mathrm{JMT}} / \mathrm{l}_{\mathrm{EIR}}\right)$ for benzaldehyde at three different temperatures

of temperature [20] and consequently shifts the equilibrium towards imine formation as illustrated by Figure 2.1. Besides, solubility of benzaldehyde in water decreases as well with the increase of temperature [21], and overall contributes to the mentioned effect.

\subsubsection{EIR bleeding}

The large hydrocarbon tail of Primene ${ }^{\circledast}$ JM-T consisting of 18-22 carbon atoms ensures a very low solubility in water. Determination of the exact value of Primene ${ }^{\circledR}$ JM$\mathrm{T}$ solubility in water proved to be difficult because preliminary experiments showed very rapidly declining concentrations which was most probably caused by the micro emulsion or high affinity of amine for glass wall. The same effect was observed by Dave and Lidman [22]. Nevertheless, in our experiment, after allowing phase separation for few days, solubility was measured to be in the range of $4-5 \mathrm{ppm}$. This value corresponds to the solubility of other comparable aliphatic amines [20, 22, 23].

After immobilization of Primene ${ }^{\circledast}$ JM-T in MPP and XAD-16 particles its solubility in water even decreases further due to the physical sorption. With the analytical method used, it was not possible to determine the exact value due to the very low concentration of the immobilized Primene ${ }^{\circledast} \mathrm{JM}-\mathrm{T}$ in water, but it is obvious from the chromatogram (Figure 2.8) that amine peak completely disappeared, indicating that 
the concentration will be considerably below $1 \mathrm{ppm}$. These values should be treated with caution due to the very low concentrations which are in the lower limit of detection of the applied analytical technique. Nevertheless, a similar effect of the decrease of the solubility in water after immobilization was also reported in the work of Traving et al. [7] for tri-n-octylamine immobilized on XAD-4 and XAD-16 particles.

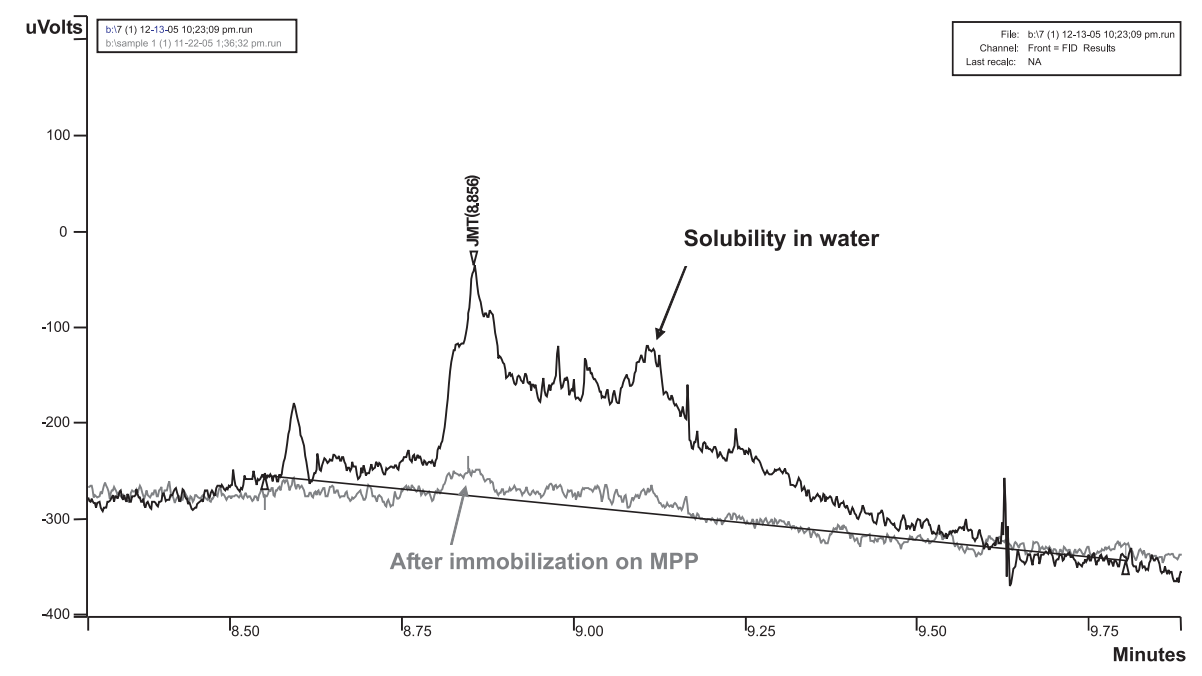

Figure 2.8: Detail of a typical chromatogram of the Primene ${ }^{\circledast} J M-T$ on VF-5ms column - solubility of Primene ${ }^{\circledast}$ JM-T in water: 4-5 ppm; after immobilization on MPP: lower than $1 \mathrm{ppm}$

\subsubsection{Kinetics}

The evolution of the benzaldehyde concentration in the aqueous phase with time is shown in Figure 2.9 for both MPP and XAD-16 resins fully impregnated with Primene JM-T. Impregnated Stamypor particles were also investigated but they showed very poor mechanical strength, and therefore were not suitable for this examination. It can be seen that MPP and XAD-16 have similar equilibration times despite the fact that MPP is a much bigger particle. The explanation for that phenomenon might lie in the particle morphology (pore sizes). MPP has much larger pores with a narrow pore size distribution and a very low percentage of micropores caused by its partial crystalline structure. In comparison, XAD-16 has the amorphous structure and higher percentage of micropores.

The experimental results also show that sorption of benzaldehyde in these EIRs is rather slow. Since that might be a drawback for practical application of this technol- 


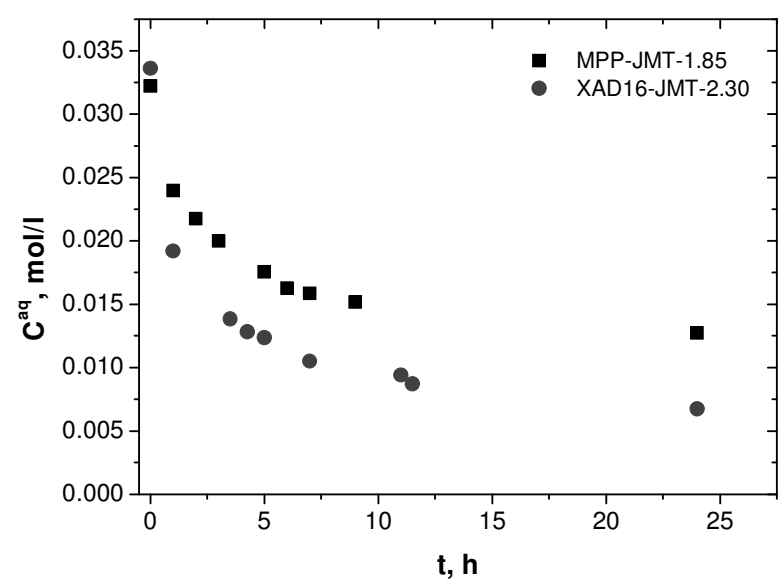

Figure 2.9: Benzaldehyde concentration in aqueous phase as a function of time

ogy, it is of a great importance to determine the rate controlling step. Overall extraction kinetics can be controlled by several mechanisms: i) the diffusion through the liquid film surrounding the particle (film diffusion), ii) intraparticle diffusion and iii) chemical reaction; or combination of two or more of limiting steps.

At present, ion exchange kinetics is usually described by models such as the homogeneous particle diffusion model (HPDM) or the shrinking core model (SCM) [24]. The conventional shrinking core model assumes irreversible reaction which is not the case here. Therefore it does not give a satisfactory description of the process.

The modified shrinking core model, derived by Bhandari et al. [25], developed for ion exchange, takes the reversibility of the process into account. This model was extended and applied to extractant impregnated resin kinetics by Juang et al. [26] to describe sorption of metal ions onto D2EHPA impregnated Amberlite XAD resins. Later it was successfully used by Ruiz et al. [27] to describe sorption of $\alpha$-phenylglycine on trialkylmethylammonium chloride impregnated XAD-4. In all these applications surface reaction between solute and impregnation liquid is assumed. In the system studied in this research there is significant contribution of physical solubility of the solute in the extractant. However, in this study we adopted this model for preliminary determination of the rate controlling step. Since it is more thoroughly described elsewhere [25-27], here only the application to this system will be discussed. The fractional conversion of the EIR at time $t$ is defined as 


$$
X=\frac{q(t)}{q_{J M T}}
$$

Where $q(t)\left(\mathrm{mol} / \mathrm{l}_{\mathrm{EIR}}\right)$ is the loading of the particle with benzaldehyde (in all its forms) at the specified time $t$ and $q_{J M T}$ is loading of the particle with the extractant. It is calculated from the experimental results. Fractional conversion of the outer surface of the EIR is given by

$$
X_{e}=\frac{C_{A l d}^{a q}(t) \cdot K}{q_{J M T}}
$$

$K$ is the equilibrium distribution ratio of benzaldehyde between particle and water.

$$
K=\frac{q}{C_{\text {Ald }}^{a q}}
$$

It should be noted that every point on the EIR outer surface is in equilibrium with the solution outside the particle so that both $X$ and $X_{e}$ are functions of time. According to the modified shrinking core model, the fractional conversion of EIR at any time is given by the following equations:

1. For the film diffusion controlled process

$$
X=\frac{3 \cdot D_{f}}{a \cdot \delta \cdot q_{J M T}} \int_{0}^{t} C_{\text {Ald }}^{a q}(t) d t
$$

2. For the particle diffusion controlled process

$$
Y=\frac{X_{e}}{K}\left[1-3 \cdot\left(1-\frac{X}{X_{e}}\right)^{2 / 3}+2 \cdot\left(1-\frac{X}{X_{e}}\right)\right]=\frac{6 \cdot D_{e} \cdot b}{a^{2} \cdot q} \int_{0}^{t} C_{A l d}^{a q}(t) d t
$$

3. For chemical reaction control

$$
Z=\frac{1}{K}\left[1-\left(1-\frac{X}{X_{e}}\right)^{1 / 3}\right]=\frac{K_{c} \cdot b}{a} \int_{0}^{t} C_{A l d}^{a q}(t) d t
$$

Where $a$ is the average radius of the particle, $\delta$ is the thickness of the stagnant liquid film, $b$ is the number of amine molecules reacted for each molecule of aldehyde (i.e. stoichiometric coefficient), $D_{e}$ is the effective diffusivity in the resin phase, $D_{f}$ is the diffusivity in the liquid film, $K_{c}$ is the apparent chemical reaction rate constant. 


\section{$30 \quad$ Chapter 2}
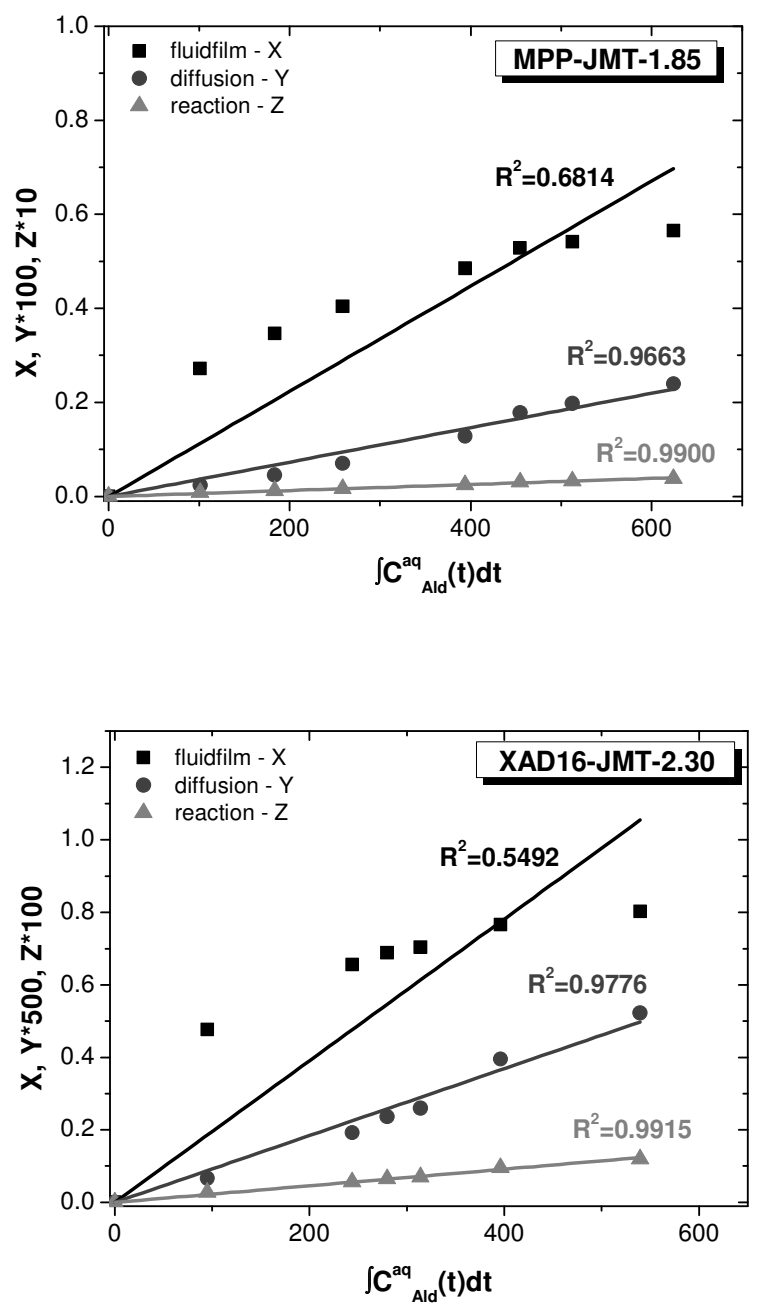

Figure 2.10: Determination of the rate controlling step in the sorption of benzaldehyde with Primene ${ }^{\circledast}$ JM-T impregnated EIRs using modified shrinking core model 
According to the modified shrinking core model the dependency of $X, Y, Z$ from $\int_{0}^{t} C_{A l d}^{a q}(t) d t$ should give a straight line if the sorption process is controlled by that mechanism. $\int_{0}^{t} C_{A l d}^{a q}(t) d t$ was calculated from the experimental data using trapezoidal integration rule.

From Figure 2.10 it is clear that no simple rate controlling step can be identified in the case of sorption of benzaldehyde on Primene ${ }^{\circledast} \mathrm{JM}-\mathrm{T}$ impregnated particles. Most likely this sorption is controlled by both chemical reaction and particle diffusion. Since, however, no clear conclusion can be made, more rigorous modelling is needed as well as more experiments that can provide better insight in the kinetics of this process. Nevertheless, it can be stated that the film diffusion resistance is not the rate controlling step confirming the validity of the performed experiments.

\subsection{Conclusions}

Branched aliphatic amines are high capacity extractants for aldehydes and being liquid at room conditions, suitable for application in EIR technology. Immobilized in macroporous particles they still keep their favorable complexation properties resulting in very high distribution ratios.

Addition of an extractant can significantly increase adsorption capacity of otherwise very poor adsorbents, which is shown for the case of MPP and Stamypor particles. Particles with a higher porosity (Amberlite XAD-16) have the ability to immobilize a higher amount of extractant, which leads to a higher capacity.

Temperature has no significant influence on chemical reaction. On the other hand, it significantly influences physical equilibria. Solubility of water in amine significantly decreases with increasing temperature, as well as solubility of benzaldehyde in water. Overall, that leads to a higher capacity of EIR particles at higher temperatures and in higher aldehyde concentration range.

Stability of EIRs regarding the loss of the extractant due to the leakage in water, was also studied. It was shown that the immobilization reduces extractant's solubility in water.

Kinetics of the sorption of benzaldehyde in EIRs impregnated with Primene ${ }^{\circledR} \mathrm{JM}$ $\mathrm{T}$ is rather slow. Simple analysis of experimental data using modified shrinking core model developed by Bhandari et al. [25] showed that no clear rate controlling step can be pointed out and it is more likely that this sorption is controlled by both chemical reaction and diffusion in the particle. Therefore, more rigorous modelling is needed for an accurate description of the kinetics. 


\section{2 || Chapter 2}

\section{Nomenclature}

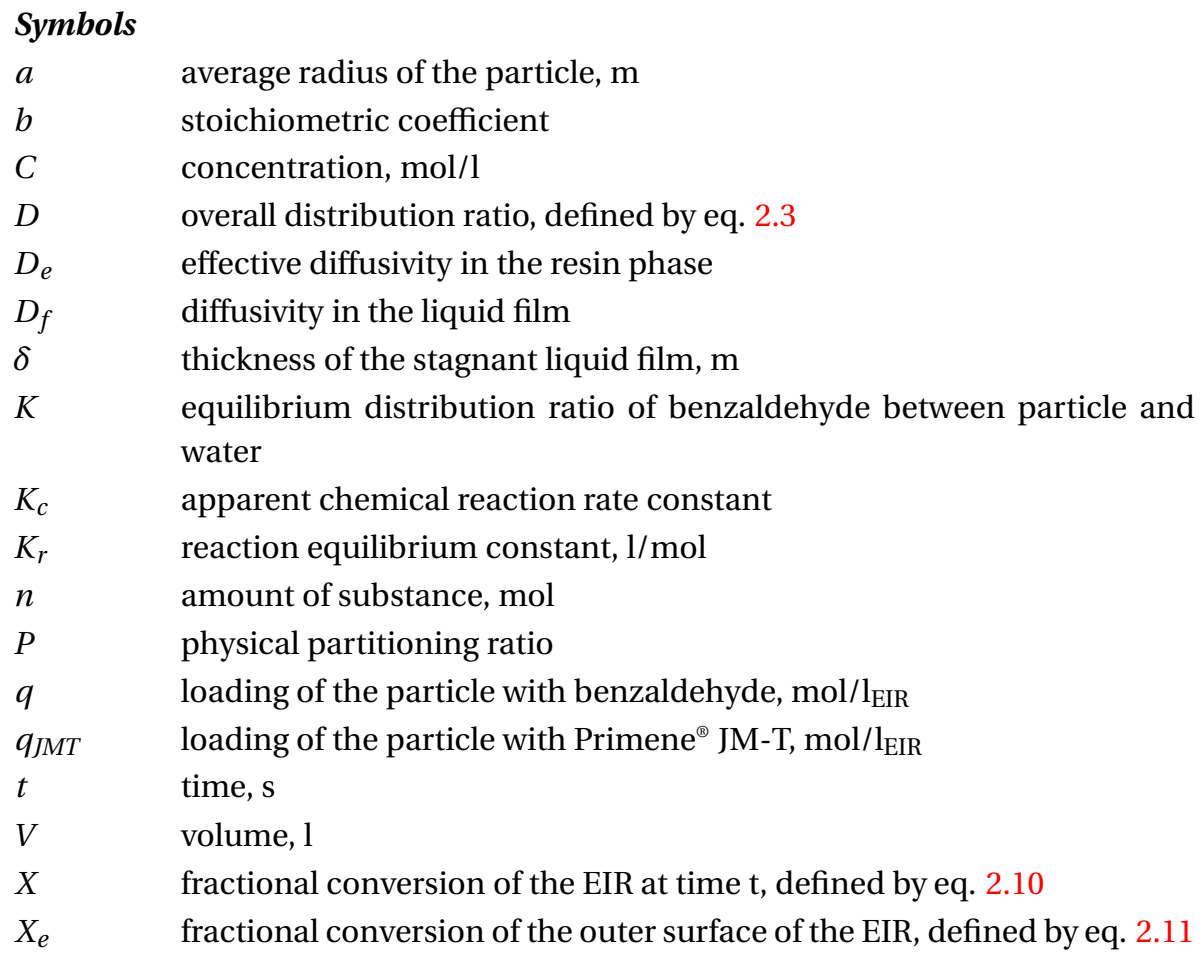

\section{Subscripts and superscripts}

0 initial

$a q \quad$ aqueous

org organic

Ald aldehyde

Am amine

AldAm complex formed between aldehyde and amine

\section{Abbreviations}

1-PD 1-phenyldodecane

SQ squalene 
MBDIPA 4,4'-Methylenebis-(2,6-diisopropylaniline)

MBIPMA 4,4'-Methylenebis(2-isopropyl-6-methylaniline)

DDA dodecylamine

ODA octadecylamine

JM-T Primene ${ }^{\circledast}$ JM-T

\section{References}

[1] A. Warshawsky. Extraction with Solvent-Impregnated Resins, volume 8 of Ion Exchange and Solvent Extraction, pages 229-310. Marcel-Dekker, New York (1981). 2.1

[2] J. L. Cortina and A. Warshawsky. Ion Exchange and Solvent Extraction, volume 13 of Ion Exchange and Solvent Extraction, chapter Developments in solid-liquid extraction by Solvent Impregnated Resins, pages 195-293. Dekker, New York (1997). 2.1

[3] C. A. Bowe, D. D. Pooré, R. F. Benson and D. F. Martin. Extraction of heavy metals by amines adsorbed onto silica gel. Journal of Environmental Science and Health, Part A, A38(11), 2653-2660 (2003). 2.1

[4] R.-S. Juang. Preparation, properties and sorption behavior of impregnated resins containing acidic organophosphorus extractants. Proceedings of the National Science Council, Republic Of China, Part A: Physical Science and Engineering, 23(3), 353-364 (1999). 2.1

[5] H. Gao and Y. Su. Solvent extraction and adsorption by extracting resins of phenol. Huadong Huagong Xueyuan Xuebao, 17(3), 249-254 (1991). 2.1

[6] H. Kitazaki, M. Ishimaru, K. Inone, K. Yoshida and S. Nakamura. Separation and recovery of flavonoids by means of solvent extraction and adsorption on solventimpregnated resin. In Proceedings of the International Solvent Extraction Conference, ISEC'96, Melbourne, Australia, pages 1667-1672 (1996). 2.1

[7] M. Traving and H.-J. Bart. Recovery of organic acids using ion-exchangerimpregnated resins. Chemical Engineering Technology, 5(10), 997-1003 (2002). $2.1,2.2 .3,2.2 .6,2.3 .4$

[8] R.-S. Juang and H.-L. Chang. Distribution equilibrium of citric acid between aqueous solutions and tri-n-octylamine-impregnated macroporous resins. Industrial and Engineering Chemistry Research, 34, 1294-1301 (1995). 2.1, 2.2 .3

[9] R.-S. Juang and T.-C. Chou. Sorption of citric acid from aqueous solutions by macroporous esins containing a tertiary amine - Equilibria. Separation Science and Technology, 31(10), 1409-1425 (1996). 2.1 


\section{$34 \quad$ Chapter 2}

[10] M. O. Ruiz, J. L. Cabezas, I. Escudero, J. R. Alvarez and J. Coca. $\alpha$-Phenylglycine extraction with a trialkylmethylammonium chloride-impregnated macroporous resin. 1. Equilibrium. Trans IChemE, 40(A), 529-536 (2002). 2.1

[11] M. O. Ruiz, J. L. Cabezas, I. Escudero, J. R. Alvarez and J. Coca. Valeric acid extraction with tri-N-butyl phosphate impregnated in a macroporous resin. I. Equilibrium and mass transfer rates. Separation Science and Technology, 39(1), 77-95 (2004). 2.1

[12] A. Kostova and H.-J. Bart. Reactive sorption of L-phenylalanine by polymers impregnated with cation exchangers (Equilibria). Chemie-Ingenieur-Technik, 76(11), 1743-1748 (2004). 2.1

[13] Y. Guan, X. Wu and G. Wu. The preparation of solvent impregnated resins and their application to the isolation of spiramycin. Chinese Journal of Antibiotics, 15(2), 90-96 (1990). 2.1

[14] R. E. Kirk and D. F. Othmer. Kirk-Othmer Encyclopaedia of Chemical Technology. Wiley-Interscience, New York (2003). 2.1

[15] T. W. G. Solomons. Fundamentals of organic chemistry. John Wiley \& Sons, New York, third edition edition (1998). 2.1, 2.3.1

[16] F. Ullmann. Ullmann's Encyclopedia of Industrial Chemistry. Wiley-Interscience, New York, sixth edition edition (2001). 2.1

[17] B. Kuzmanović, M. L. van Delden, N. J. M. Kuipers and A. B. de Haan. Fully automated workstation for liquid-liquid equilibrium measurements. Journal of Chemical and Engineering Data, 48(5), 1237-1244 (2003). 2.2 .2

[18] Rohm and Haas. Primene Amines, Physical Properties, Available from: http://www.rohmhaas.com/Primene/physical_prop.html, Accessed 14 October 2004. 2.3.1

[19] B. Kuzmanović, N. J. M. Kuipers, A. B. de Haan and G. Kwant. Reactive extraction of carbonyl compounds from apolar hydrocarbons using aqueous salt solutions. Industrial and Engineering Chemistry Research, 42(13), 2885-2896 (2003). 2.3.3

[20] R. M. Stephenson. Mutual solubility of water and aliphatic amines. Journal of Chemical and Engineering Data, 38(4), 625-629 (1993). 2.3.3, 2.3.4

[21] R. M. Stephenson. Mutual solubility of water and aldehydes. Journal of Chemical and Engineering Data, 38(4), 630-633 (1993). 2.3.3

[22] G. Dave and U. Lidman. Biological and toxicological effects of solvent extraction chemicals. Range finding acute toxicity in rainbow trout (Salmo gairdnerii Rich.) and in the rat (Rattus norwegicus L.). Hydrometallurgy 3 (1978) 201-216, 3, 201216 (1978). 2.3.4 
[23] A. V. Nikolaev, G. M. Grishin, A. A. Kolesnikov and G. I. Pogadaev. Tri-noctylamine solubility in aqueous solutions of some acids and salts. Izv. Sib. Otd. Akad. Nauk SSSR, Ser. Khim. Nauk, 2, 145-148 (in Russian) (1969). 2.3.4

[24] F. Helfferich. Ion Exchange. McGraw-Hill Book Co., New York (1962). 2.3.5

[25] V. M. Bhandari, V. A. Juvekar and S. R. Pathwardhan. Modified shrinking core model for reversible sorption on ion-exchange resins. Separation Science and Technology, 27(8-9), 1043-1064 (1992). 2.3.5, 2.4

[26] R. S. Juang and H. C. Lin. Metal sorption with extractant-impregnated macroporous resins. 1. Particle diffusion kinetics. Journal of Chemical Technology and Biotechnology, 62, 132-140 (1995). 2.3.5

[27] M. O. Ruiz, J. L. Cabezas, I. Escudero and J. Coca. $\alpha$-Phenylglycine extraction with a trialkylmethylammonium chloride-impregnated macroporous resin. 2. Kinetics. Trans IChemE, 80(A), 537-542 (2002). 2.3.5 



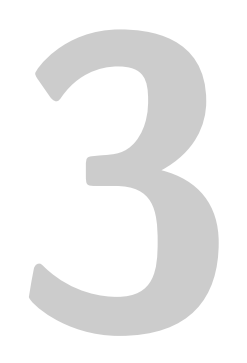

\section{Reactive extraction of aldehydes from aqueous solutions with Primene ${ }^{\circledR}$ JM-T}

The reactive extraction of aldehydes from aqueous solutions with primary amine Primene $e^{\circledast} M-T$ was explored. The extraction capability of Primene ${ }^{\circledast} J M-T$ towards several aldehydes with different molecular structure, ranging from straight chain or branched, saturated or unsaturated aliphatic to aromatic and heterocyclic is investigated. The influences of the process parameters such as initial concentration of both amine and aldehydes as well as the effect of temperature on the extraction equilibrium are investigated. In addition, a simple model incorporating both physical and chemical equilibrium is developed to describe the experimentally observed behaviour. It is noticed that higher initial concentration of the amine results in a higher overall distribution ratio, while for a higher initial concentration of aldehyde, the distribution ratio is lower. The overall extraction performance of the Primene ${ }^{\circledast} J M-T$ depends highly on the molecular structure of the aldehyde. It decreases in the following order: pentanal $>3-$ methylbutanal $>$ benzaldehyde $>$ furfural $>2$-methyl-2-butenal. It is observed that the temperature effect on the distribution coefficient is highly dependent on the system studied. 



\title{
3.1 Introduction
}

\begin{abstract}
A QUEOUS STREAMS containing organic chemicals are present in many industrial processes. The production of organics at relatively low concentration in aqueous solutions is typical when using electrochemical and biochemical synthetic methods [1]. Besides valuable, desirable products that need to be recovered from the reaction broths very often organics cause contamination of the environment.
\end{abstract}

Reactive extraction, as a method for the recovery of polar organics from aqueous solutions has received increasing attention over the past decades. Up to date, there is a large number of papers mainly focusing on carboxylic and amino acids and phenols [2-22]. Acids and phenols are extracted mainly with different kinds of amines and ammonium salts, or organophosphorus extractants or their synergistic mixtures.

In the present work, the reactive extraction of aldehydes is considered. Aldehydes are compounds very frequently processed in the chemical and pharmaceutical industry. Due to their moderate polarity, they are often found in aqueous steams from which they need to be recovered. As a typical example, furfural is a widely used solvent in the petrochemical industry and petroleum refineries, and thus one of the major components present in the wastewater from these industries [23]. Due to azeotrope formation its recovery from the aqueous solution by distillation is not very feasible, putting forward the need of developing a suitable liquid-liquid extraction system [24]. The other example is the production of ethanol by fermentation, during which the furfural is also formed. Since it inhibits the fermenting micro-organisms, it needs to be removed from the reaction broth $[25,26]$. Similar problem is observed in the production of benzaldehyde by microbial degradation of L-phenylalanine with fungi $[27,28]$ and of benzoyl formate with bacteria [29], where the yield is limited by the toxicity of the aldehyde to the micro-organism.

In this research the reactive extraction of aldehydes with primary amines is explored. When contacted, aldehydes and primary amines reversibly react to form a relatively stable [30] complex (Figure 3.1). To prevent potential loss of the extractant to the water phase, an amine with a large apolar organic tail should be chosen. In our previous research (Chapter 2), a commercially available primary amine with a C18-22 hydrocarbon tail, Primene ${ }^{\circledast}$ JM-T (Figure 3.2), was already identified as a promising extractant for the recovery of benzaldehyde [31]. In the present work the extraction capability of Primene ${ }^{\circledast} \mathrm{JM}-\mathrm{T}$ towards several aldehydes is investigated. For this study aldehydes with different molecular structure were chosen, ranging from straight chain or branched, saturated or unsaturated aliphatic to aromatic and heterocyclic (Figure 3.3). The influences of the process parameters such as initial concentration of both amine and aldehydes as well as the effect of temperature on the extraction equilibrium are investigated. In addition, a simple model incorporating both physical and chemical equilibria is developed to describe experimentally observed behaviour. 


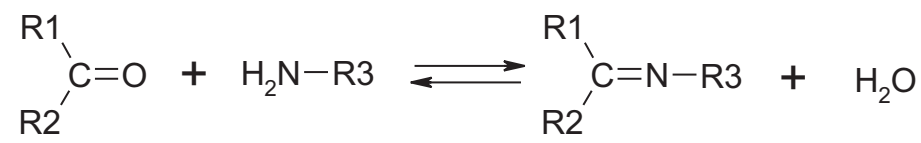

Figure 3.1: Reaction between aldehyde and primary amine<smiles>[R]C([R])([R])N</smiles>

Figure 3.2: Molecular structure of Primene ${ }^{\circledast} J M-T$ (R groups are branched alkyl groups)

\subsection{Experimental}

\subsubsection{Reagents}

Benzaldehyde (99\%), furfural (99\%), ethanol (99\%) and n-hexane (99\%) were purchased from Merck, Germany. Pentanal (98\%), 3-methylbutanal (98\%)and tiglic aldehyde (2-methyl-2-butenal, $98 \%$ ) were obtained from Fluka, Germany. Dibenzofuran $(98 \%)$ was purchased from Acros, Belgium. A sample of the primary amine Primene JM-T was received from Rohm and Haas, Europe. All chemicals were used as received. All aqueous solutions were made using MiliQ water.<smiles>CCCCC=O</smiles>

pentanal (valeraldehyde)<smiles>CC(C)CC=O</smiles>

3-methylbutanal (isovaleraldehyde)<smiles>CC=C(C)C=O</smiles>

2-methyl-2-butenal (tiglic aldehyde)<smiles>O=Cc1ccccc1</smiles>

benzaldehyde<smiles>O=Cc1ccco1</smiles>

furfural

Figure 3.3: Molecular structures of aldehydes 


\subsubsection{Experimental procedure}

Liquid-liquid equilibrium experiments were conducted on a fully automated workstation, described by Kuzmanović et al. [32]. The extraction was done in closed 2-ml glass vials that were agitated for $24 \mathrm{~h}$ at $25^{\circ} \mathrm{C}$ to ensure equilibrium. After agitation, the vials were transferred into thermostated $\left(25^{\circ} \mathrm{C}\right)$ trays, and a settling time of at least $2 \mathrm{~h}$ was allowed and shown to be sufficient. After settling, $70 \mu \mathrm{l}$ samples of the aqueous phase were taken and diluted with $255 \mu \mathrm{l}$ of ethanol to prevent phase separation as well as evaporation of the aldehydes. Finally, $25 \mu \mathrm{l}$ of an internal standard solution (dibenzofuran in ethanol, $0.025 \mathrm{M}$ for high concentrations and $0.0025 \mathrm{M}$ for low concentrations of aldehydes) was added to the vial and quantitative analysis was done using a gas chromatograph, Varian CP-3800 system equipped with a capillary VF-5ms column (30 m, $0.25 \mathrm{~mm}$; $0.50 \mu \mathrm{m}$ packing) and a FID detector. Samples of known concentration of an aldehyde were used for calibration. Accuracy of the analytical method was determined to hold within $2.5 \%$.

The concentration of aldehydes in the organic phase was calculated from the mass balance.

\subsection{Model}

For the interpretation of the observed equilibrium behaviour, a simple model, based on both physical and chemical equilibrium and mass balances, was developed.

\subsubsection{Model description}

The reactive extraction of an aldehyde with a primary amine can be schematically represented as shown in Figure 3.4. The aldehyde first dissolves in the organic phase where it subsequently reacts with the amine. Thus, the extraction occurs due to both the physical partitioning and the chemical reaction. The set of physical and chemical equilibrium equations and mass balances describing this particular system was already presented in our previous work [31]. Here it will be just briefly explained. To keep the model as simple as possible, it was assumed that

- activities could be replaced with concentrations,

- the concentration of water is constant and therefore can be incorporated in the equilibrium constant $K_{r}$, and

- the physical partitioning ratio remains constant through the whole range of concentrations. 


\section{2 || Chapter 3}

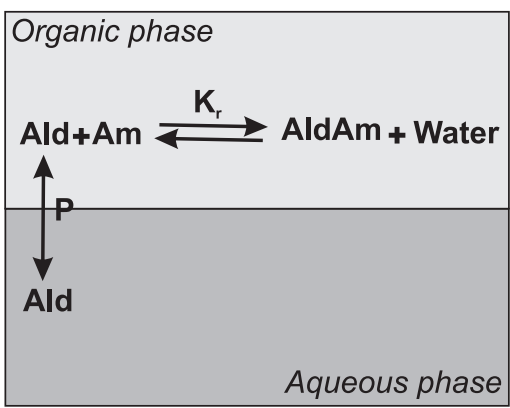

Figure 3.4: Schematic representation of the reactive extraction system

The reaction equilibrium constant is defined by eq. 3.1.

$$
K_{r}=\frac{C_{\text {AldAm }}^{\text {org }}}{C_{\text {Ald }}^{\text {org }} \cdot C_{A m}^{\text {org }}}
$$

The physical partitioning ratio of an aldehyde is given by eq. 3.2.

$$
P=\frac{C_{\text {Ald }}^{\text {org }}}{C_{\text {Ald }}^{a q}}
$$

The overall equilibrium, as a consequence of physical and chemical equilibria, is expressed with the overall distribution ratio of the aldehyde (eq. 3.3).

$$
D=\frac{C_{\text {total }}^{\text {org }}}{C_{\text {Ald }}^{a q}}=\frac{C_{\text {Ald }}^{\text {org }}+C_{\text {AldAm }}^{\text {org }}}{C_{\text {Ald }}^{a q}}
$$

Mass balances for all the species present in the system are

$$
\begin{gathered}
\left(C_{\text {Ald }, 0}^{a q}-C_{\text {Ald }}^{a q}\right) \cdot V^{a q}=\left(C_{\text {Ald }}^{\text {org }}+C_{\text {AldAm }}^{\text {org }}\right) \cdot V^{\text {org }} \\
C_{\text {Am }, 0}^{\text {org }}=C_{A m}^{\text {org }}+C_{\text {AldAm }}^{\text {org }}
\end{gathered}
$$

$C$ represents the concentration in mol/l. Subscripts Ald and Am stand for aldehyde and amine, respectively, while AldAm stands for the complex formed by aldehyde and amine. Superscripts org and $a q$ indicate the organic and aqueous phase, respectively.

By combining equations 3.1-3.5, the total concentration of aldehyde in the organic phase can be calculated as a function of the concentration of aldehyde in the aqueous phase at equilibrium and the initial concentration of amine in the organic phase (eq. 
3.6). As model parameters, the reaction equilibrium constant $K_{r}$ and physical partitioning coefficient $P$ have to be known.

$$
C_{\text {total }}^{\text {org }}=P \cdot C_{A l d}^{a q} \cdot\left(1+\frac{K_{r} \cdot C_{A m, 0}^{o r g}}{1+P \cdot K_{r} \cdot C_{A l d}^{a q}}\right)
$$

Substituting eq. 3.3 in eq. 3.6

$$
D=\frac{C_{\text {total }}^{\text {org }}}{C_{\text {Ald }}^{a q}}=P \cdot\left(1+\frac{K_{r} \cdot C_{A m, 0}^{\text {org }}}{1+P \cdot K_{r} \cdot C_{A l d}^{a q}}\right)
$$

\subsubsection{Parameter estimation}

The physical partitioning ratio of an aldehyde between Primene ${ }^{\circledast} \mathrm{JM}-\mathrm{T}$ and water can not be determined independently due to the chemical reaction. Therefore it has to be estimated based on partitioning ratio for some molecularly similar solvent without chemical reaction. Since Primene ${ }^{\circledast}$ JM-T, besides amino group, has a hydrophobic alkyl chain, n-hexane was used as a model solvent. However, this assumption can introduce some error in the subsequent fitting results.

The unknown reaction equilibrium constant was estimated by fitting eq. 3.7 to the experimentally measured data (Figure 3.5). The fitting was done using the LeverbergMarquardt algorithm implemented in the Nonlinear Least Squares Fitter of Microcal Origin. The obtained values are listed in Table 3.1.

\subsection{Results and discussion}

\subsubsection{Influence of the initial extractant and initial aldehyde concentration}

Experimentally obtained values as well as model results are presented in Figures 3.53.7. Figure 3.5(a) shows the distribution ratio of pentanal at three different temperatures and two initial aldehyde concentrations as a function of the amine concentration (in n-hexane). As the initial amine concentration increases, the distribution ratio increases, reaching very high values for the pure amine concentration $(3.1 \mathrm{~mol} / \mathrm{l})$. For the lower initial concentration of pentanal the overall distribution ratios are higher. Both effects are observed for all the temperatures studied. It can also be noticed that equation 3.7 gives a rather good fit of the experimental data.

Figure 3.5(b) presents the dependency of the distribution ratio on the initial amine concentration obtained for 3-methylbutanal, whereas figures 3.5(c), 3.5(d) and 3.5(e) 


\section{$44 \quad$ Chapter 3}

Table 3.1: Model parameters for the systems investigated at different temperatures ( $P$ is based on the system aldehyde-water-hexane; $K_{r}$ is estimated from the experimental results)

\begin{tabular}{|c|c|c|c|}
\hline \multirow[t]{3}{*}{ aldehyde } & temperature & $\begin{array}{l}\text { physical partition } \\
\text { coefficient }\end{array}$ & $\begin{array}{l}\text { reaction equilibrium } \\
\text { constant }\end{array}$ \\
\hline & $\mathrm{T}$ & $P$ & $K_{r}$ \\
\hline & ${ }^{\circ} \mathrm{C}$ & - & $1 / \mathrm{mol}$ \\
\hline \multirow[t]{3}{*}{ pentanal } & 25 & 15.8 & $198.6 \pm 10.9$ \\
\hline & 50 & 20.1 & $82.7 \pm 6.6$ \\
\hline & 70 & $\sim 25$ & $37.3 \pm 6.5$ \\
\hline \multirow[t]{2}{*}{ 3-methylbutanal } & 25 & 11.6 & $182.9 \pm 11.3$ \\
\hline & & n-hexane & \\
\hline \multirow[t]{3}{*}{ benzaldehyde } & 25 & 14.8 & 168 \\
\hline & 50 & 3.45 & 192.3 \\
\hline & 70 & 5.7 & 243.7 \\
\hline \multirow[t]{3}{*}{ furfural } & 25 & 0.65 & $58.6 \pm 1.9$ \\
\hline & 50 & 1.19 & $126.8 \pm 7.7$ \\
\hline & 70 & 1.50 & $149.1 \pm 5.9$ \\
\hline 2-methyl-2-butenal & 25 & 2.22 & $1.7 \pm 0.1$ \\
\hline
\end{tabular}

show the results for furfural, 2-methyl-2-butenal and benzaldehyde, respectively. For 3-methylbutanal and benzaldehyde the overall distribution ratios are comparable to those of pentanal. For furfural they are significantly lower, whereas for 2-methyl-2butenal the distribution ratios are the lowest. The general trends regarding the influence of the initial amine and aldehyde concentration are the same as those observed for pentanal. Due to the relatively low solubility in the aqueous phase and thus difficulty in quantification, the influence of the initial concentration of benzaldehyde was not studied. Again, it can be stated that the model (eq. 3.7) gives a very good fit.

\subsubsection{Influence of the molecular structure of aldehyde}

The extraction capability of pure Primene ${ }^{\circledR} \mathrm{JM}$-T towards different aldehydes was compared on Figure 3.6. It shows the total aldehyde concentration in the pure amine at equilibrium as a function of the aldehyde concentration in the aqueous phase. 


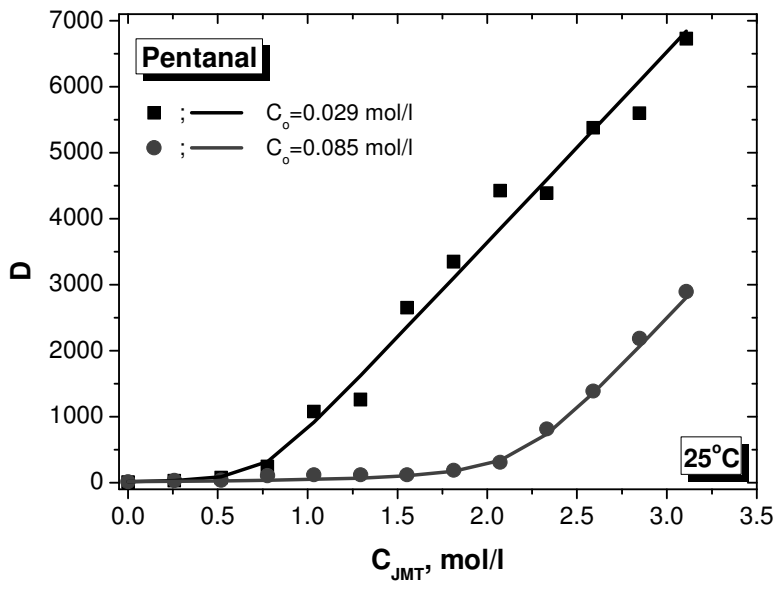

(a)

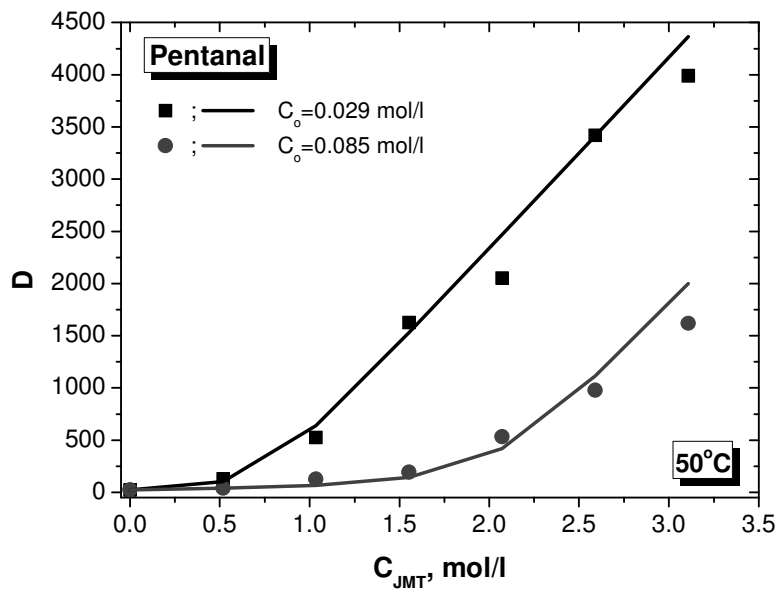

(a) 
46 || Chapter 3

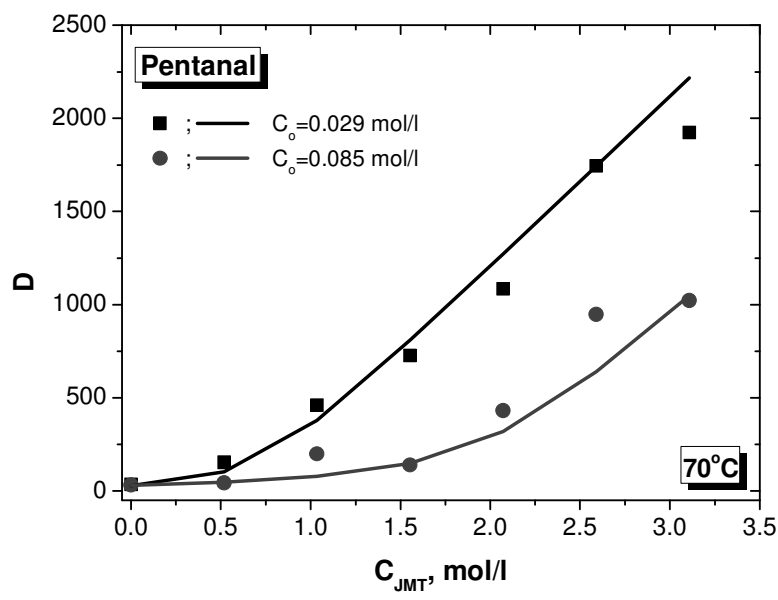

(a)

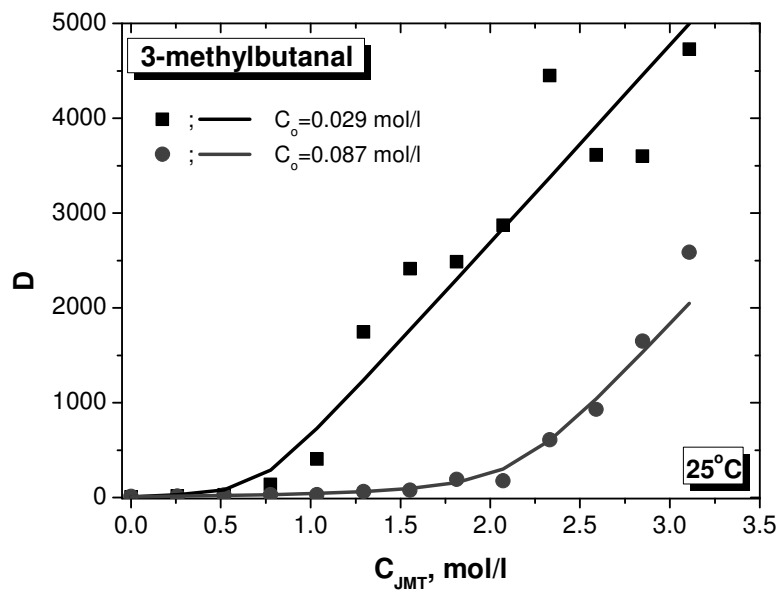

(b) 


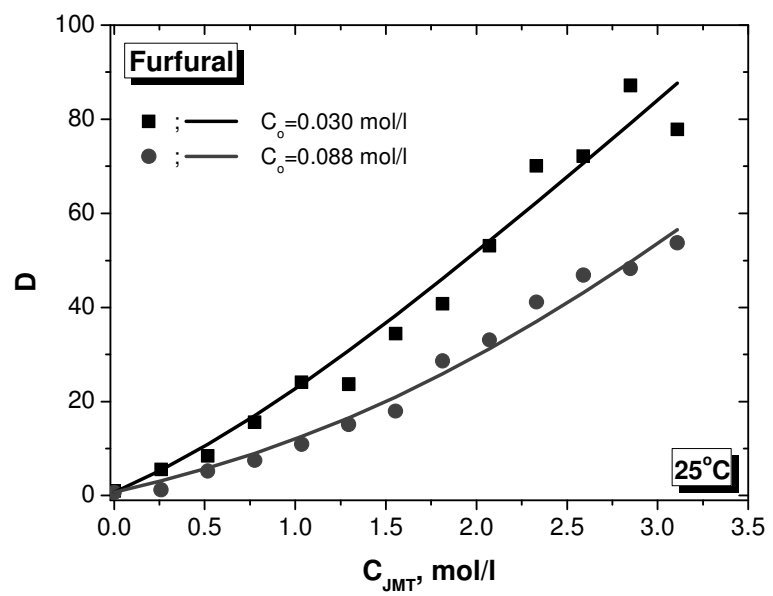

(c)

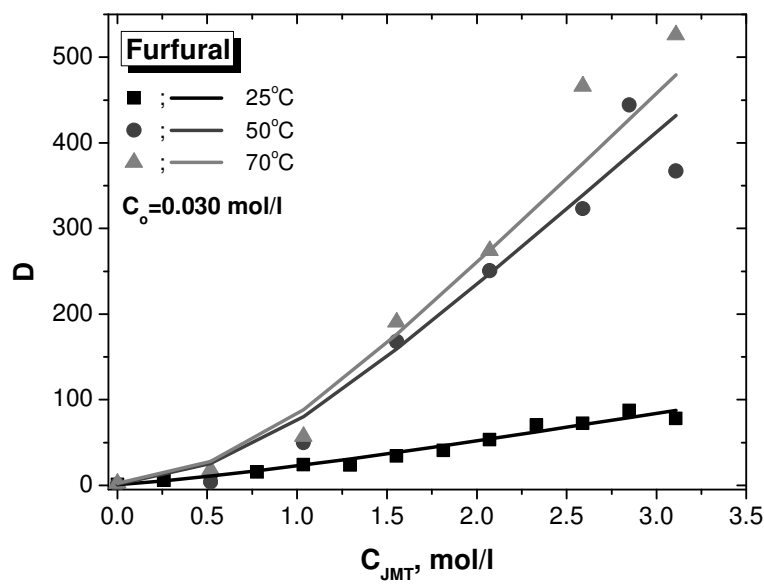

(c) 


\section{$48 \quad$ || Chapter 3}

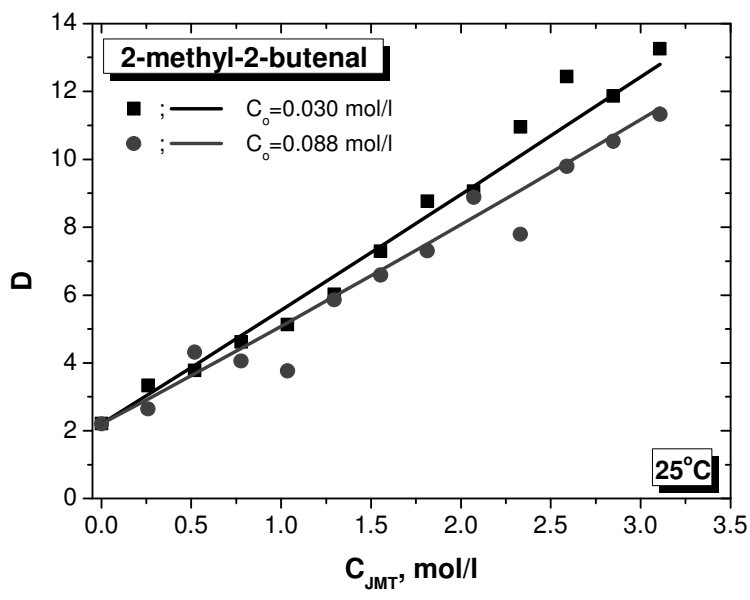

(d)

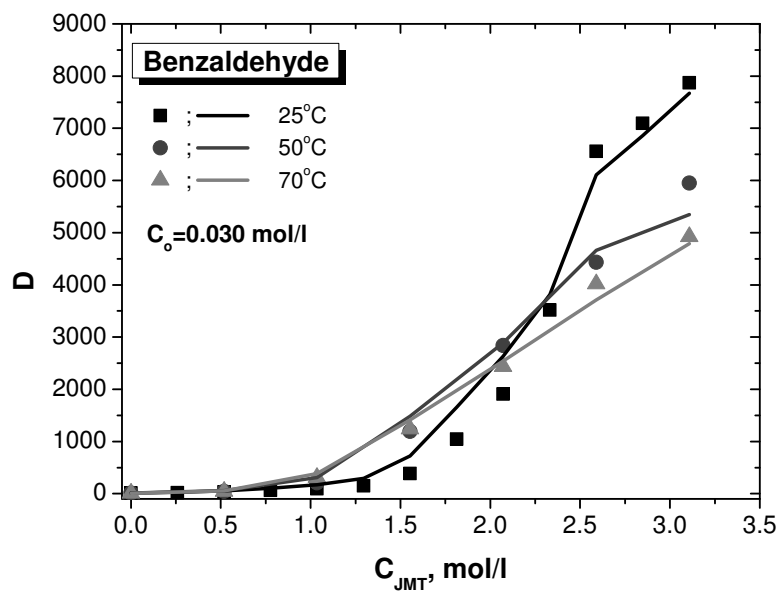

(e)

Figure 3.5: Distribution ratio of aldehydes between aqueous and organic solutions as a function of the initial Primene ${ }^{\circledast} J M-T$ concentration in hexane and initial concentration of aldehyde in aqueous solution and at different temperatures (points - experimental data; lines - model):(a) pentanal; (b) 3-methylbutanal; (c) furfural; (d) 2-methyl-2-butenal; (e) benzaldehyde 
Straight chain aliphatic aldehydes have the highest physical partitioning as well as the complexation constant (see Table 3.1). In this case there is no steric hindrance and therefore the carbonyl group is the most accessible to a nucleophilic attack. 3methylbutanal has one methyl group at a $\beta$-position which has sufficient distance not to cause too much steric hindrance. Therefore only a small decrease in $K_{r}$ is found. However, the overall solubility of 3-methylbutanal in water is slightly higher than that of pentanal. As a consequence, the physical partitioning is lower.

Due to the steric hindrance, the complexation constant of benzaldehyde is lower than of the aliphatic aldehydes. However, benzaldehyde is a molecule with a rigid planar structure and therefore the nucleophile (in this case amine) has still room for an attack from above and below the plane [30].

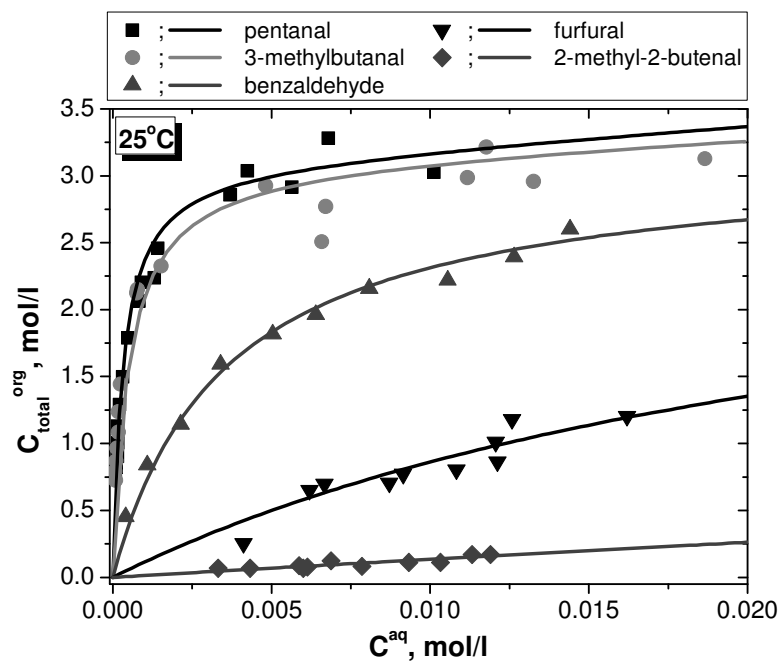

Figure 3.6: Comparison of equilibrium isotherms for the reactive extraction with pure Primene ${ }^{\circledast} \mathrm{JM}$ - $T$ for different aldehydes at $25^{\circ} \mathrm{C}$ (points - experimental data; lines - model)

Concerning physical partitioning of benzaldehyde, it is observed that, unlike the other four aldehydes, there is a significant difference between hexane and Primene JM-T. When used to predict the equilibrium isotherms, the physical partitioning measured with hexane did not give a satisfactory result. Therefore, to obtain the partitioning coefficient for JM-T eq. 3.6 was fitted to the experimentally measured data (Figure 3.7). The obtained coefficient in JM-T is lower than in hexane. Due to its aromatic ring, benzaldehyde has a rather rigid structure which reduces the number of possible steric conformations it can take. Possibly due to this fact, it is less solvated by a bulky 


\section{$50 \quad$ || Chapter 3}

molecule such as JM-T, which is in addition intermolecularly hydrogen bonded [33]. Moreover, when reacted benzaldehyde and JM-T form a complex containing both an aromatic ring and a double bond next to each other. This complex is even more rigid and probably less capable of solvating additional benzaldehyde molecules.

Furfural does not partition favourably between hydrocarbon and water. Due to the additional oxygen it is able to form more hydrogen bonds with water molecules. Moreover, heterocyclic oxygen donates an electron pair to the $\pi$ system and has an additional electron pair in a $\mathrm{sp}^{2}$ orbital orthogonal to the system. All this makes it less soluble in an organic solvent and less prone to a nucleophilic attack by the amine.

Tiglic aldehyde (2-methyl-2-butanal) exhibits a very low complexation with the amine. This is largely due to the considerable steric hindrance caused by the methyl group at the $\alpha$ position. In addition, due to the delocalization of electrons caused by the double bond, the partial positive charge of the carbonyl $\mathrm{C}$ atom is reduced.

\subsubsection{Influence of the temperature}

The influence of temperature on the extraction equilibrium with Primene ${ }^{\circledast} \mathrm{JM}-\mathrm{T}$ was studied for pentanal, benzaldehyde and furfural. It is noticed that the temperature effect is highly dependent on the system studied. The results can be seen in Figures 3.5(a), 3.5(c), 3.5(e) and 3.7.

In general the physical partition coefficient increases with increasing temperature, as can be noticed from the Table 3.1. In the case of pentanal, the solubility in water decreases with increasing temperature [34], favouring the partition in the organic phase. In the case of furfural and benzaldehyde, with the increase of temperature, solubility in water increases [34], however, the physical partitioning also increases. It is possible that with increase of temperature the coextraction of water is lowered (due to the lower solubility of water in the amine [35]) promoting the extraction of the aldehyde. Additionally, the amine molecules are less hydrogen bonded at higher temperatures, thus able to solvate the aldehyde molecules better. Physical partitioning of benzaldehyde between water and hexane decreases with the temperature increase due to the increased hydrogen bonding between benzaldehyde and water and thus higher solubility, while the apolar hexane does not offer any additional interaction to compensate that.

The equilibrium constant of the reaction is also influenced by temperature. In case of pentanal, $K_{r}$ decreases with the temperature increase, whereas for benzaldehyde and furfural the opposite dependency is observed. The literature data are contradictory, while some report exothermic behaviour [36] the others report the opposite [37], so apparently the molecular structure of the aldehyde has a major influence. Enthalpy and entropy changes are calculated from the experimentally obtained equilib- 


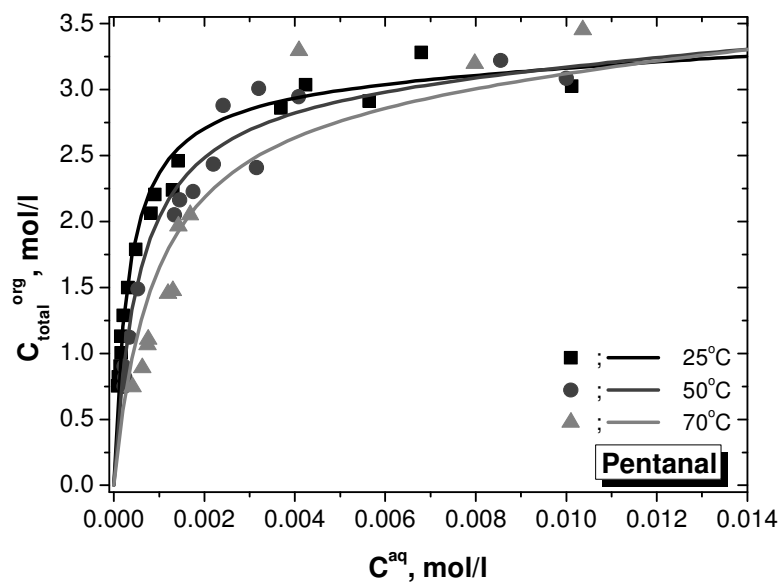

(a)

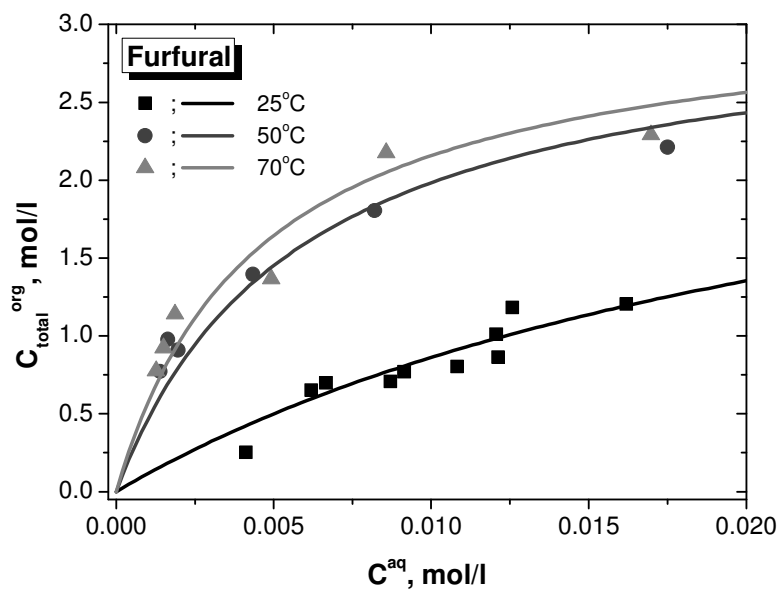

(b) 


\section{2 || Chapter 3}

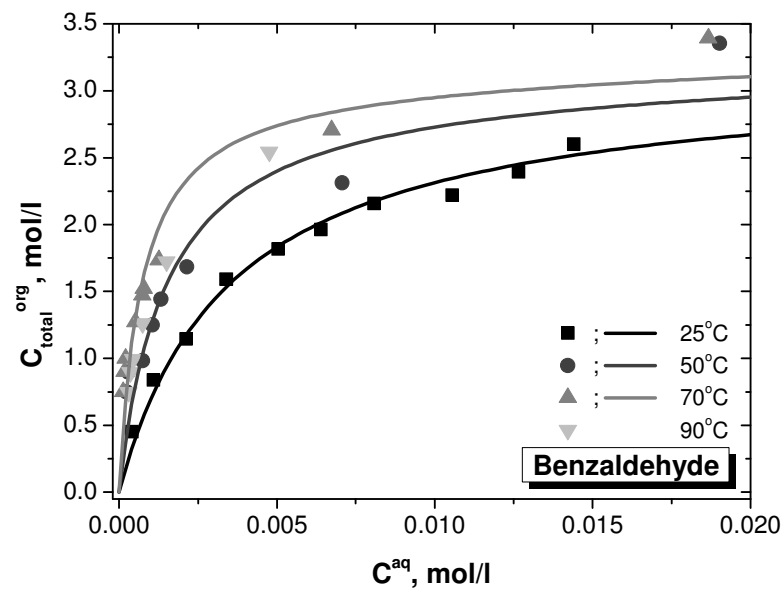

(c)

Figure 3.7: Equilibrium isotherms for the reactive extraction of different aldehydes with pure Primene ${ }^{\circledast} J M-T$ at different temperatures (points - experimental data; lines - model):(a) pentanal; (b) furfural; (c) benzaldehyde

rium constants (Table 3.2). It can be noticed that while for benzaldehyde and furfural the entropy increases, for pentanal it is decreased. The temperature at which Gibbs energy equals zero $\mathrm{T}^{*}$ is also given in Table 3.2. The forward reaction of pentanal and Primene $^{\circledast} \mathrm{JM}-\mathrm{T}$ is spontaneous below $\mathrm{T}^{*}$, while forward reactions of benzaldehyde and furfural with JM-T are spontaneous above $\mathrm{T}^{*}$. This suggests that the temperature shift is not a suitable option for the regeneration of benzaldehyde and furfural. On the other hand the option of regenerating pentanal with hot air or steam might be feasible.

Table 3.2: Enthalpy and entropy change for the reaction of aldehydes with Primene ${ }^{\circledR} J M-T$

\begin{tabular}{cccc}
\hline aldehyde & $\begin{array}{c}\Delta \mathrm{S} \\
\mathrm{J} / \mathrm{molK}\end{array}$ & $\begin{array}{c}\Delta \mathrm{H} \\
\mathrm{kJ} / \mathrm{mol}\end{array}$ & $\begin{array}{c}\mathrm{T}^{*}=\Delta \mathrm{H} / \Delta \mathrm{S} \\
{ }^{\circ} \mathrm{C}\end{array}$ \\
\hline pentanal & -53.1 & -28.9 & 272.6 \\
benzaldehyde & 63.6 & 6.3 & -173.9 \\
furfural & 90.7 & 16.6 & -89.5 \\
\hline
\end{tabular}




\title{
3.5 Conclusions
}

The reactive extraction of aldehydes with primary amine Primene ${ }^{\circledR}$ JM-T was explored. For the explanation of the experimental results a simple equilibrium model, taking into account both physical solubility and chemical reaction, is also developed.

Higher initial concentration of the amine results in a higher overall distribution ratio. On the other hand, for a higher initial concentration of aldehyde, the distribution ratio is lower. Both effects are observed for all the temperatures studied. The overall extraction performance of the Primene ${ }^{\circledast} \mathrm{JM}-\mathrm{T}$ depends highly on the molecular structure of the aldehyde. It decreases in the following order: pentanal $>3$-methylbutanal $>$ benzaldehyde $>$ furfural $>2$-methyl-2-butenal. The model correlates the experimental data rather well.

It is noticed that the temperature effect is highly dependent on the system studied. For pentanal, the reaction is exothermic whereas for furfural it is endothermic. For benzaldehyde, temperature does not have very strong influence. The temperature shift is not a suitable option for regeneration of benzaldehyde and furfural, while for pentanal use of hot air or steam might be an option.

\section{Nomenclature}

\author{
Symbols \\ C concentration, $\mathrm{mol} / \mathrm{l}$ \\ $D \quad$ overall distribution ratio, defined by eq. 3.3 \\ $K_{r} \quad$ reaction equilibrium constant, $1 / \mathrm{mol}$ \\ $P \quad$ physical partitioning ratio \\ V volume, 1
}

\section{Subscripts and superscripts}

0 initial

$a q \quad$ aqueous

org organic

Ald aldehyde

Am amine

AldAm complex formed by aldehyde and amine 


\section{$54 \quad$ Chapter 3}

\section{References}

[1] A. S. Kertes and C. J. King. Extraction chemistry of fermentation product carboxylic acids. Biotechnology and Bioengineering, 28, 269-282 (1986). 3.1

[2] K. Inoue and S. Nakayama. Solvent extraction of phenol with primary and tertiary amines and a quaternary ammonium compound. Solvent Extraction and Ion Exchange, 2(7\&8), 1047-1067 (1984). 3.1

[3] A. M. Baniel, R. Blumbrerg and K. Hadju. Recovery of acids from aqueous solutions, US Patent No. 4,275,234 (1981). 3.1

[4] M. Reshke and K. Schügerl. Reactive extraction of penicillin. I: Stability of penicillin $\mathrm{G}$ in the presence of carriers and relationships for distribution coefficients and degrees of extraction. Chemical Engineering Journal, 28, B1-B9 (1984). 3.1

[5] M. Reshke and K. Schügerl. Reactive extraction of penicillin. II: Distribution coefficients and degrees of extraction. Chemical Engineering Journal, 28, B11-B20 (1984). 3.1

[6] E. Schlichting, W. Halwachs and K. Schügerl. Reactive extraction of salicylic acid and D,L-phenylalanine in a bench-scale pulsed sieve plate column. Chemical Engineering and Processing, 19, 317-328 (1985). 3.1

[7] R. Haensel, W. Halwachs and K. Schügerl. Reactive extraction of D,Lphenylalanine with trioctylmethylammonium chloride (TOMAC) as a carrier. III Equilibrium and mass transfer investigations. Chemical Engineering Science, 41(7), 1811-1815 (1986). 3.1

[8] Z. Likidis and K. Schügerl. Reactive extraction and reextraction of penicillin with different carriers. Journal of Biotechnology, 5, 293-303 (1987). 3.1

[9] S.-T. Yang, S. White and S.-T. Hsu. Extraction of carboxylic acids with tertiary and quaternary amines: Effect of $\mathrm{pH}$. Industrial and Engineering Chemistry Research, 30, 1335-1342 (1991). 3.1

[10] T. Hano, T. Ohtake, M. Matsumoto, D. Kitayama, F. Hori and F. Nakshio. Extraction equilibria of amino acids with quaternary ammonium salt. Journal of Chemical Engineering of Japan, 24, 20-24 (1991). 3.1

[11] E. K. Watson and W. A. Rickelton. A review of the industrial and recent potential applications of trioctylphosphine oxide. Solvent Extraction and Ion exchange, 10(5), 879-889 (1992). 3.1

[12] V. Bizek, J. Horaček, M. Koušova, A. Heyberger and J. Prochaska. Mathematical model of extraction of citric acid with amine. Chemical Engineering Science, 47(6), 1433-1440 (1992). 3.1

[13] V. Bizek, J. Horaček and M. Koušova. Amine extraction of citric acid: Effect of diluent. Chemical Engineering Science, 48(8), 1447-1457 (1993). 3.1 
[14] J. Hartl and R. Marr. Extraction processes for bioproduct separation. Separation Science and Technology, 28(1-3), 805-819 (1993). 3.1

[15] R.-S. Juang and W.-T. Huang. Equilibrium studies on the extraction of citric acid from aqueous solutions with tri-n-octylamine. Journal of Chemical Engineerin of Japan, 27(4), 498-504 (1994). 3.1

[16] R.-S. Juang and Y.-S. Lin. Distribution equilibrium of penicillin G between water and organic solutions of Amberlite LA-2. Chemical Engineering Journal, 62, 231236 (1996). 3.1

[17] T. Kirsch, H. Ziegenfußand G. Maurer. Distribution of citric, acetic and oxalic acids between water and organic solutions of tri-n-octylamine. Fluid Phase Equilibria, 129, 235-266 (1997). 3.1

[18] J. T. Scarpello and D. C. Stuckey. The reactive extraction of phenylalanine with Aliquat 336: Buffer co-extraction equilibrium and mass transfer kinetics. Biotechnology and Bioengineering, 69, 469-477 (2000). 3.1

[19] S. C. Lee, B. S. Ahn and J. G. Kim. Reaction equilibrium of penicillin G with Amberlite LA-2 in a nonpolar organic solvent. Biotechnology Progress, 18, 108-115 (2002). 3.1

[20] W. Qin, Z. Li and Y. Dai. Extraction of monocarboxylic acids with trioctylamine: Equilibria and correlation of apparent reactive equilibrium constant. Industrial and Engineering Chemistry Research, 42, 6196-6204 (2003). 3.1

[21] K. L. Wasewar, A. A. Yawalkar, J. A. Moulijn and V. G. Pangarkar. Fermentation of glucose to lactic acid coupled with reactive extraction: A review. Industrial and Engineering Chemistry Research, 43, 5969-5982 (2004). 3.1

[22] B. P. Nikhade and V. G. Pangarkar. Equilibria and kinetics of extraction of citric acid from aqueous solutions in Alamine 336 - Cyclohexanone system. Separation Science and Technology, 40, 2539-2554 (2005). 3.1

[23] P. Gupta, A. Nanoti, M. O. Garg and A. N. Goswami. The removal of furfural from water by adsorption with polymeric resins. Separation Science and Technology, 36(13), 2835-2844 (2001). 3.1

[24] J. Coca and R. Diaz. Extraction of furfural from aqueous solutions with chlorinated hydrocarbons. Journal of Chemical Engineering Data, 25, 80-83 (1980). 3.1

[25] J. R. Weil, B. Dien, R. Bothast, R. Hendrickson, N. S. Mosier and M. R. Ladisch. Removal of fermentation inhibitors formed during pretreatment of biomass by polymeric adsorbents. Industrial and Engineering Chemistry Research, 41, 61326138 (2002). 3.1

[26] I. M. de Manchilha and M. N. Karim. Evaluation of ion exchange resins for removal of inhibitory compounds from corn stover hydrolyzate for xylitol fermentation. Biotechnology Progress, 19, 1837-1841 (2003). 3.1 


\section{$56 \quad$ Chapter 3}

[27] U. Krings and R. G. Berger. Biotechnological production of flavours and fragrances. Applied Microbiology and Biotechnology, 49, 1-8 (1998). 3.1

[28] T. Lamer, H. E. Spinnler, I. Souchon and A. Voilley. Extraction of benzaldehyde from fermentation broth by pervaporation. Process Biochemistry, 31(6), 533-542 (1996). 3.1

[29] J. Simmonds and G. K. Robinson. Formation of benzaldehyde by Pseudomonas putida ATCC 12633. Applied Microbiology and Biotechnology, 50, 353-358 (1998). 3.1

[30] T. W. G. Solomons. Fundamentals of organic chemistry. John Wiley \& Sons, New York, third edition edition (1998). 3.1, 3.4.2

[31] K. Babić, L. van der Ham and A. de Haan. Recovery of benzaldehyde from aqueous streams using extractant impregnated resins. Reactive and Functional Polymers, 66(12), 1494-1505 (2006). 3.1, 3.3.1

[32] B. Kuzmanović, M. L. van Delden, N. J. M. Kuipers and A. B. de Haan. Fully automated workstation for liquid-liquid equilibrium measurements. Journal of Chemical and Engineering Data, 48(5), 1237-1244 (2003). 3.2.2

[33] J. N. Spencer, W. S. Wolbach, J. W. Hovick, L. Ansel and K. J. Modarress. Hydrogen bonding by alcohols and amines. Journal of Solution Chemistry, 14(11), 805-814 (1985). 3.4.2

[34] R. M. Stephenson. Mutual solubility of water and aldehydes. Journal of Chemical and Engineering Data, 38(4), 630-633 (1993). 3.4.3

[35] R. M. Stephenson. Mutual solubility of water and aliphatic amines. Journal of Chemical and Engineering Data, 38(4), 625-629 (1993). 3.4 .3

[36] B. Kuzmanović, N. J. M. Kuipers, A. B. de Haan and G. Kwant. Reactive extraction of carbonyl compounds from apolar hydrocarbons using aqueous salt solutions. Industrial and Engineering Chemistry Research, 42(13), 2885-2896 (2003). 3.4.3

[37] A. de Carvalho Alcantara, D. Pilo-Veloso and D. Nelson. A study of the formation and stability of $\mathrm{N}$-alkylbutanimines by $1 \mathrm{H}-\mathrm{NMR}$ spectroscopy. Journal of Brazillian Chemical Society, 7(4), 225-232 (1996). 3.4.3 


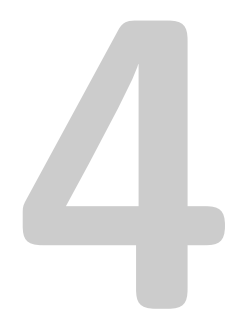

\section{Sorption equilibrium for the removal of aldehydes from aqueous streams with Primene $^{\circledast} \mathrm{JM}-\mathrm{T}$ impregnated resins}

The reactive sorption equilibrium of aldehydes of different molecular structure with polymeric resins impregnated with Primene ${ }^{\circledast} J M-T$ was investigated. As solid support, commercially available macroporous adsorbents Amberlite XAD-16 and XAD-4 (polystyrene - divinyl benzene), MPP (macroporous polypropylene) and Stamypor (macroporous polyethylene), were used and their performances compared. Particles with the highest porosity can retain the highest amount of amine, resulting in the highest capacity for the aldehyde recovery. The molecular structure of aldehyde influences the complexation with amine and thus has a large influence on the overall sorption capacity, which decreases in following order: pentanal $>3$-methylbutanal > benzaldehyde $>$ furfural. Only for benzaldehyde does the support material have a significant influence, probably due to the additional adsorption on the particle surface. With the temperature increase the overall sorption capacity for pentanal decreases, while for benzaldehyde it increases. A simple mathematical model, based on the known liquid-liquid behavior is proposed to explain the experimentally obtained data. The model appeared to successfully predict the equilibrium behavior for all the aldehydes investigated, while resulting in considerable underestimation for benzaldehyde due to additional adsorption. Correcting the model with the Freundlich isotherm demonstrated that a more detailed modeling approach is required. 



\subsection{Introduction}

$\mathrm{E}$

XTRACTANT IMPREGNATED RESIN (EIR) technology [1, 2] is a hybrid process that combines the characteristics of adsorption and reactive liquid-liquid extraction offering high capacity and selectivity together with the simplicity of the continuous fixed bed operation for processing dilute or viscous solutions. Moreover, it minimizes the problems of emulsion formation and extractant losses. In EIRs the extractant is physically immobilized in the adsorbent particle. Preparation of such particles by soaking the adsorbent in the extractant solution is rather simple yielding a relatively inexpensive separation medium. Additionally, by changing the extractant liquid inside the pores this technique can be tuned to meet the requirements of a specific separation problem.

EIRs were first developed for hydrometallurgical applications [1, 2]. Relatively recently their application was extended for the recovery of organic substances, mainly carboxylic and amino acids from fermentation broths [3-9]. In the present work, the application of this technique for the recovery of aldehydes is investigated. Aldehydes are very often found in aqueous streams of the chemical and pharmaceutical industry, from which they need to be recovered either to prevent contamination of the environment or to obtain a valuable product.

In our previous study [10] the potential of EIRs was already proven for the removal of benzaldehyde from aqueous streams (see Chapter 2). Benzaldehyde was recovered from water using primary amines impregnated in different polymeric supports. Aldehydes and primary amines are able to reversibly react [11], increasing the organic phase affinity toward aldehydes and thus improving the overall capacity of the adsorbent. In our previous work [10] Primene ${ }^{\circledR}$ JM-T was selected as a suitable extractant for this application. It has a large hydrocarbon tail consisting of 18 to 22 carbon atoms, assuring its insolubility in water, consequently minimizing the possible extractant loss due to leaching. A highly branched organic tail lowers its melting point and makes it a liquid at room conditions. Therefore no additional diluent needs to be used. The reaction capabilities of Primene ${ }^{\circledast}$ JM-T towards different aldehydes were also explored in the reactive liquid-liquid extraction [12] and shown to be highly dependant on the molecular structure of the aldehyde (see Chapter 3).

In the present study we investigate the reactive sorption equilibrium of aldehydes of different molecular structure with polymeric resins impregnated with Primene ${ }^{\circledast}$ JMT. As solid support, commercially available macroporous adsorbents Amberlite XAD16 and XAD-4 (polystyrene-divinyl benzene), MPP (macroporous polypropylene) and Stamypor (macroporous polyethylene), were used. It was investigated how the particle material and extractant loading influence the sorption equilibrium and whether the molecular structure of an aldehyde has the same influence on the sorption as on the liquid-liquid equilibrium. Aldehydes of a different molecular structure, ranging 


\section{$60 \quad$ Chapter 4}

from straight chain or branched aliphatic to aromatic and heterocyclic, were studied. A simple mathematical model, based on the known liquid-liquid behavior is proposed to explain the experimentally obtained data.

\subsection{Experimental}

\subsubsection{Reagents}

Benzaldehyde (99\%), furfural (99\%), ethanol (99\%) and n-hexane (99\%) were purchased from Merck, Germany. Pentanal (98\%) and 3-methylbutanal (98\%) were obtained from Fluka, Germany. Dibenzofuran (98\%) was purchased from Acros, Belgium. A sample of primary amine Primene ${ }^{\circledast} \mathrm{JM}-\mathrm{T}$ was received from Rohm and Haas, Europe. All chemicals were used as received. All aqueous solutions were made using MiliQ water. Amberlite XAD-16 and XAD-4 were purchased from Sigma Aldrich, Germany. Macroporous polypropylene (MPP) particles were donated by Akzo Nobel, the Netherlands. Macroporous polyethylene (Stamypor) particles were donated by SabicEurope, the Netherlands.

\subsubsection{Impregnation procedure}

Resins were impregnated with Primene ${ }^{\circledast}$ JM-T using the dry impregnation method. Impregnation was done according to the procedure described in our previous work (see Chapter 2) [10]. The loading of the resin with extractant was determined by measuring the increase of the mass. EIRs were also characterized by density, measured with a helium pycnometer (AccuPyc 1330, Micromeritics). The properties of the particles used in this study are listed in Table 4.1.

\subsubsection{Sorption equilibria}

The experimental procedure as well as the analytical method was described in more detail in our previous work (see Chapter 2) [10]. Therefore only information relevant for this study will be given here. Different amounts of impregnated resins were placed in a flask. Then $15 \mathrm{ml}$ of aqueous solution of an aldehyde was added. The system was allowed to equilibrate in a thermostated shaking bath for $24 \mathrm{~h}$ before a sample of the aqueous phase was taken and the concentration of aldehyde determined. Quantitative analysis of the aldehydes in the aqueous solution was done using a gas chromatograph, Varian CP-3800 equipped with a capillary VF-5ms column and a FID detector. A solution of dibenzofuran in ethanol was used as an internal standard. Accuracy of the 
Table 4.1: Properties of the impregnated resins used in this study

\begin{tabular}{|c|c|c|c|c|}
\hline \multicolumn{5}{|c|}{ EIR particle properties } \\
\hline resin & extractant & $\begin{array}{l}\text { loading } \\
\mathrm{mol} / \mathrm{l}_{\mathrm{EIR}}\end{array}$ & $\begin{array}{c}\epsilon_{p}^{*} \\
- \\
\end{array}$ & $\begin{array}{l}\text { density } \\
\mathrm{g} / \mathrm{ml}_{\mathrm{EIR}}\end{array}$ \\
\hline \multirow[t]{5}{*}{ XAD-16 } & JM-T & 1.25 & 0.5132 & 1.0182 \\
\hline & & 1.83 & 0.5806 & 1.0079 \\
\hline & & 2.04 & 0.6546 & 0.9893 \\
\hline & & 2.11 & 0.7009 & 0.9699 \\
\hline & & 2.30 & 0.7346 & 0.9667 \\
\hline \multirow[t]{2}{*}{ XAD-4 } & JM-T & 1.83 & 0.5641 & 0.9722 \\
\hline & & 2.04 & 0.6362 & 0.9558 \\
\hline \multirow[t]{2}{*}{ MPP } & JM-T & 1.35 & 0.4379 & 1.0441 \\
\hline & & 1.85 & 0.5945 & 0.9932 \\
\hline Stamypor & JM-T & 1.97 & 0.6282 & 0.8900 \\
\hline
\end{tabular}

* the fraction of the EIR particle occupied by the liquid extractant, defined by eq. 4.9

applied analytical method was determined to hold within $2.5 \%$. The concentration of aldehyde in the particle was calculated via a mass balance.

\subsection{Mathematical model}

A detailed description of the reactive liquid-liquid system (thus, without particle present) was already presented in our previous study [10, 12] (see Chapters 2 and 3). In the present study this model is extended to explain the equilibrium behavior of the impregnated reactive system. When contacted with a particle impregnated with the Primene $^{\circledast} \mathrm{JM}-\mathrm{T}$, the aldehyde molecules first dissolve in the organic liquid and then react with the amine forming an imine according to the reaction

$$
R_{1} R_{2} \mathrm{CO}+\mathrm{R}_{3} \mathrm{NH}_{2} \rightleftharpoons \mathrm{R}_{1} \mathrm{R}_{2} \mathrm{C}=\mathrm{NR}_{3}+\mathrm{H}_{2} \mathrm{O}
$$

The equilibrium of the aldehydes' sorption with Primene ${ }^{\circledR}$ JM-T impregnated resins is influenced by both the physical and the chemical equilibrium, characterized by the partitioning coefficient $P$ and the reaction equilibrium constant $K_{r}$ (eq. 4.2 and 4.3). 


\section{2 || Chapter 4}

$$
\begin{gathered}
P=\frac{C_{\text {Ald }}^{\text {org }}}{C_{\text {Ald }}^{a q}} \\
K_{r}=\frac{C_{\text {Ald }}^{\text {org }}}{C_{\text {Ald }}^{\text {org }} \cdot C_{A m}^{\text {org }}}
\end{gathered}
$$

Here, Ald represents aldehyde, Am stands for amine and AldAm for the complex. Superscripts org and $a q$ refer to the organic and aqueous phase, respectively, whereas $C$ stands for concentration (expressed in $\mathrm{mol} / \mathrm{l}$ of the corresponding phase).

The basic assumption of the EIR model follows from the fact that the reaction takes place in the liquid organic phase only and thus, the polymeric backbone can be considered to be inert. This assumption is valid only in the case that the adsorption on the particle surface is negligible. It follows than that the amount of species in the organic phase is equal to the amount in the EIR phase (eq. 4.4).

$$
n_{i}^{\text {org }}=n_{i}^{E I R} \quad, \quad i=A l d, A m, \text { Ald Am }
$$

The mass balances of the reactive species can be written as follows

$$
\begin{gathered}
\left(C_{\text {Ald }, 0}^{a q}-C_{A l d}^{a q}\right) \cdot V^{a q}=\left(C_{\text {Ald }}^{\text {IIR }}+C_{\text {AldAm }}^{E I R}\right) \cdot V^{E I R} \\
C_{\text {Am }, 0}^{\text {org }}=C_{\text {Am }}^{\text {org }}+C_{\text {AldAm }}^{\text {org }}
\end{gathered}
$$

Superscript EIR represents the EIR phase, whereas subscript 0 stands for the initial condition. It should be noted that the volume of the EIR particle consists of the volume of the organic liquid $V^{\text {org }}$ and the volume of the polymeric backbone $V^{E I R}$. The volumes are defined with equations 4.7-4.8.

$$
\begin{gathered}
V^{\text {org }}=\frac{m_{A m}}{\rho_{A m}} \\
V^{E I R}=\frac{m_{E I R}}{\rho_{E I R}}
\end{gathered}
$$

For convenience, the value of $\epsilon_{p}$ is defined as a fraction of the EIR particle occupied by the liquid extractant (eq. 4.9).

$$
\epsilon_{p}=\frac{V^{\text {org }}}{V^{E I R}}
$$


The sorption capacity $q$ is defined as the total amount of aldehyde, both free and complexed, retained in the unit volume of EIR particle (eq. 4.10).

$$
q=\frac{n_{\text {Ald }}^{\text {EIR }}+n_{\text {AldAm }}^{\text {EIR }}}{V^{E I R}}
$$

Combining equations $4.2-4.10$, the sorption capacity can be expressed as a function of the aldehyde concentration in the aqueous phase at equilibrium. The sorption isotherm is given by eq. 4.11 .

$$
q=P \cdot \epsilon_{p} \cdot C_{A l d}^{a q} \cdot\left(1+\frac{K_{r} \cdot C_{A m, 0}^{o r g}}{1+K_{r} \cdot P \cdot C_{A l d}^{a q}}\right)
$$

For comparison with the liquid-liquid equilibrium isotherms (presented in our previous study, see Chapter 3 or reference [12]), it is convenient to calculate the total concentration of the aldehyde in the organic phase with the following equation (also derived previously, see Chapter 3 or reference [12])

$$
C_{\text {total }}^{\text {org }}=\frac{n_{\text {Ald }}^{\text {org }}+n_{\text {AldAm }}^{\text {org }}}{V^{\text {org }}}=P \cdot C_{\text {Ald }}^{a q} \cdot\left(1+\frac{K_{r} \cdot C_{A m, 0}^{\text {org }}}{1+K_{r} \cdot P \cdot C_{A l d}^{a q}}\right)
$$

The values for the model parameters $K_{r}$ and $P$ were determined in our previous study (see Chapter 3 or reference [12]). Parameter $\epsilon_{p}$ depends on the impregnation ratio of the particular EIR. The values are listed in table 4.1. Since Primene ${ }^{\circledast}$ JM-T does not require any diluent, the initial amine concentration $C_{A m, 0}^{\text {org }}$ is equal to the concentration of the pure amine $(3.1 \mathrm{~mol} / \mathrm{l})$. Since all the parameters are known, the model can be used to predict the equilibrium of the aldehyde sorption on Primene ${ }^{\circledR}$ JM-T impregnated resins.

\subsection{Results and discussion}

\subsubsection{Influence of the extractant loading on the particle}

To investigate the influence of the extractant loading on the particle, XAD-16 was impregnated with Primene ${ }^{\circledR} \mathrm{JM}-\mathrm{T}$ in different impregnation ratios. Then equal volumes of the impregnated XAD-16 $(0.3 \mathrm{ml})$ were taken and the capacity for pentanal sorption was determined. Results are presented in Figure 4.1. It can be concluded that the increase in amine loading results in an increase in sorption capacity. Thus, with the same volume of particles more aldehyde can be recovered. The same behaviour was noticed for the benzaldehyde sorption (see Chapter 3 or reference [10]) on XAD-16, 


\section{Chapter 4}

MPP and Stamypor impregnated with the amine. In Figure 4.2 equilibrium isotherms of pentanal on XAD-16 impregnated resins for two different impregnation ratios are shown. Again, it is clear that the higher amine loading gives a higher overall sorption capacity. Moreover, the developed model, based only on the knowledge of the liquidliquid equilibrium $\left(P\right.$ and $K_{r}$ ), predicts the experimentally observed behaviour very well. The rather close agreement between experiments and model suggests that for the sorption of pentanal the assumption of the inert support was justified.

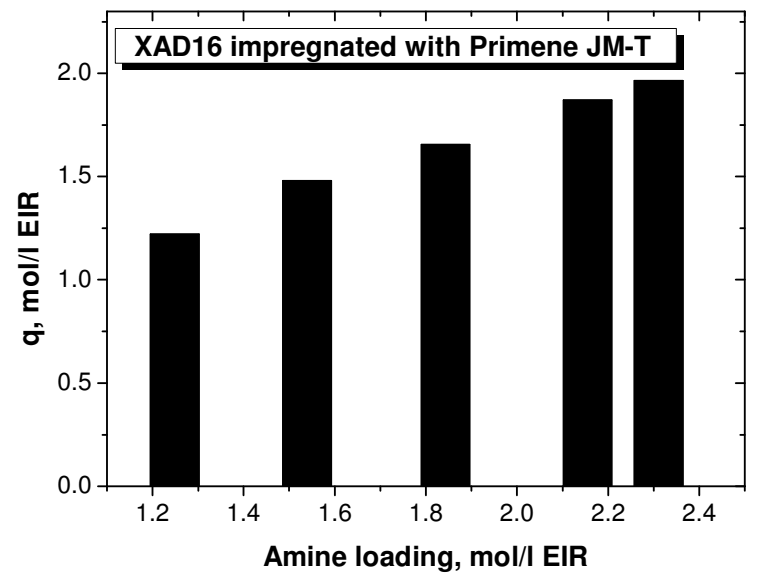

Figure 4.1: Capacity of XAD-16 impregnated with different amounts of amine for the sorption of pentanal

\subsubsection{Influence of the molecular structure of aldehyde}

The extraction performance of Primene ${ }^{\circledast}$ JM-T strongly depends on the molecular structure of the aldehyde, i.e. the accessibility of the carbonyl group. Moreover, the physical partitioning is also strongly influenced by the aldehyde structure [12]. In the present study we investigated whether the same follows for the sorption with EIRs. Equilibrium isotherms of different aldehydes on MPP fully impregnated with Primene ${ }^{\circledast}$ JM-T are presented in Figure 4.3. The sorption capacity for the recovery of aldehydes decreases in the following order pentanal $>3$-methylbutanal $>$ benzaldehyde $>$ furfural. The same order was reported for the reactive liquid-liquid system. Additionally, it can be noticed that the model predicts the equilibrium behavior very well for all the investigated aldehydes, except for benzaldehyde. In this case an increase in the capacity is observed compared to the one expected by the model. It is evident that in 


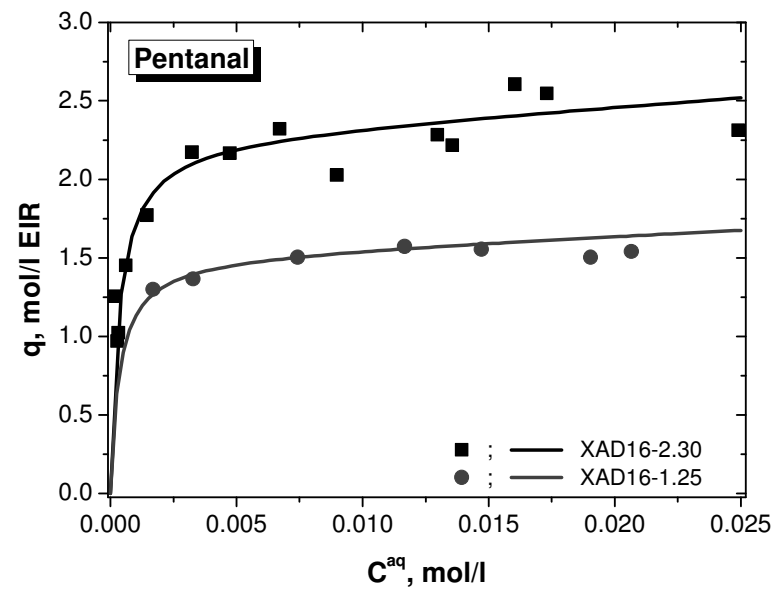

Figure 4.2: Equilibrium isotherms of pentanal on XAD-16 impregnated with Primene ${ }^{\circledast} J M-T$ with different impregnation ratio at $25^{\circ} \mathrm{C}$ (points - experimental data; lines - model prediction)

this case there is an additional effect, which will be addressed in more detail towards the end of this chapter.

\subsubsection{Influence of the polymeric support}

The particle properties do influence the overall performance of the EIRs. In Figure 4.4 the equilibrium isotherm of pentanal on fully impregnated XAD-16, MPP and Stamypor is presented. These particles have different saturation capacities, thus different amine loadings. It follows that the more porous particle, i.e. the one that can retain the highest amount of the amine has the highest capacity for the aldehyde recovery. It can be noticed that the model predicts the actual equilibrium behaviour rather well.

To highlight the influence of the polymeric support material on the overall partitioning of aldehydes, the performance of EIRs is compared with the reactive liquidliquid extraction reported previously [12]. The equilibrium isotherms of pentanal are presented in Figure 4.5(a). It can be noticed that the experimental points for all the impregnated particles studied are spread around the theoretically calculated curve (with eq. 4.12). The same is noticed for 3-methylbutanal and furfural (Figures 4.5(b) and 4.5(c)). This once more justifies the model assumption of an inert support for these aldehydes. 


\section{6 || Chapter 4}

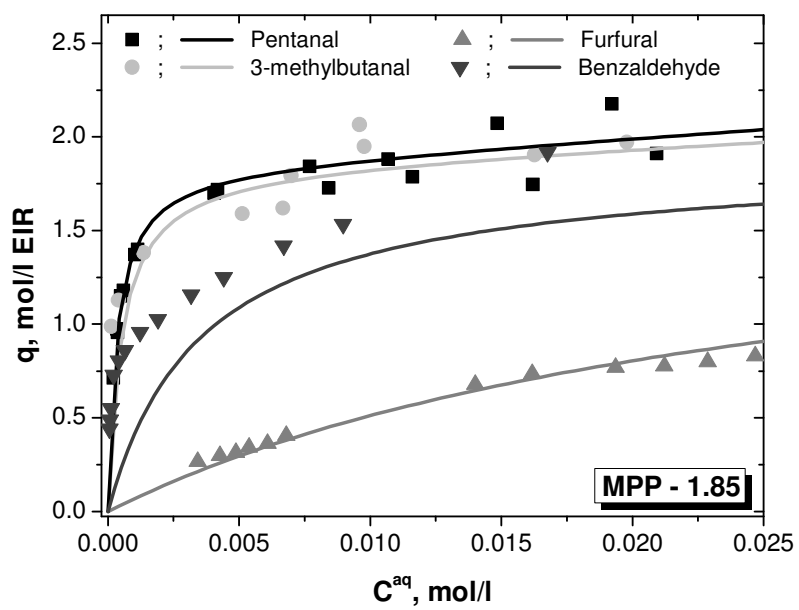

Figure 4.3: Equilibrium isotherms of different aldehydes on fully impregnated $M P P$ at $25^{\circ} \mathrm{C}$ (points - experimental data; lines - model prediction)

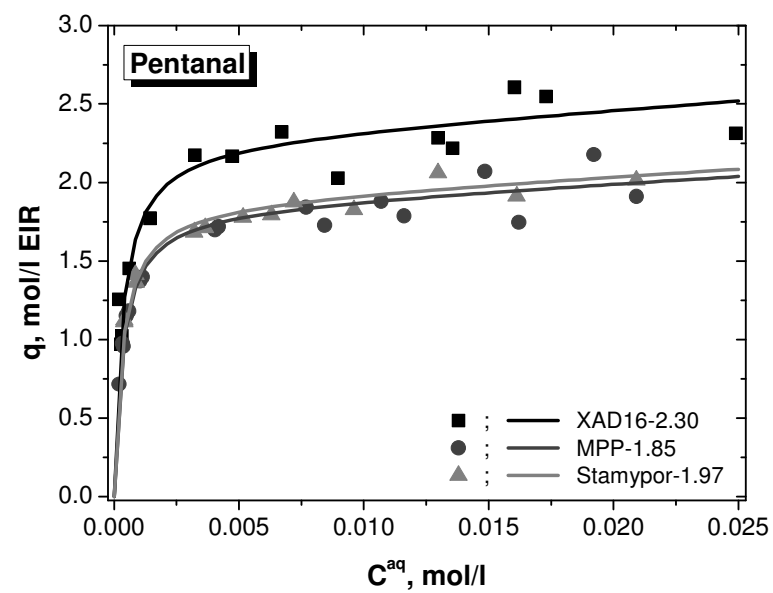

Figure 4.4: Equilibrium isotherms of pentanal on fully impregnated EIRs with different polymeric supports at $25^{\circ} \mathrm{C}$ (points - experimental data; lines - model prediction) 


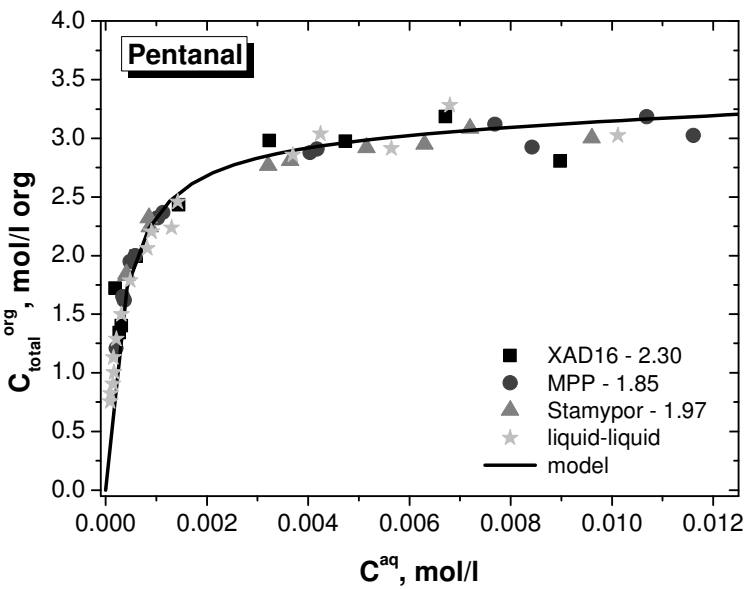

(a)

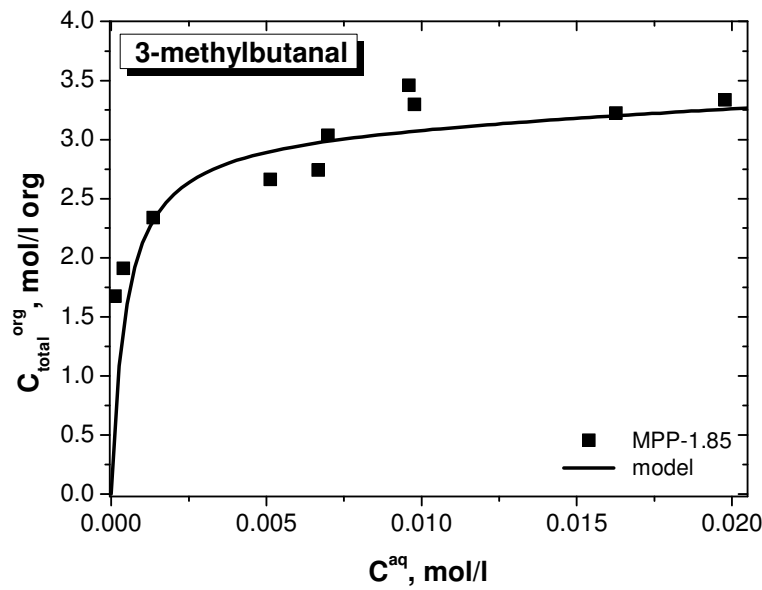

(b) 


\section{8 || Chapter 4}

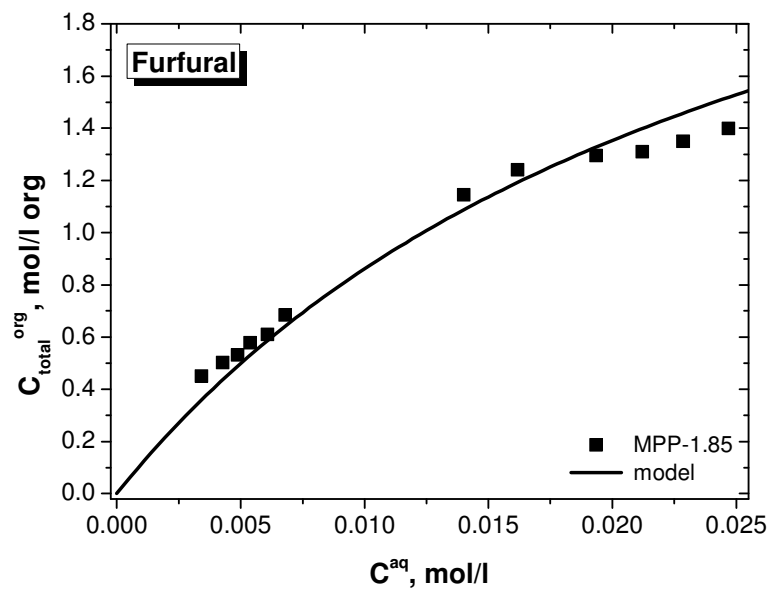

(c)

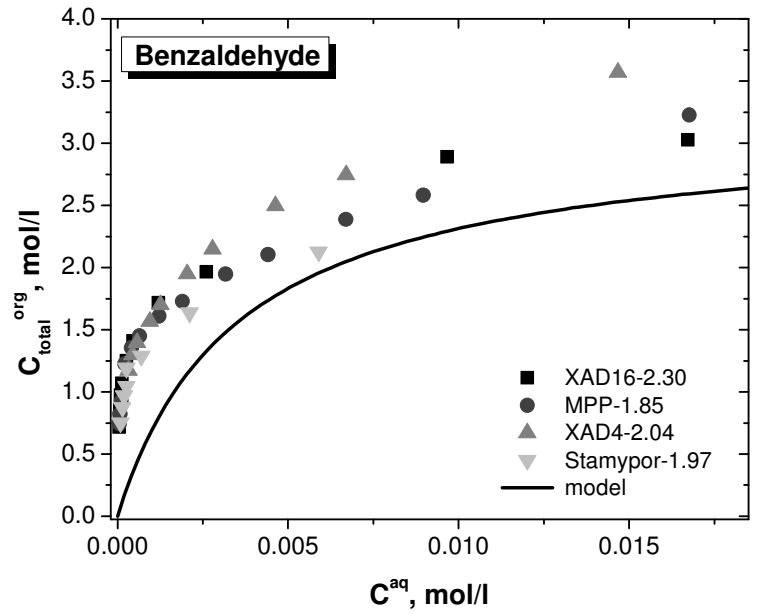

(d)

Figure 4.5: Comparison between reactive liquid-liquid extraction and extractant impregnated resins at $25^{\circ} \mathrm{C}$ for the recovery of (a) pentanal; liquid-liquid experimental results are taken from reference [12]; (b) 3-methylbutanal; (c) furfural; (d) benzaldehyde (model predictions are calculated with eq. 4.12) 
However, different behaviour is observed for benzaldehyde in Figure 4.5(d) where the equilibrium isotherms of fully impregnated resins are shown. In the case that there would be no particle influence, all the points should coincide with the theoretically predicted curve (eq. 4.12) as this is the case for pentanal. However, it is shown that for all the impregnated resins there is an increase in the total organic concentration compared with the liquid-liquid isotherm. The increase is especially large in the low concentration region. If different polymeric supports are compared, the additional capacity increases in the following order Stamypor $<$ MPP $<$ XAD-16 $<$ XAD-4. Taking into account resin properties it can be concluded that the two least polar particles, Stamypor and MPP, increase the overall capacity less than two slightly more polar ones. Moreover, XAD-16 and XAD-4 are aromatic resins and have some affinity towards aromatic components. XAD- 4 has a larger surface area than XAD-16 and therefore a higher adsorption capacity. These results indicate that, besides extraction with the amine, benzaldehyde is additionally being adsorbed on the particle surface.

\subsubsection{Influence of temperature}

The experiments were performed at $25^{\circ} \mathrm{C}, 50^{\circ} \mathrm{C}$ and $70^{\circ} \mathrm{C}$ to determine whether and how the temperature influences the sorption equilibrium of pentanal. The obtained isotherms are presented in Figure 4.6(a). In the low concentration region the sorption capacity decreases with the increase of the temperature. In the high concentration region the physical partitioning coefficient has the main influence on the equilibrium. Since the value of $P$ increases with increasing temperature, the overall capacity is thus increased. Even though there is some scattering of the experimental points, it can be concluded that the temperature influence is well encountered by the model. The scattering of the experimental data is probably due to the high volatility of pentanal, which increases with temperature.

The influence of the temperature on the sorption of benzaldehyde with fully impregnated MPP resins is shown in Figure 4.6(b) [10]. Model isotherms are calculated with eq. 4.12, which does not take the additional adsorption on the particle surface into account. The difference between experimental and model isotherms is the highest at $25^{\circ} \mathrm{C}$ and it decreases with the temperature increase. At $70^{\circ} \mathrm{C}$ the predicted and experimentally obtained isotherms almost overlap. Adsorption is known to be an exothermic phenomenon [13]. Therefore these results confirm the proposed explanation of the observed deviation for benzaldehyde by additional sorption capacity caused by the surface adsorption, which is decreased at the elevated temperatures. 


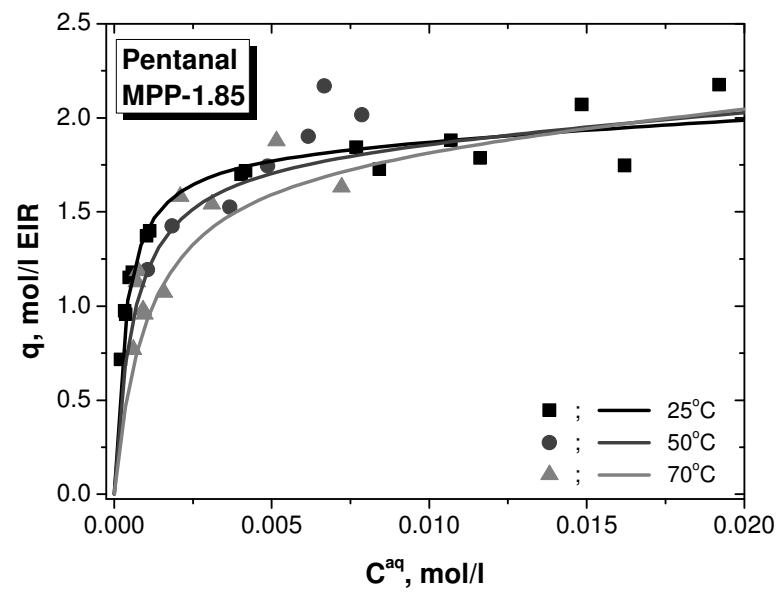

(a)

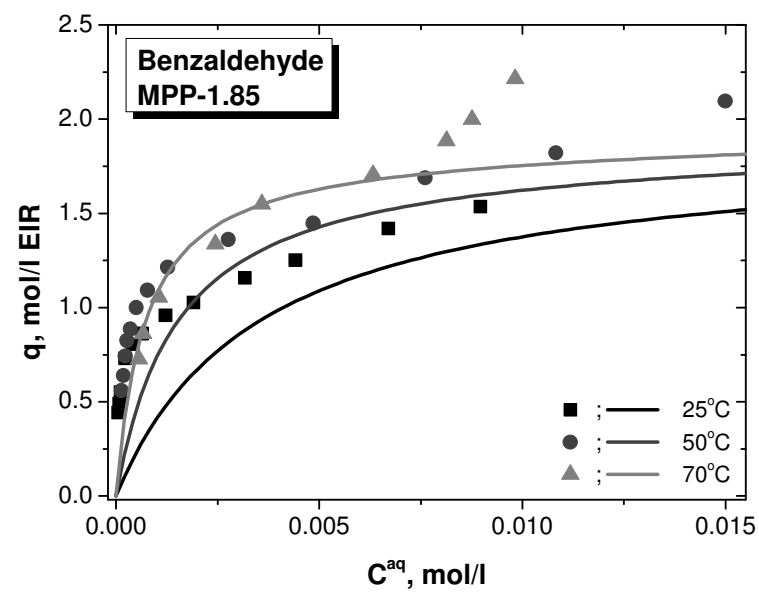

(b)

Figure 4.6: Equilibrium isotherms of (a) pentanal and (b) benzaldehyde on fully impregnated MPP for three different temperatures (points - experimental data; lines - model predictions) 


\subsubsection{Sorption of benzaldehyde}

It has been observed that the sorption of benzaldehyde differs from the other investigated aldehydes. The mathematical model based on liquid-liquid equilibrium successfully predicts the sorption equilibrium behavior for all the aldehydes investigated except for benzaldehyde. Opposite to the other aldehydes, the particle material appeared to have a large influence on the sorption of benzaldehyde (Figure 4.5(d)). This particle material effect significantly decreases at higher temperatures (Figure 4.6(b)). Thus, it is clear that, in the case of benzaldehyde, adsorption on the particles surface, which increases the overall capacity comparing to that expected based on the assumption of inert particle material, cannot be neglected. The particle effect on benzaldehyde sorption is once again highlighted in Figure 4.7 which presents the equilibrium isotherms for XAD-16 with different amine loadings. It can be noticed that the isotherms differ not only from the liquid-liquid equilibrium based prediction but also with amine loading on the particle.

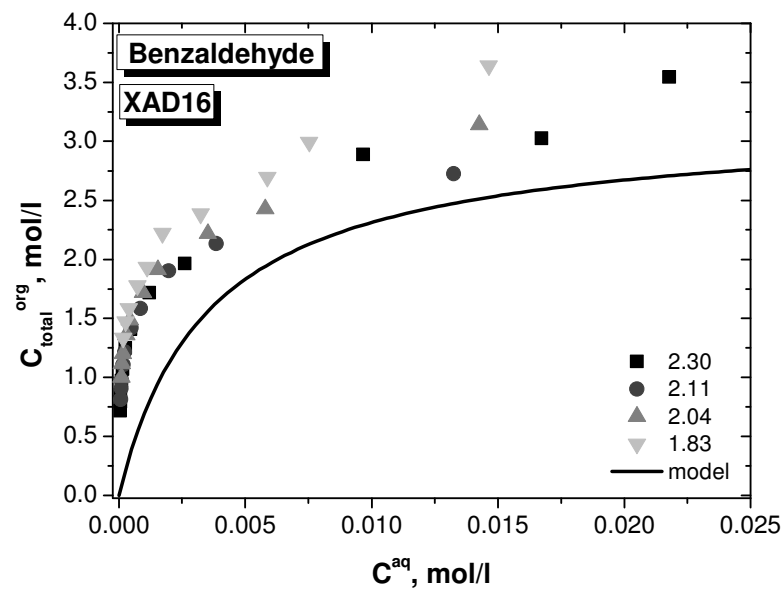

Figure 4.7: Equilibrium isotherms of benzaldehyde on Primene ${ }^{\circledast} J M-T$ impregnated XAD-16 with different amine loading at $25^{\circ} \mathrm{C}$, compared with the liquid-liquid isotherm (model prediction based on eq. 4.12) with the pure amine

The highest organic concentration is observed for the resin with the lowest amine loading (XAD16-1.83), most probably because its pore volume is partly filled with the amine, leaving some "free" polymeric surface for benzaldehyde adsorption [10]. The same goes for the XAD16-2.04 resin only the "free" surface area is lower. The two resins with the highest amine loading show overlapping isotherms, i.e. they offer the same 


\section{2 || Chapter 4}

"additional capacity". This suggests that the additional adsorption capacity highly depends on the type of interaction with the surface. This interaction is different for the active sites that are "free" and in direct interaction with the aqueous phase and those in interaction with the amine. It can be considered that the amine is also adsorbed on the surface, changing its availability for the benzaldehyde molecules.

It is obvious that the adsorption on the polymeric surface is highly influenced by the surrounding solution. Also, it is difficult to specify which species exactly get adsorbed, benzaldehyde or the complex or both. Moreover, the polymer support surface is in equilibrium with the organic phase inside the pores, not directly with the aqueous phase. All this makes it difficult to theoretically describe the additional adsorption isotherm. Nevertheless, since the sorption of benzaldehyde is most likely caused by both reactive extraction and benzaldehyde adsorption on the polymer surface, an attempt was made to express the total capacity as a contribution of these two effects (eq. 4.13).

$$
q^{\text {total }}=q+q^{a d s}
$$

in which a Freundlich form adsorption term $q^{a d s}$ was used to correlate the experimental data (eq. 4.14).

$$
q^{a d s}=k \cdot\left(C_{\text {Ald }}^{a q}\right)^{n}
$$

A similar approach was already applied by Ruiz et al. [7] for the modelling of valeric acid sorption. The results are presented in Figure 4.8 for fully impregnated XAD-16 and MPP (which represent extremes in the fitting with eqs. 4.13-4.14). The parameter values for these two resins are listed in Table 4.2. While a satisfactory fit is obtained for the XAD16-2.30 resin $\left(R^{2}=0.9609\right)$, this is not the case for MPP-1.85 $\left(R^{2}=0.8782\right)$. However, the development of a more detailed approach for correlating the "additional adsorption" surpasses the scope of this research.

Table 4.2: Parameters of the Freundlich isotherms presented in Figure 4.8

\begin{tabular}{lccc}
\hline Freundlich parameters & & \\
\hline & \multicolumn{4}{c}{ eqs. $4.13-4.14$} \\
\cline { 2 - 4 } & $\mathrm{k}$ & $\mathrm{n}$ & $\mathrm{R}^{2}$ \\
& $\mathrm{~mol}^{(1-\mathrm{n})} 1^{\mathrm{n}} / \mathrm{l}_{\mathrm{EIR}}$ & & \\
\hline XAD-16-2.30 & $0.607 \pm 0.042$ & $0.0051 \pm 0.0010$ & 0.9609 \\
MPP-1.85 & $0.370 \pm 0.053$ & $0.0012 \pm 0.0005$ & 0.8782 \\
\hline
\end{tabular}




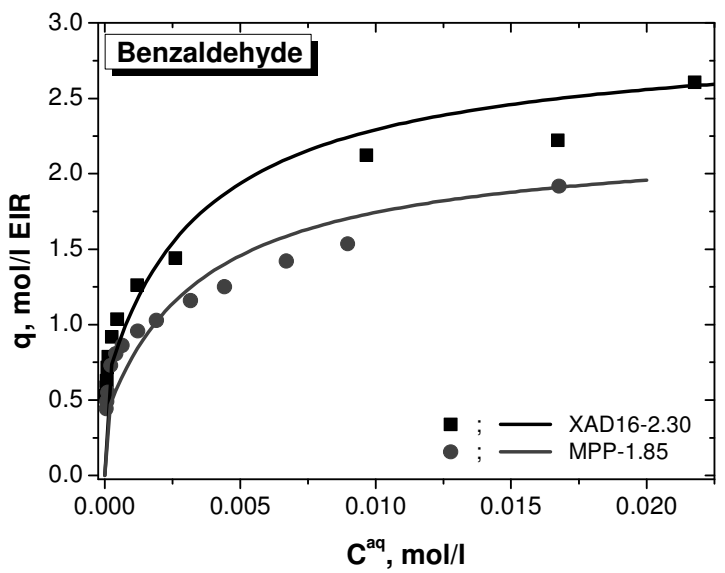

Figure 4.8: Correlation of experimental data with model presented with eqs. 4.13-4.14 for XAD16-2.30 and MPP-1.85 impregnated resins (points - experiment; lines - model predictions)

\subsection{Conclusions}

The sorption of different aldehydes from aqueous solutions with macroporous polymeric adsorbents impregnated with a primary amine (Primene ${ }^{\circledR}$ JM-T) was investigated. The molecular structure of the aldehyde displayed a large influence on the overall sorption capacity, which decreased in the order pentanal > 3-methylbutanal > benzaldehyde $>$ furfural. The same order was reported for the reactive liquid-liquid extraction system [12]. It is observed that the particles with the highest porosity can retain the highest amount of amine, resulting in the highest capacity for the aldehyde recovery. The polymeric support material does not significantly influence the sorption of pentanal, 3-methylbutanal and furfural. In contrast, the particle material has a large influence on the sorption of benzaldehyde, where the capacity for the recovery is increased compared to the liquid-liquid systems. This increase is most likely caused by the additional adsorption on the particle surface.

The influence of the temperature on the overall sorption capacity for both pentanal and benzaldehyde corresponds to the one reported for the reactive liquid-liquid system [12]. In case of pentanal, in the low concentration region the capacity is decreased at elevated temperature, while for the high concentrations the effect is opposite. In case of benzaldehyde, the capacity is increased at elevated temperatures for the whole concentration region studied, whereas the additional capacity caused by the surface adsorption decreases at elevated temperatures. 


\section{$74 \quad$ Chapter 4}

Based on the known liquid-liquid behavior, a previously developed reactive extraction model [12], extended to explain the equilibrium of the sorption with extractant impregnated resins, is able to successfully predict the equilibrium isotherms of the aldehydes investigated. In the case of benzaldehyde, however, an additional adsorption isotherm has to be taken into account.

\section{Nomenclature}

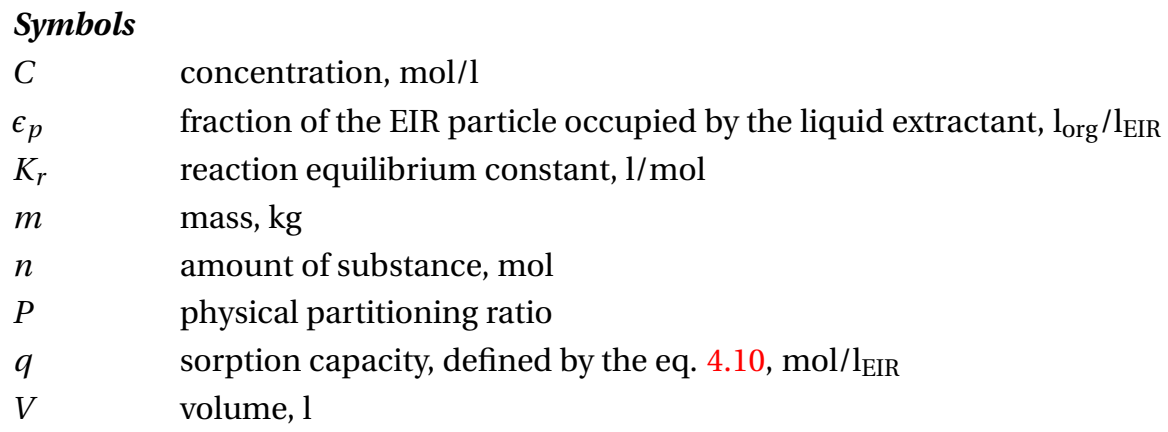

\section{Subscripts and superscripts}

$0 \quad$ initial

aq aqueous

org organic

Ald aldehyde

Am amine

AldAm complex formed by aldehyde and amine

\section{References}

[1] A. Warshawsky. Extraction with Solvent-Impregnated Resins, volume 8 of Ion Exchange and Solvent Extraction, pages 229-310. Marcel-Dekker, New York (1981). 4.1

[2] J. L. Cortina and A. Warshawsky. Ion Exchange and Solvent Extraction, volume 13 of Ion Exchange and Solvent Extraction, chapter Developments in solid-liquid extraction by Solvent Impregnated Resins, pages 195-293. Dekker, New York (1997). 4.1

[3] R.-S. Juang and H.-L. Chang. Distribution equilibrium of citric acid between 
aqueous solutions and tri-n-octylamine-impregnated macroporous resins. Industrial and Engineering Chemistry Research, 34, 1294-1301 (1995). 4.1

[4] R.-S. Juang and T.-C. Chou. Sorption of citric acid from aqueous solutions by macroporous esins containing a tertiary amine - Equilibria. Separation Science and Technology, 31(10), 1409-1425 (1996). 4.1

[5] M. Traving and H.-J. Bart. Recovery of organic acids using ion-exchangerimpregnated resins. Chemical Engineering Technology, 5(10), 997-1003 (2002). 4.1

[6] M. O. Ruiz, J. L. Cabezas, I. Escudero, J. R. Alvarez and J. Coca. $\alpha$-Phenylglycine extraction with a trialkylmethylammonium chloride-impregnated macroporous resin. 1. Equilibrium. Trans IChemE, 40(A), 529-536 (2002). 4.1

[7] M. O. Ruiz, J. L. Cabezas, I. Escudero, J. R. Alvarez and J. Coca. Valeric acid extraction with tri-N-butyl phosphate impregnated in a macroporous resin. I. Equilibrium and mass transfer rates. Separation Science and Technology, 39(1), 77-95 (2004). 4.1, 4.4.5

[8] M. Ruiz, I. Escudero and A. Horta. Extraction equilibria of $\alpha$-phenylglycine and aspartic acid with TOMAC-impregnated resins. Chemical Engineeing Science, 62, 2737-2749 (2007). 4.1

[9] A. Kostova and H.-J. Bart. Equilibrium study of amino acid reactive sorption with solvent impregnated resins, Part I. Solvent Extraction and Ion Exchange, 25, 109126 (2007). 4.1

[10] K. Babić, L. van der Ham and A. de Haan. Recovery of benzaldehyde from aqueous streams using extractant impregnated resins. Reactive and Functional Polymers, 66(12), 1494-1505 (2006). 4.1, 4.2.2, 4.2.3, 4.3, 4.4.1, 4.4.4, 4.4.5

[11] T. W. G. Solomons. Fundamentals of organic chemistry. John Wiley \& Sons, New York, third edition edition (1998). 4.1

[12] K. Babić, A. G. J. van der Ham and A. B. de Haan. Reactive extraction of aldehydes from aqueous solutions with Primene ${ }^{\circledast}$ JM-T. Submitted to Separation and Purification Technology. 4.1, 4.3, 4.3, 4.3, 4.4.2, 4.4.3, 4.5, 4.5

[13] D. Ruthven. Principles of adsorption and adsorption processes. Wiley, New York (1984). 4.4.4 



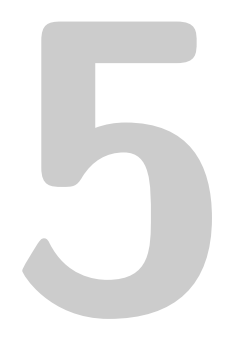

\section{Sorption kinetics for the removal of aldehydes from aqueous streams with extractant impregnated resins}

The sorption kinetics for the removal aldehydes from aqueous solutions with Amberlite XAD-16 and MPP particles impregnated with Primene ${ }^{\circledast} J M-T$ was investigated. A model, accounting for the simultaneous mass transfer and chemical reaction, is developed to describe the process. It is based on the analogy to the diffusion and reaction in a stagnant liquid sphere, but corrected for the porosity and particle properties influencing the diffusion. The model describes the kinetic behavior of the process in the low concentration region rather well. However, in the high concentration region, larger discrepancies are observed. Initially, the influence of the flow rate was investigated to eliminate the effect of the external mass transfer. The influence of the particle morphology was investigated for both physical and reactive sorption. Physical sorption experiments were used to determine the factor $\tau$ that accounts for the particle properties influencing the diffusion. The diffusion is faster in XAD-16 than in MPP impregnated systems. Reaction rate constant $k_{x}$ was determined by fitting the model to the experimental data. Sorption of benzaldehyde appears to be significantly slower $\left(k_{x} \sim 10^{-4} \mathrm{l} / \mathrm{mol} s\right)$ than the sorption of pentanal $\left(k_{x} \sim 10^{-3} \mathrm{l} / \mathrm{mol} \mathrm{s}\right)$ due to the slower chemical reaction. The influence of the particle size was investigated for the sorption of pentanal with XAD-16. The particle size does influence the diffusion term, but does not have an effect on the reaction rate. The extractant loading influences the reaction rate slightly in the low concentration region, whereas the initial concentration of the solute has a more pronounced effect. 



\subsection{Introduction}

$\mathrm{E}$

XTRACTANT IMPREGNATED RESIN (EIR) technology [1] was proposed by us for the removal of aldehydes from aqueous streams, yielding residual concentrations of ppb-level [2], either to protect the environment or to obtain a valuable product. Since EIR technology is a synergistic combination of adsorption and reactive extraction, it combines a high capacity and selectivity with relatively simple equipment and operation. The concept of EIRs is based on the incorporation of a selective extractive reagent into a porous particle by physical impregnation. When contacted with an aqueous solution the reagent forms a complex with a solute. Both reagent and the formed complex remain in the resin phase as they are insoluble in the aqueous phase.

As complexing agent the primary amine Primene ${ }^{\circledast} \mathrm{JM}-\mathrm{T}$ was used. It shows a reversible yet sufficiently strong reaction with aldehydes, being able to selectively increase the aldehydes affinity for the organic phase by several orders of magnitude. The extraction capability towards benzaldehyde, in both liquid-liquid and impregnated resin systems was tested in our previous work (see Chapter 2) [2]. In that work three different macroporous adsorbents, Amberlite XAD-16, MPP and Stamypor, were evaluated as solid support.

For the complete understanding of the sorption process, as well as the subsequent equipment and process design, besides equilibrium data, also the sorption kinetics has to be known. Sorption kinetics for extractant impregnated resin systems was mainly investigated assuming the analogy with the ion-exchange resins [3] and described by two frequently used models: the homogeneous particle diffusion model and the shrinking core model [4-6]. Some papers also report more rigorous modeling based on Fick's law of diffusion [4, 7-12] assuming a surface reaction between the solute and the impregnated extractant. In almost all of these kinetics studies, intraparticle diffusion was identified as the rate controlling step.

In our previous study [2] a preliminary investigation of the sorption kinetics of benzaldehyde on Primene ${ }^{\circledast}$ JM-T impregnated XAD-16 and MPP using a stirred cell was reported. Using the modified shrinking core model [13] it was shown that the kinetics of sorption is influenced by both intraparticle diffusion and the chemical reaction between the aldehyde and the amine. Up to our knowledge, among all the EIR studies reported in literature, this case was described only by Juang and Lin for the recovery of $\mathrm{Zn}^{2+}$ from aqueous solutions with D2EHPA impregnated Amberlite XAD-2 and XAD-4 [14].

In this chapter, we present a more extensive kinetic analysis and develop a model that describes the sorption of aldehydes in more detail. In the case of the sorption of aldehydes in resins impregnated with a primary amine, the reaction takes place in the bulk of the organic amine phase and not at the surface interface of the resin. For derivation of the model it is assumed that the particle is inert and fully impregnated 


\section{$80 \quad$ || Chapter 5}

with a reactive liquid. The description of diffusion and reaction is then identical to that of diffusion and reaction in a stagnant liquid sphere taking porosity and other particle properties (like tortuosity) into account. This concept was previously applied by Hogendoorn [15] and evaluated for the absorption of the acid gases $\mathrm{CO}_{2}$ and $\mathrm{H}_{2} \mathrm{~S}$ in alumina particles impregnated with reactive alkanolamine solutions [16].

The developed model was experimentally evaluated for the sorption kinetics of pentanal and benzaldehyde using the Zero Length Column (ZLC) method [17-19]. Experiments were performed at sufficiently high flow rates to eliminate the effect of external mass transfer and axial dispersion. Furthermore, the influence of the EIR properties like particle support material, particle size and extractant loading as well as the influence of the molecular structure of the aldehyde and its initial concentration was studied.

\subsection{Experimental}

\subsubsection{Reagents}

Benzaldehyde (99\%)and 1-phenyldodecane (98\%) were purchased from Merck, Germany. Pentanal (98\%) was obtained from Fluka, Germany. A sample of primary amine Primene $^{\circledast} \mathrm{JM}$-T was received from Rohm and Haas, Europe. All chemicals were used as received. All aqueous solutions were made using MiliQ water. Amberlite XAD-16 was purchased from Sigma Aldrich, Germany. Macroporous polypropylene (MPP) particles were donated by Akzo Nobel, the Netherlands.

Impregnation of the resins was done as described in our previous work (see Chapter 2 or reference [2]). The extractant loadings of the particles used in this study are listed in Table 5.1. Impregnated particles were sieved in the following diameter fractions: $0.25-0.5 \mathrm{~mm}, 0.5-0.71 \mathrm{~mm}, 0.71-1.0 \mathrm{~mm}$ and $>1.0 \mathrm{~mm}$. In all of the experiments, the fraction of $0.71-1.0 \mathrm{~mm}$ was used, except in those experiments where the influence of the particle size was investigated.

\subsubsection{Experimental set-up and operating procedure}

The ZLC set-up used for the kinetics experiments is shown in figure 5.1. The set-up comprised a glass vessel, a piston pump, an UV/Vis detector and a column packed with a thin layer of EIRs.

For experiments with pentanal $40 \mathrm{ml}$ of aqueous solution of various concentrations $(0.0048,0.011$ and $0.027 \mathrm{~mol} / \mathrm{l})$ was used. Experiments with benzaldehyde were done with $50 \mathrm{ml}$ of aqueous solution with an initial concentration of $0.001 \mathrm{~mol} / 1$. 


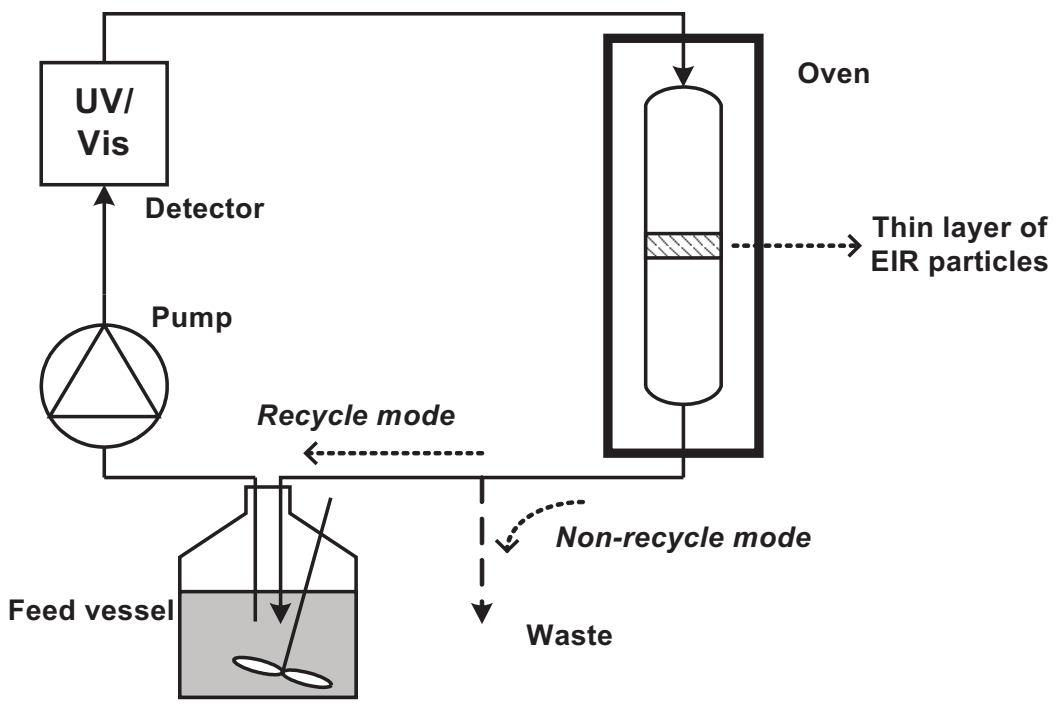

Figure 5.1: ZLC set-up

For adjusting the flow rates a piston pump (Knauer K-100) was used. The flow was varied from 10 to $40 \mathrm{ml} / \mathrm{min}$. The change in concentration was monitored on-line with a fast-scanning UV/Vis spectrophotometer (Wellchrom/Knauer K-2600) equipped with a $2 \mu \mathrm{l}$ flow cell. Pentanal was detected at $249 \mathrm{~nm}$ and benzaldehyde at $283 \mathrm{~nm}$.

EIR particles were packed in a $15 \mathrm{~mm}$ diameter column (Omnifit, UK). The volume of the impregnated particles was $0.21 \mathrm{ml}$ in all experiments yielding a packed layer thickness of approximately $2 \mathrm{~mm}$. To assure a constant temperature throughout the experiment the column was placed in an oven. All the experiments were done at $25^{\circ} \mathrm{C}$ (similar to the equilibrium experiments in our previous work [2, 20]).

The ZLC set-up can be operated in recycle and non-recycle mode. Before each experiment, the set-up was equilibrated with pure water. Then the feed tube was placed in the vessel containing the aqueous solution of an aldehyde. As a consequence, the UV detector detected an increase in the sorbate concentration. The feed solution was well mixed to assure homogeneous concentration (simulating a perfectly mixed system).

Calibration of the set-up. Prior to the experiments, the set-up needs to be calibrated [19]. The volume of the total set-up was determined to be able to calculate the dilution of the initial solution caused by the residual solvent present in the system, i.e. volume of all tubing, pump cell and UV/Vis detector cell as well as the volume of the porous part of the bed. In all experiments, the bed porosity was 0.41 (calculated as one minus the ratio of the volume of the EIRs present and the total volume of the 


\section{2 || Chapter 5}

column). The system volume was calculated from the difference in aldehyde concentration measured in the set-up with an empty bed in both recycle and non-recycle mode. The typical blank response curves can be found in the work of Dunnewijk et al. [19]. For the set-up used in these experiments, it was determined that this volume is $3.2 \pm 0.1 \mathrm{ml}$.

\subsubsection{Mathematical model}

\section{Model description}

When a particle impregnated with Primene ${ }^{\circledR} \mathrm{JM}-\mathrm{T}$ is contacted with an aqueous solution of aldehyde, the aldehyde molecules first dissolve in the organic liquid where they subsequently react with the amine forming a complex (Schiff base) according to the reaction

$$
R_{1} R_{2} \mathrm{CO}+\mathrm{R}_{3} \mathrm{NH}_{2} \rightleftharpoons \mathrm{R}_{1} \mathrm{R}_{2} \mathrm{C}=\mathrm{NR}_{3}+\mathrm{H}_{2} \mathrm{O}
$$

For convenience we will proceed with using the following abbreviations as subscripts: Ald for the aldehyde $\left(\mathrm{R}_{1} \mathrm{R}_{2} \mathrm{CO}\right), A m$ for the amine $\left(\mathrm{R}_{3} \mathrm{NH}_{2}\right)$ and AldAm for the Schiff base complex $\left(\mathrm{R}_{1} \mathrm{R}_{2} \mathrm{C}=\mathrm{NR}_{3}\right)$. When first order in the reactants is assumed, the reaction rate becomes

$$
R_{\text {Ald }}=k_{x} \cdot C_{\text {Ald }}^{\text {org }} \cdot C_{\text {Am }}^{\text {org }}-k_{-x} \cdot C_{\text {AldAm }}^{\text {org }}=k_{x}\left(\begin{array}{l}
\text { org } \\
\text { Ald }
\end{array} C_{A m}^{\text {org }}-\frac{1}{K_{r}} C_{\text {AldAm }}^{\text {org }}\right)
$$

where the superscript org refers to the organic phase and the equilibrium constant is given by

$$
K_{r}=\frac{k_{x}}{k_{-x}}=\frac{C_{\text {AldAm }}^{\text {org }}}{C_{\text {Ald }}^{\text {org }} \cdot C_{A m}^{\text {org }}}
$$

It is assumed that the particle is inert and spherical. In that case the analogy with the stagnant liquid sphere (droplet) can be applied. Simultaneous mass transfer and chemical reaction in a small sphere should be non-stationary because of the finite capacity of the droplet. The non-stationary mass transfer accompanied by a chemical reaction can be described, for each component in the EIR, by the following mass balance [15]

$$
\epsilon_{p} \frac{\partial C_{i}^{o r g}}{\partial t}=\epsilon_{p} \frac{D_{i}}{\tau} \frac{1}{r^{2}} \frac{\partial}{\partial r}\left(r^{2} \frac{\partial C_{i}^{o r g}}{\partial r}\right)-\epsilon_{p} \gamma_{i} R_{A} \quad, \quad i=\text { Ald, Am, Ald Am }
$$


where the stoichiometric coefficient $\gamma$ is 1 for Ald and Am and -1 for AldAm. $\epsilon_{p}$ is the fraction of the EIR particle occupied by the liquid extractant

$$
\epsilon_{p}=\frac{V^{\text {org }}}{V^{E I R}}
$$

and $\tau$ is the correction factor encountering for the particle properties influencing the diffusion (like tortuosity). The decrease of the aldehyde concentration in the aqueous phase can be calculated from the following mass balance

$$
V^{a q} \frac{\partial C_{A l d}^{a q}}{\partial t}=-a_{S} V^{E I R} J_{A l d}
$$

where $J_{\text {Ald }}$ is the flux of the aldehyde through the outer particle surface. The superscript $a q$ refers to the aqueous phase. Since the reaction between aldehyde and amine is of a finite rate, the flux is given by

$$
J_{\text {Ald }}=\left.\epsilon_{p} \frac{D_{\text {Ald }}}{\tau} \frac{\partial C_{\text {Ald }}^{o r g}}{\partial r}\right|_{r=R}
$$

The specific surface area $a_{S}$ for spherical particles equals

$$
a_{S}=\frac{3}{R}
$$

To improve the scalability of the model a dimensionless variable for the radius is introduced

$$
\varphi=\frac{r}{R}
$$

Combining eqs. $5.2,5.4,5.6-5.9$, the model equations can finally be written as follows.

EIR phase:

$$
\begin{gathered}
\epsilon_{p} \frac{\partial C_{i}^{\text {org }}}{\partial t}=\epsilon_{p} \frac{D_{i}}{\tau R^{2}} \frac{1}{\varphi^{2}} \frac{\partial}{\partial \varphi}\left(\varphi^{2} \frac{\partial C_{i}^{\text {org }}}{\partial \varphi}\right)-\epsilon_{p} \gamma_{i} k_{x}\left(C_{\text {Ald }}^{\text {org }} C_{\text {Am }}^{\text {org }}-\frac{1}{K_{r}} C_{\text {AldAm }}^{\text {org }}\right) \\
i=A l d, A m, \text { Ald Am }
\end{gathered}
$$

Aqueous phase:

$$
\frac{\partial C_{A l d}^{a q}}{\partial t}=-\left.3 \epsilon_{p} \frac{D_{A l d}}{\tau R^{2}} \frac{V^{E I R}}{V^{a q}} \frac{\partial C_{A l d}^{o r g}}{\partial \varphi}\right|_{\varphi=1}
$$




\section{$84 \quad$ Chapter 5}

Since there is a clear physical solubility of aldehydes in the organic phase, it is not likely that the chemical reaction will be restricted to the interface. It is to be expected that it takes place in the bulk of the organic phase. However, at the interface, it can be assumed that there is a physical equilibrium of the solute. Therefore, following boundary condition can be written

$$
\left.C_{\text {Ald }}^{\text {org }}\right|_{\varphi=1}=P \cdot C_{\text {Ald }}^{a q}
$$

where $P$ is the physical distribution constant of the aldehyde. Both the amine and the formed complex are not soluble in the aqueous phase and we assume that it is not likely that they will diffuse out of the particle. Therefore, it can be stated

$$
\left.\frac{\partial C_{i}^{o r g}}{\partial \varphi}\right|_{\varphi=1}=0 \quad, \quad i=A m, \text { Ald Am }
$$

Because of the process symmetry

$$
\left.\frac{\partial C_{i}^{o r g}}{\partial \varphi}\right|_{\varphi=0}=0 \quad, \quad i=A l d, \text { Am, Ald Am }
$$

In general, initial conditions can be written as follows

$$
\begin{gathered}
C_{i, 0}^{\text {org }}=\mathrm{constant}, \quad \varphi \in[0,1] \quad, \quad i=\text { Ald }, A m, \text { Ald Am } \\
C_{A l d, 0}^{a q}=\mathrm{constant}
\end{gathered}
$$

For the experiments done in this work, the initial concentration of the aldehyde

and the complex (Schiff base) in the organic phase $C_{i, 0}^{\text {org }}$ was zero. Thus, initially the amine is present in the particle in the pure form $\left(C_{A m, 0}^{\text {org }}=3.1 \mathrm{~mol} / \mathrm{l}\right)$.

\section{Model parameters}

To successfully solve this model, the values of the model parameters need to be known. The equilibrium constants as well as physical distribution ratios were measured in our previous work [20]. Diffusivity of aldehydes in Primene ${ }^{\circledast} \mathrm{JM}-\mathrm{T}$ in the lower concentration region was estimated using the Wilke-Chang correlation [21] combined with the Le Bas [21] contribution method for estimation of the molar volume at boiling point. Compared to the small aldehyde, the diffusion of both the bulky amine and the formed complex was assumed to be negligible and therefore corresponding diffusivities were 
set to zero. Values of the parameters as well as the initial conditions used in the calculations are listed in the Table 5.1. Since no study of the reaction kinetics for the reaction of the aldehydes with Primene ${ }^{\circledR} \mathrm{JM}$-T was reported in literature, the reaction rate constant had to be estimated by fitting the model to the experimental data. Factor $\tau$ was determined from independent physical diffusion experiments, also by fitting the model (without reaction terms) to the experimental data. It is important to mention that the volume of the aqueous phase $V^{a q}$ was corrected for the system volume. Also, the initial concentration of the solution was calculated taking into account the dilution caused by this residual volume.

Table 5.1: Parameters used in the model calculations

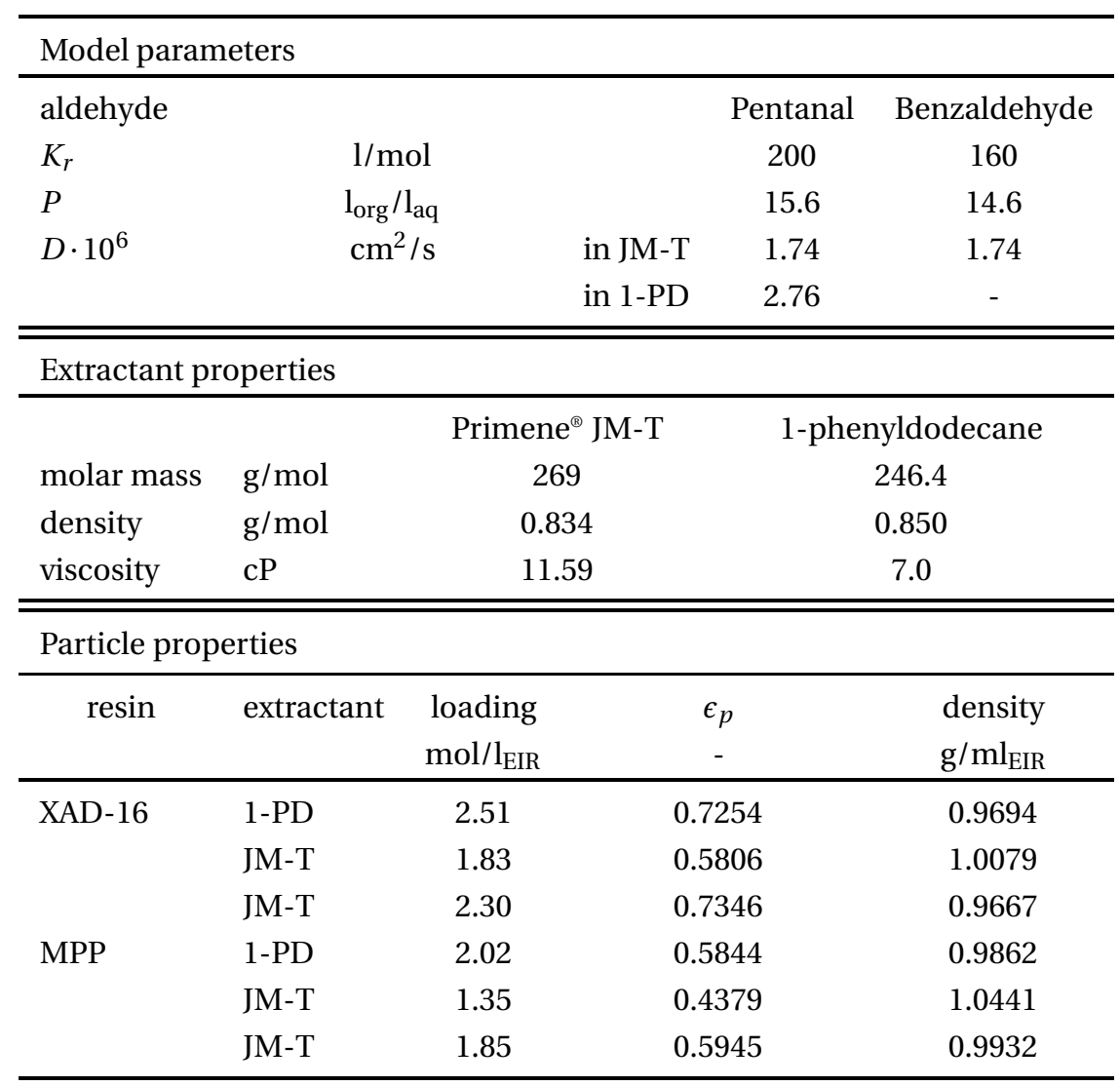




\section{$86 \quad$ || Chapter 5}

\section{Parameter estimation procedure}

The model was implemented in the computer program gPROMS ${ }^{\circledast}$ (Process Systems Enterprise Limited, London, UK) and the difference between experimentally measured data and model was minimized to obtain the optimum value for the reaction rate constant $k_{x}$. The fitting was done with the parameter estimation subroutine within gPROMS $^{\circledast}$ using the maximum likelihood estimator and a heteroscedastic variance model of the measured values [22].

\subsection{Results and discussion}

\subsubsection{Influence of the flow rate}

Investigation of the intraparticle phenomena can be done if the experiments are conducted in such a way that the external mass transfer can be neglected. With the ZLC set-up this can be achieved by using sufficiently high flow rates. For the selection of the proper experimental conditions it is important to determine the influence of the flow rate on the sorption rate. Therefore flow rates of $10-40 \mathrm{ml} / \mathrm{min}$ were applied. The results for the pentanal sorption on XAD-16 impregnated with Primene ${ }^{\circledR}$ JM-T (particle size $0.71-1 \mathrm{~mm}$ ) are presented in Figure 5.2, where it is seen that for flow rates higher than $30 \mathrm{ml} / \mathrm{min}$ the external mass transfer is negligible. The same effect of the flow rate was observed for all other systems investigated in this study (not shown). For this reason all subsequent experiments were done at flow rates of $40 \mathrm{ml} / \mathrm{min}$.

\subsubsection{Influence of the material}

\section{Physical sorption system (particles impregnated with non-reactive liquid)}

The influence of the polymeric support is expressed by the parameter $\tau$ in the mathematical model. To determine $\tau$ independent from the complexation reaction, particles were impregnated with a non-reactive liquid (1-phenyldodecane). The mathematical expression of the physical sorption is the same as for the reactive (eqs 5.9-5.16) except for the "reaction terms". By fitting the model to the experimental data the value of $\tau$ was determined to be $3.03 \pm 0.55$ for XAD-16 impregnated systems and $6.51 \pm$ 0.50 for MPP impregnated systems. Although, the standard deviation of the model from the experimental results was not exceeding $2.5 \%$, the standard deviation of the experimental measurements is rather high (about 10\%). This is due to the relatively low physical solubility of pentanal in 1-phenyldodecane. Subsequently the change in concentration between the initial and the equilibrium value is rather small for more accurate detection by the UV detector used in this research. 


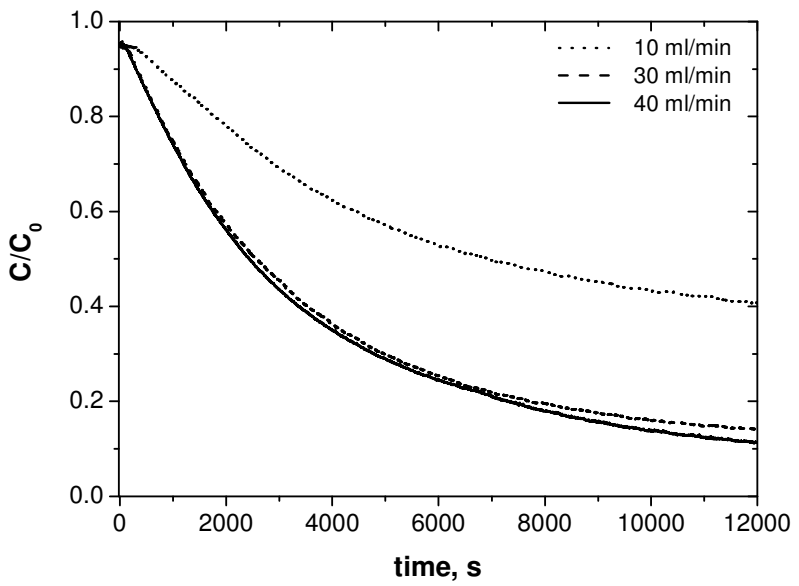

Figure 5.2: Influence of the flow rate on the pentanal sorption on XAD-16 impregnated with Primene $^{\circledast} J M-T$ (particle size $0.71-1.0 \mathrm{~mm}$ )

Considering only the particle morphology (pore sizes and pore size distribution), the difference in obtained values for $\tau$ is surprising. However, XAD-16 is somewhat less hydrophobic than MPP which most probably promotes the diffusion of polar organic like aldehyde [23]. Moreover, it should be noted that XAD-16 is a spherical and MPP a cylindrical particle. Nevertheless, from the work of Ma and Evans [24] it follows that the cylinders with a length to diameter ratio of about 1 can be approximated by a sphere with an identical radius. For MPP particles used in this research this condition is satisfied. When differences between XAD-16 and MPP are discussed, it should also be noted that even within the same particle size fraction, the particle size distribution was not the same. For the experiments, a fraction of $0.71-1.0 \mathrm{~mm}$ was used, but for XAD-16 the average particle size was $0.8 \mathrm{~mm}$, where for MPP it was $0.95 \mathrm{~mm}$.

\section{Reactive sorption system (particles impregnated with Primene ${ }^{\circledast} \mathrm{JM}-\mathrm{T}$ )}

Experimental results for the sorption of pentanal with resins impregnated with Primene ${ }^{\circledast} \mathrm{JM}-\mathrm{T}$ are presented in Figure 5.3. It can be seen that the sorption is faster for XAD-16 impregnated systems. Fitting the model to the experimental results revealed that the reaction rate constant is the same (within the error of estimation) for both XAD-16 and MPP impregnated systems (Table 5.2). Therefore, it can be concluded that the difference in sorption rates comes from the particle properties (correlated by the factor $\tau$ ). 


\section{$88 \quad$ || Chapter 5}

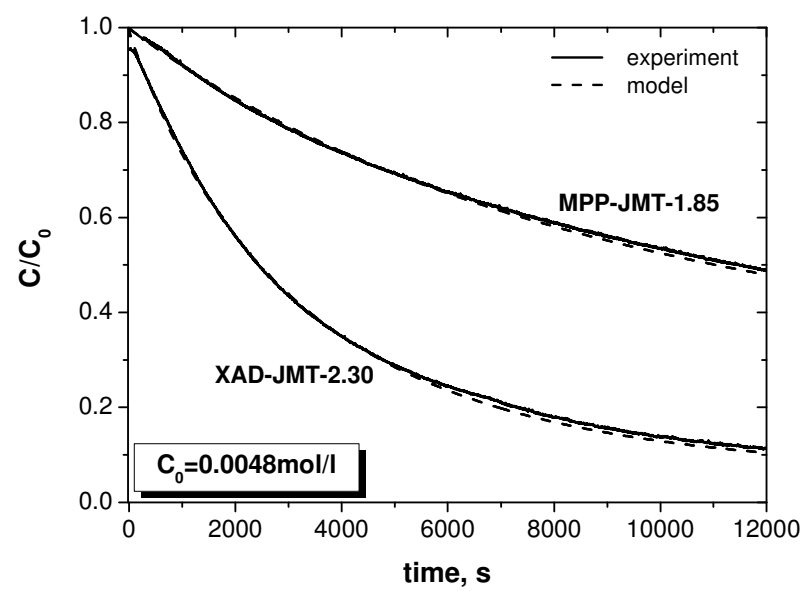

(a)

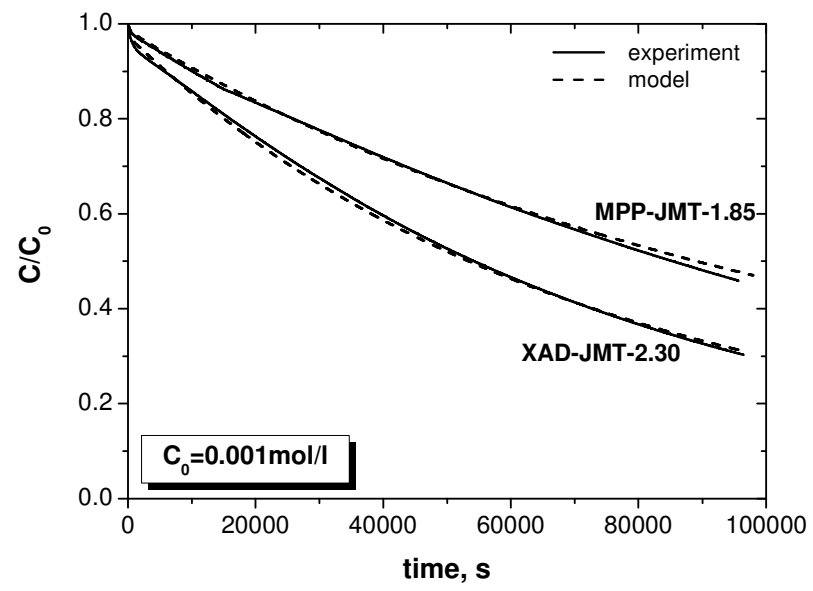

(b)

Figure 5.3: Influence of the particle material on the sorption of (a) pentanal and (b) benzaldehyde 
Table 5.2: Determined reaction rate constants

\begin{tabular}{|c|c|c|c|}
\hline Reaction rate const & & & \\
\hline aldehyde & particle & $\begin{array}{l}\text { reaction rate } \\
\text { constant } \\
k_{x} \cdot 10^{3} \\
1(\mathrm{~mol} \mathrm{~s})^{-1}\end{array}$ & $\begin{array}{c}\text { standard } \\
\text { deviation } \\
\sigma^{2} \cdot 10^{6} \\
1(\mathrm{~mol} \mathrm{~s})^{-1}\end{array}$ \\
\hline \multirow[t]{2}{*}{ pentanal } & XAD-16 & 4.431 & 8.250 \\
\hline & MPP & 4.130 & 9.851 \\
\hline \multirow[t]{2}{*}{ benzaldehyde } & $\mathrm{XAD}-16$ & 0.151 & 0.040 \\
\hline & MPP & 0.141 & 0.566 \\
\hline
\end{tabular}

\subsubsection{Influence of the particle size}

The influence of the particle size on the sorption of pentanal was investigated with fully impregnated particles XAD16-JMT-2.30. The experimental results as well as the model predictions are presented in Figure 5.4. Unlike the previous paragraph, where the value of parameter $k_{x}$ was determined by fitting to the experimental data, here the already determined value (Table 5.2) was used for simulation of the kinetics behavior. From Figure 5.4 it is evident that the model gives rater good predictions of the sorption kinetics for all the particle sizes studied. The model deviation from the experimentally measured data is not more than $5 \%$.

Since all the parameters are identical for all the particle sizes, it can be concluded that there is no influence on the effective diffusion coefficient $\left(\epsilon D_{\text {Ald }} / \tau\right)$. However, since the diffusion term (diffusion time constant) is inversely proportional to $R^{2}$, the diffusion is subsequently faster in smaller particles.

\subsubsection{Influence of the extractant loading}

The effect of the Primene ${ }^{\circledast} \mathrm{JM}$-T loading is presented in Figure 5.5. It can be noticed that the sorption rate slightly increases with the increase of the extractant loading (and thus, the volume of the organic phase). When the volume of the organic phase influences the reaction rate, the chemical reaction is slow and occurs in the bulk organic phase $[25,26]$. This confirms the justification of the initial model assumption. Increased loading of the extractant means an increased value of the parameter $\epsilon_{p}$ and from eq. 5.10 it follows that the decrease in aqueous concentration of aldehyde will be larger. However, for the low aldehyde concentrations this effect is not so pronounced since there is an excess of amine for the reaction. 


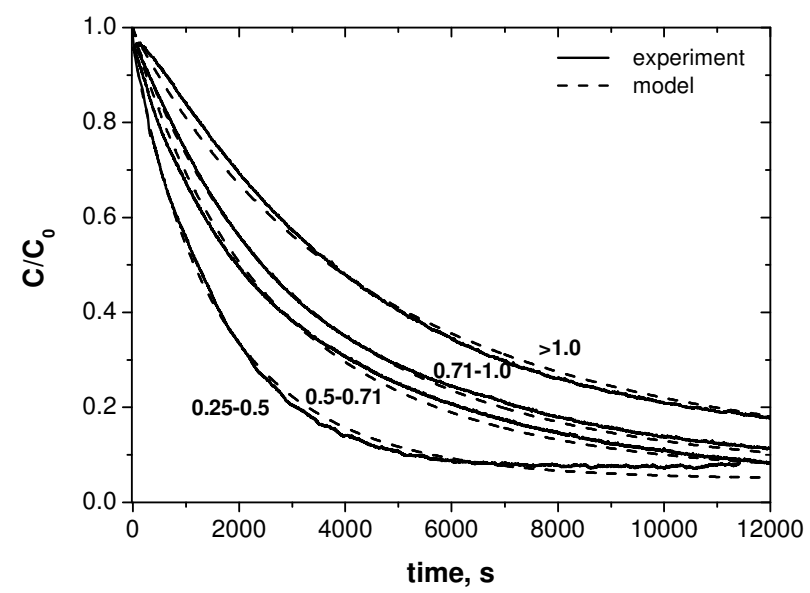

Figure 5.4: Influence of the particle size for the XAD16-JMT-2.3 EIR (particle sizes: $0.25-0.5 \mathrm{~mm} ; 0.5-0.71 \mathrm{~mm} ; 0.71-1.0 \mathrm{~mm} ;>1.0 \mathrm{~mm}$ ) and initial pentanal concentration of $0.0048 \mathrm{~mol} / \mathrm{l}$

\subsubsection{Influence of the solute's initial concentration}

The influence of the initial concentration of aldehydes was investigated for both XAD16 and MPP fully impregnated systems. It is known from literature [26, 27] that the higher the initial concentration the faster the reaction rate. After the chemical equilibrium is reached the diffusion becomes the only limiting resistance. The experimental results as well as model predictions are presented in Figure 5.6. A large discrepancy between the model prediction and the experimental values can be observed for the high solute's concentration. Even though the initial sorption rate is well predicted, when approaching the equilibrium, the model starts deviating from the experimental data. It is observed that the equilibrium value differs significantly from our previous work [20]. It is possible that this is due to the extractant loss during the experiment. This most likely happens as a consequence of the organic phase swelling which influences the immobilization of the extractant. On the other hand, it is possible that the effective diffusivity is lowered due to the increased concentration of the solute and complex inside the pores. The concentration dependency of the effective diffusivity is often taken into account using Darken correction. This effect is also observed for the sorption of phenylglycine on tricaprylylmethylammonium chloride impregnated $\mathrm{XAD}$ resins by Kostova et al. [12].

In Figure 5.7 the experimental data of the benzaldehyde sorption measured in a 


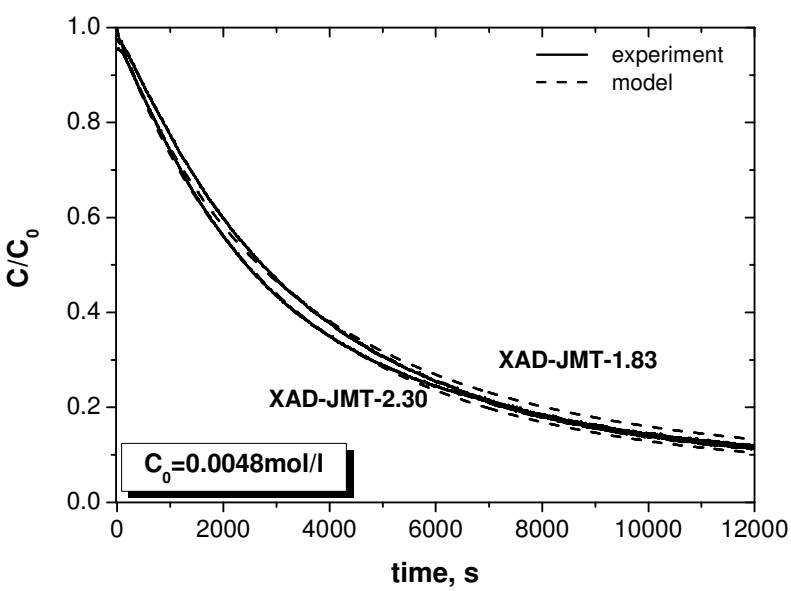

(a)

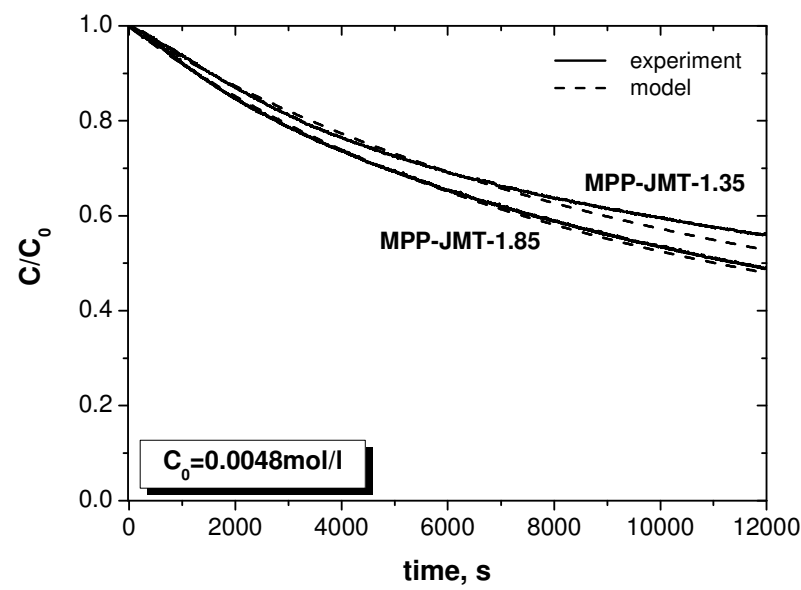

(b)

Figure 5.5: Influence of the extractant loading on the sorption of pentanal (initial concentration $0.0048 \mathrm{~mol} / \mathrm{l}$, particle size $0.71-1.0 \mathrm{~mm}$ ): polymeric support (a) XAD-16 (b) MPP 


\section{2 || Chapter 5}

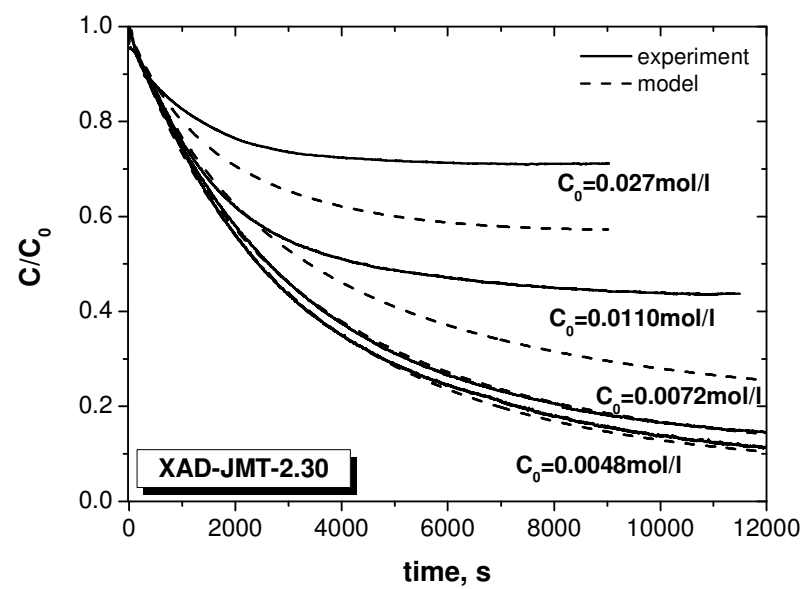

(a)

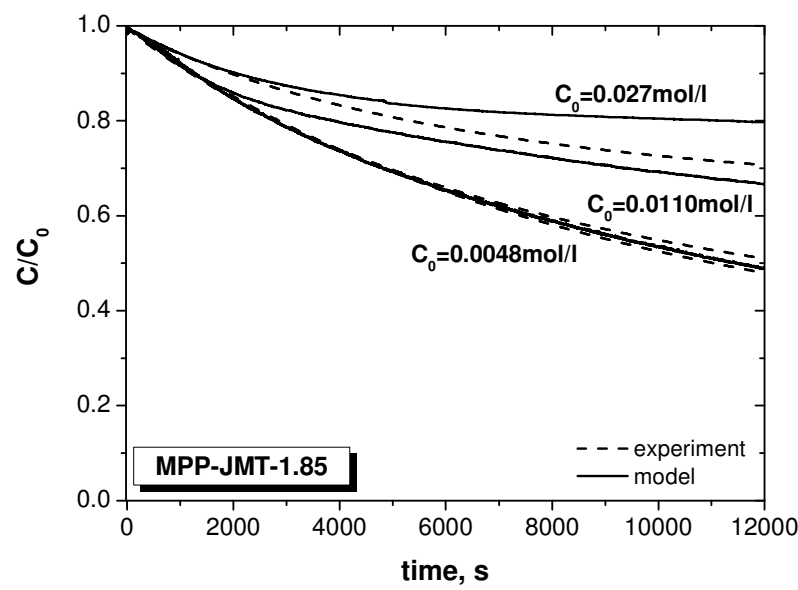

(b)

Figure 5.6: Influence of the initial concentration of pentanal: polymeric support (a) XAD-16 (b) MPP 
stirred vessel, reproduced from our previous work [2], are presented together with the predictions based on the model described here. The initial concentration of benzaldehyde was $0.033 \mathrm{~mol} / \mathrm{l}$. Compared to the results presented in Figure 5.3(b), it can be noticed that the initial sorption rate is higher at the higher initial concentration. Similar was observed by Lee [27] for the reactive extraction of penicillin G by Amberlite LA-2, as well as by Nikhade and Pangarkar [26] for the extraction of citric acid with Alamine 336. As well as for the sorption of pentanal at the higher concentrations, the discrepancy between the predicted and measured values is observed. Since the instability of the EIRs has a serious consequence on the future industrial application, further research should provide more insight to this problem.

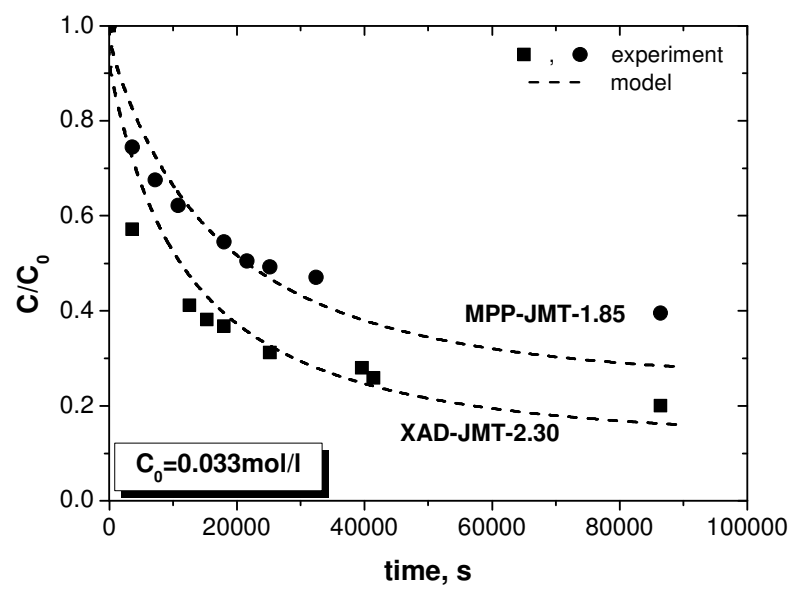

Figure 5.7: Sorption of benzaldehyde (initial concentration $0.033 \mathrm{~mol} / \mathrm{l})$ : points - data from the stirred vessel measurements [2], line-model

\subsubsection{Benzaldehyde sorption}

Experimental results of benzaldehyde sorption are compared with pentanal in Figure 5.8. Compared to the sorption of pentanal it is shown that the sorption of benzaldehyde is rather slow. Obtained reaction rate constants are listed in Table 5.2. It appears that they are an order of magnitude lower than those of pentanal. It is possible that this is due to the steric hindrances in case of benzaldehyde. Additionally, it is observed and explained by several authors [28-30] that the Schiff base formation mechanism is different for aromatic and aliphatic compounds. In general, this reaction is acid cat- 


\section{4 || Chapter 5}

alyzed, but in case of aromatics the acid catalyses the formation of the intermediate tetrahedral complex, whereas for aliphatics it catalyses the subsequent water elimination.

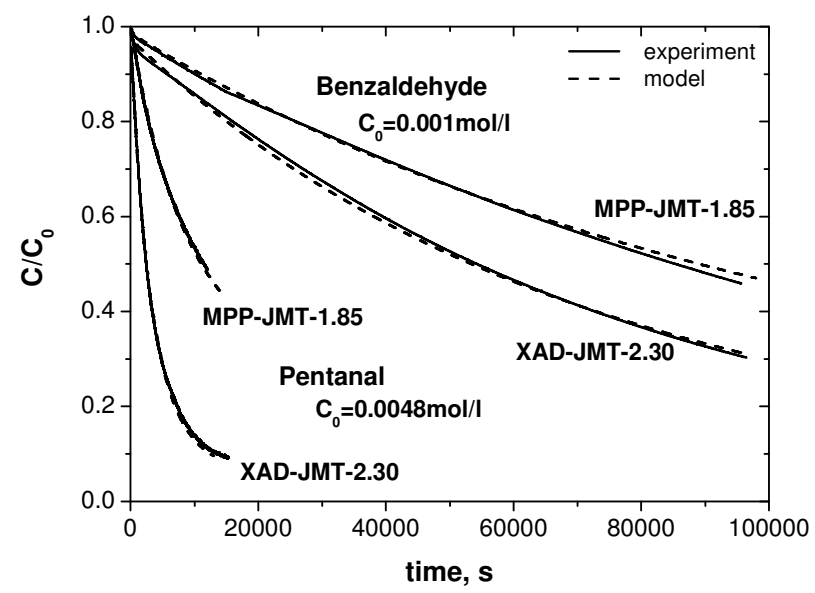

Figure 5.8: Comparison of the sorption kinetics of benzaldehyde and pentanal with particles fully impregnated with Primene ${ }^{\circledast} J M-T$ (particle size fraction $0.71-1.0 \mathrm{~mm}$ )

Unlike the sorption of pentanal, the sorption of benzaldehyde with impregnated resins is influenced by both reactive extraction and surface adsorption [2]. Therefore it can not be assumed that the polymeric support is inert. However, it can be seen from Figure 5.8 that the model fits the experimental data rather well. This suggests that the surface diffusion is negligible [16, 31].

\subsection{Conclusions}

The sorption kinetics of aldehydes from aqueous solutions with Primene ${ }^{\circledast}$ JM-T impregnated Amberlite XAD-16 and MPP particles, was successfully investigated in a ZLC setup. A model to describe the sorption process in the EIR was developed in analogy to diffusion and reaction in a stagnant liquid sphere, but correcting for the porosity and particle properties influencing the diffusion. The developed model describes the kinetic behavior of the process in the low concentration region rather well. In the high concentration region the initial sorption rate is well predicted. However, approaching the equilibrium the model starts deviating from the experimental data. 
Particle morphology and the support material do influence the sorption rate. The effective diffusivity of aldehydes is faster in XAD-16 than in MPP impregnated particles. The reaction rate constants were determined by fitting the model to the experimental data. For both EIRs the same value of the reaction rate constant was obtained. The sorption of benzaldehyde is much slower than the sorption of pentanal due to the difference in the chemical reaction rate constant which is an order of magnitude lower for benzaldehyde $\left(\sim 10^{-4} \mathrm{l} / \mathrm{mols}\right)$ than for pentanal $\left(\sim 10^{-3} \mathrm{l} / \mathrm{mols}\right)$. This is probably due to the difference in the reaction mechanism of aromatic and aliphatic Schiff base formation. The effect of initial aldehyde concentration, extractant loading and particle size on the sorption rate is well described by the model. Particle size effect is dominated by the diffusion time constant which is inversely proportional to $R^{2}$.

\section{Nomenclature}

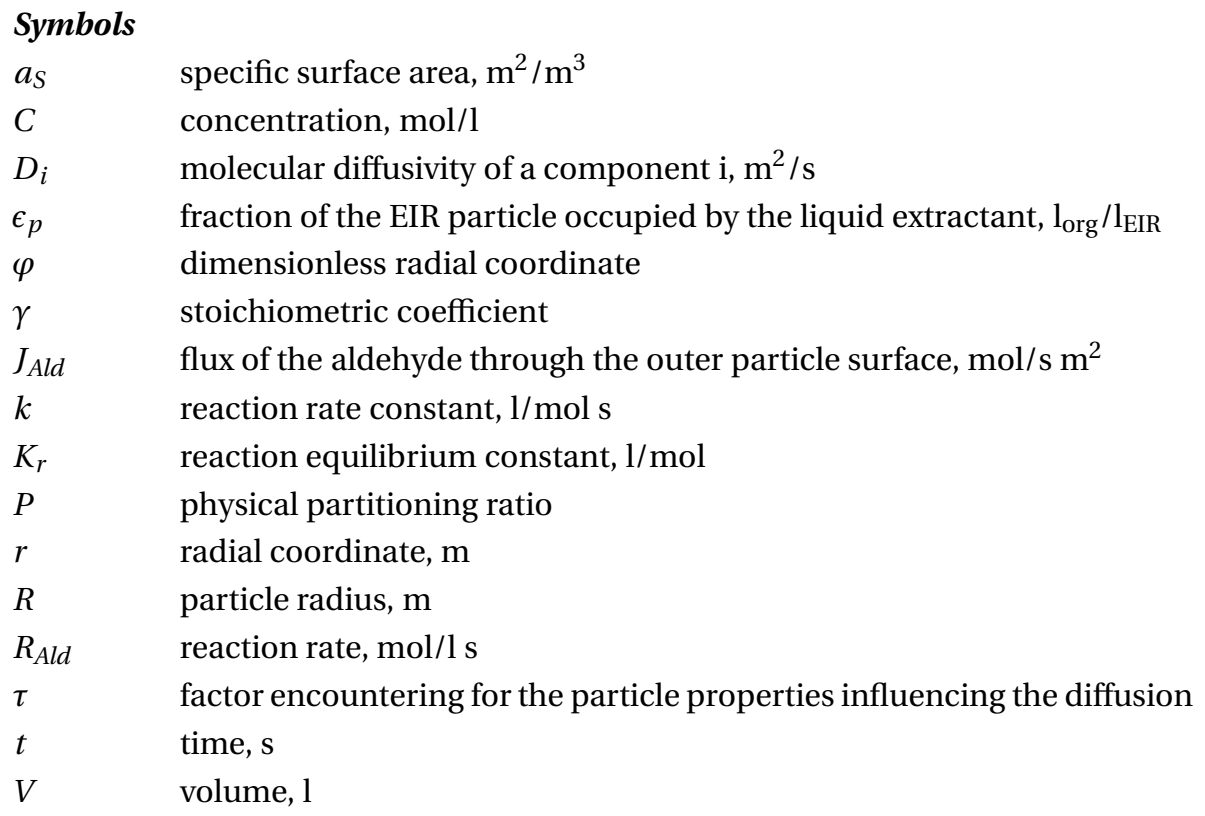

\section{Subscripts and superscripts}

0 initial

$a q \quad$ aqueous 


\section{$96 \quad$ || Chapter 5}

$\begin{array}{ll}\text { org } & \text { organic } \\ \text { Ald } & \text { aldehyde } \\ \text { Am } & \text { amine } \\ \text { AldAm } & \text { complex formed by aldehyde and amine } \\ x & \text { forward } \\ -x & \text { backward }\end{array}$

\section{References}

[1] J. L. Cortina and A. Warshawsky. Ion Exchange and Solvent Extraction, volume 13 of Ion Exchange and Solvent Extraction, chapter Developments in solid-liquid extraction by Solvent Impregnated Resins, pages 195-293. Dekker, New York (1997). 5.1

[2] K. Babić, L. van der Ham and A. de Haan. Recovery of benzaldehyde from aqueous streams using extractant impregnated resins. Reactive and Functional Polymers, 66(12), 1494-1505 (2006). 5.1, 5.2.1, 5.2.2, 5.3.5, 5.7, 5.3.6

[3] J. Cortina, R. Arad-Yellin, N. Miralles, A. Sastre and A. Warshawsky. Kinetics studies on heavy metal ions extraction by Amberlite XAD2 impregnated resins containing a bifunctional organophosphorous extractant. Reactive and Functional Polymers, 38, 269-278 (1998). 5.1

[4] R. S. Juang and H. C. Lin. Metal sorption with extractant-impregnated macroporous resins. 1. Particle diffusion kinetics. Journal of Chemical Technology and Biotechnology, 62, 132-140 (1995). 5.1

[5] N. Kabay, M. Arda, B. Saha and M. Streat. Removal of Cr(VI) by solvent impregnated resins (SIR) containing Aliquat 336. Reactive and Functional Polymers, 54, 103-115 (2003). 5.1

[6] B. Saha, R. Gill, D. Bailey, N. Kabay and M. Arda. Sorption of $\operatorname{Cr}(\mathrm{VI})$ from aqueous solution by Amberlite XAD-7 resin impregnated with Aliquat 336. Reactive and Functional Polymers, 60, 223-244 (2004). 5.1

[7] M. Traving and H.-J. Bart. Recovery of organic acids using ion-exchangerimpregnated resins. Chemical Engineering Technology, 5(10), 997-1003 (2002). 5.1

[8] M. O. Ruiz, J. L. Cabezas, I. Escudero, J. R. Alvarez and J. Coca. Valeric acid extraction with tri-N-butyl phosphate impregnated in a macroporous resin. I. Equilibrium and mass transfer rates. Separation Science and Technology, 39(1), 77-95 (2004). 5.1

[9] J. Serarols, J. Poch, M. Llop and I. Villaescusa. Determination of the effective diffusion coefficient for gold(III) on a macroporous resin XAD-2 impregnated 
with triisobutyl phosphine sulfide. Reactive and Functional Polymers, 41, 27-35 (1999). 5.1

[10] J. Serarols, J. Poch and I. Villaescusa. Determination of the effective diffusion coefficient of $\mathrm{Zn}$ (II) on a macroporous resin XAD-2 impregnated with di-2ethylhexyl phosphoric acid (DEHPA). Influence of metal concentration and particle size. Reactive and Functional Polymers, 48, 53-63 (2001). 5.1

[11] M. O. Ruiz, J. L. Cabezas, I. Escudero and J. Coca. $\alpha$-Phenylglycine extraction with a trialkylmethylammonium chloride-impregnated macroporous resin. 2. Kinetics. Trans IChemE, 80(A), 537-542 (2002). 5.1

[12] A. Kostova, Tsibranska and H.-J. Bart. Study of phenylalanine sorption kinetics on solvent impregnated resins, Part II. Solvent Extraction and Ion Exchange, 25(1), 127-145 (2007). 5.1, 5.3.5

[13] V. M. Bhandari, V. A. Juvekar and S. R. Pathwardhan. Modified shrinking core model for reversible sorption on ion-exchange resins. Separation Science and Technology, 27(8-9), 1043-1064 (1992). 5.1

[14] R. S. Juang and H. C. Lin. Metal sorption with extractant-impregnated macroporous resins. 2. Chemical reaction and particle diffusion kinetics. Journal of Chemical Technology and Biotechnology, 62, 141-147 (1995). 5.1

[15] J. Hogendoorn, G. Versteeg and W. van Swaaij. Mass transfer accompanied by reversible chemical reactions in an inert porous sphere impregnated with a stagnant liquid. Chemical Engineering Science, 48(15), 2727-2740 (1993). 5.1, 5.2.3

[16] J. Hogendoorn, G. Versteeg and W. van Swaaij. Experimental study of the absorption of acid gases in porous particles impregnated with aqueous alkanolamine solutions. Chemical Engineering Science, 49(20), 3421-3438 (1994). 5.1, 5.3.6

[17] M. Eić and D. Ruthven. A new experimental technique for measurement of intercrystalline diffusivity. Zeolites, 8, 40-45 (1988). 5.1

[18] M. Ruthven and P. Stapleton. Measurement of liquid phase counter-diffusion in zeolites by the ZLC method. Chemical Engineering Science, 48, 89-98 (1993). 5.1

[19] J. Dunnewijk, H. Bosch and A. B. de Haan. Adsorption kinetics of $\mathrm{CoCl}_{2}$ and $\mathrm{PPh}_{3}$ over macroreticular and gel type adsorbents by a generalized ZLC method. Chemical Engineering Science, 61, 4813-4826 (2006). 5.1, 5.2.2

[20] K. Babić, A. G. J. van der Ham and A. B. de Haan. Sorption equilibrium for the removal of aldehydes from aqueous streams with Primene ${ }^{\circledast} \mathrm{JM}-\mathrm{T}$ impregnated resins. Manuscript in preparation. 5.2.2, 5.2.3, 5.3.5

[21] R. Reid, J. Prausnitz and B. Poling. The Properties of Gases and Liquids. McGrawHill International Editions (2001). 5.2.3

[22] gPROMS ${ }^{\oplus}$ Advanced User Guide, Chapter 3. Process System Enterprise, London, UK (2007). 5.2.3 


\section{$98 \quad$ || Chapter 5}

[23] H. Komiyama and J. Smith. Intraparticle mass transport in liquid-filled pores. AIChE Journal, 20(4), 728-734 (1974). 5.3.2

[24] Y. Ma and L. Evans. Transient diffusion from a well stirred reservoir to a body of arbitrary shape. AIChE Journal, 14(6), 956-961 (1968). 5.3.2

[25] L. Doraiswamy and M. Sharma. Heterogeneous reactions: Analysis, examples and reactor design, Vol 2.: Fluid-Fluid-Solid Reactions. John Wiley \& Sons, New York, first edition edition (1984). 5.3.4

[26] B. P. Nikhade and V. G. Pangarkar. Equilibria and kinetics of extraction of citric acid from aqueous solutions in Alamine 336 - Cyclohexanone system. Separation Science and Technology, 40, 2539-2554 (2005). 5.3.4, 5.3.5, 5.3.5

[27] S. Lee. Kinetics of reactive extraction of penicillin G by Amberlite LA-2 in kerosene. AIChE Journal, 50(1), 119-126 (2004). 5.3.5, 5.3.5

[28] E. Cordes and W. Jencks. On the mechanism of Schiff base formation and hydrolysis. Journal of American Chemical Society, 84(5), 832-837 (1962). 5.3.6

[29] E. Cordes and W. Jencks. The mechanism of hydrolisis of Schiff bases derived from aliphatic amines. Journal of American Chemical Society, 85(18), 2843-2848 (1963). 5.3.6

[30] R. Martin. Reactions of carbonyl compounds with amines and derivatives. Journal of Physical Chemistry, 68(6), 1369-1377 (1964). 5.3.6

[31] B. Prasher and Y. Ma. Liquid diffusion in microporous alumina pellets. AIChE Journal, 23(3), 303-312 (1977). 5.3.6 


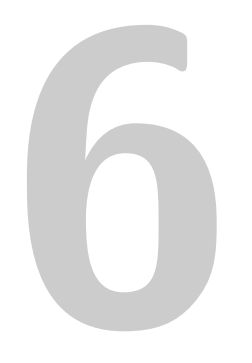

\section{Chiral separation of amino-alcohols using extractant impregnated resins}

The performance of Extractant Impregnated Resin (EIR) technology for chiral separation of amino-alcohols has been investigated. Phenylglycinol was selected as an archetype model enantiomer and azophenolic crown ether was used as a versatile enantioselective extractant. 1-Phenyloctane was selected as a suitable solvent for this application because of its very low solubility in water. The extraction system was first evaluated by liquid-liquid equilibrium experiments. It was shown that the crown ether dissolved in 1-phenyloctane has an intrinsic selectivity of 11.5. However, due to very low solubility of phenylglycinol in 1-phenyloctane, the overall capacity of the crown ether solution in 1-phenyloctane is limited. The extractant solution was immobilized in macroporous polypropylene particles. Competitive sorption isotherms were obtained from batch experiments and successfully described with a predictive model based on the complexation constants and partitioning ratios, either obtained from literature or from independent experiments. The equilibrium selectivity of these EIRs approaches the intrinsic selectivity for low phenylglycinol concentrations. The dynamic behaviour and stability of the system were examined in column experiments. Breakthrough profiles as well as the elution curves of the R enantiomer are less sharp than those of the S enantiomer proving that the R enantiomer is strongly retained on the column. Separation of phenylglycinol enantiomers is favoured by using lower feed flow rates. The column was regenerated by water with only atmospheric carbon dioxide dissolved which proved to be sufficient. After several cycles the breakthrough profiles remain unchanged suggesting that these EIRs will be sufficiently stable. 



\subsection{Introduction}

$\mathrm{O}$

PTICALLY PURE SUBSTANCES, used as raw materials, intermediates and very often as the end products, are very important for the (pharmaceutical and related) life science industries. To obtain optically pure products it is, in most of the cases, necessary to separate racemic mixtures. On industrial scale this is usually done by either crystallisation or by chromatography. Crystallisation is generally considered as inflexible and thus its development for each new racemic mixture is quite time consuming [1]. This process is also relatively slow, difficult to control and requires complicated handling of solids/slurries. Chromatography is more flexible than crystallisation because only a relatively low selectivity is required due to a large number of theoretical stages present, indicating that the same column material can be used to separate several enantiomers. However, existing specific enantioselective adsorbents are very expensive and have a low capacity [2]

In this work we propose Extractant Impregnated Resin (EIR) technology, the concept introduced by Warshawsky [3], as a possible alternative. It is a synergistic combination of adsorption and reactive extraction that combines high selectivity and capacity with simple equipment and operation. This concept is based on the incorporation of an enantioselective reagent into a porous particle by physical impregnation (Figure 6.1). When contacted with a racemic mixture the reagent preferentially forms a complex with one of the enantiomers. The formed complex as well as the reagent, remains in the resin phase as they are insoluble in the other phase. The reaction should be reversible but sufficiently strong to increase the enantiomer's affinity for the organic phase by several orders of magnitude to obtain an economically feasible process. In comparison with conventional enantioselective adsorbents, it is expected that a chiral reagent in free solution can be present at a larger concentration than only on a surface, resulting in a higher capacity of the reagent phase. Furthermore, the costs of this way prepared enantioselective particles are considerably lower.

Extractant Impregnated Resins have been extensively studied for removal of traces of metals from aqueous solutions [3-5]. There have been reports of using EIRs for recovery of organic compounds like phenols [6], flavonoids [7], carboxylic [8-11] and amino acids [12, 13], aldehydes [14] and antibiotics [15]. However, according to our knowledge, this technique has not yet been applied for separation of enantiomers.

The objective of this research was to evaluate the use of EIRs for chiral separations. Phenylglycinol (Figure 6.2(a)) was selected as an archetype model enantiomer. A versatile enantioselective extractant was selected, so the EIR technology can be applied to separate several components from the same chemical class with sufficient enantioselectivity.

In the field of chromatography for enantiomer separation various chiral stationary phases based on different chiral crown ethers have been known to be very effective in 


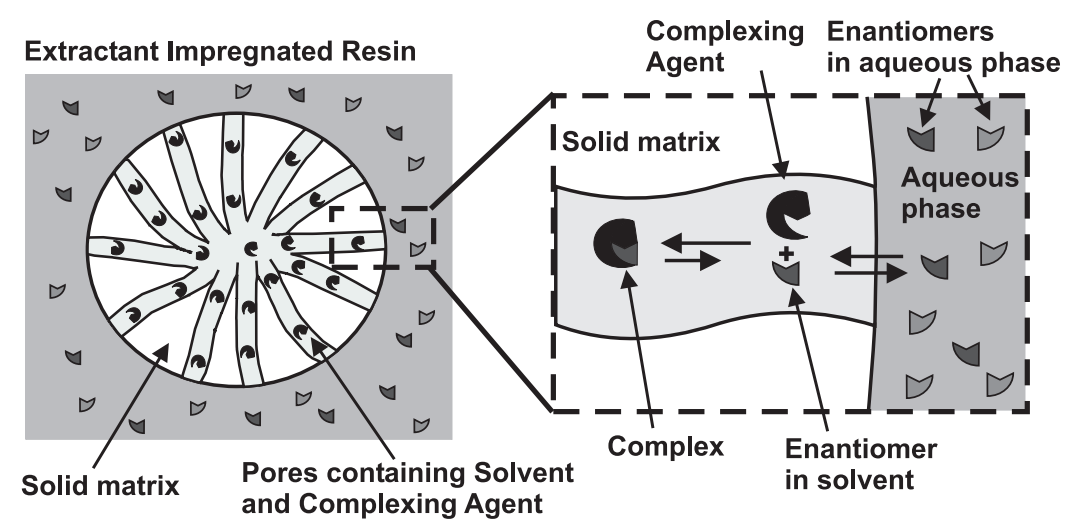

Figure 6.1: Extractant impregnated resins

resolving racemic components containing primary amino group [16-25]. In these chiral stationary phases chiral crown ethers are mainly covalently bonded to polystyrene or silica gel. Also, some supported liquid membrane applications of crown ethers have been reported in literature [26-29]. Although this technique can be considered similar to EIR its major drawback is that the selectivity is strongly depending on the permeation rate of the complexes inside the membrane, not on the distribution ratio. As a consequence, the data obtained from liquid-liquid extraction can not be straightforwardly used in liquid membrane separation processes [5].

In the work of Steensma et al. [30, 31] an azophenolic crown ether, presented in Figure 6.2(b) (in the rest of the text just crown ether), dissolved in toluene was identified as a promising extractant for the chiral separation of amines and amino-alcohols. However, toluene is not an environmentally benign solvent and due to its high volatility and high solubility in water not suitable for this application. Thus, as an alternative for toluene, 1-phenyloctane was selected. The selection of an alternative solvent was made according to the recommendations given by Steensma et al [31]. Since the solvent has a large influence on the enantioselective performance of the crown ether, a new extraction system had to be evaluated. The extraction system was characterized by liquid-liquid equilibrium experiments. Afterwards, the crown ether dissolved in 1phenyloctane was immobilized into a porous particle. Competitive sorption equilibrium isotherms were obtained from batch experiments. It was investigated if sorption equilibria can be successfully predicted from the complexation constants and partitioning ratios, which can be obtained from literature or from independent liquidliquid equilibrium experiments. The predictive model was based on the equilibrium liquid-liquid model already developed [31]. This model was first extended to include the influence of the absorption of atmospheric carbon dioxide, then applied to predict sorption equilibria and experimentally verified. It was also tested if physical im- 
pregnation reduces the enantioselectivity like it is the case with covalent bonding [32]. Finally, the dynamic behaviour and stability of the system were examined in column experiments.<smiles>N[C](CO)c1ccccc1</smiles>

(a)

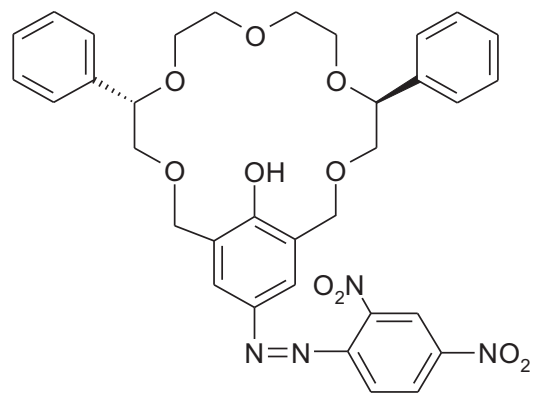

(b)

Figure 6.2: Structures of (a) phenylglycinol $\left({ }^{*}\right.$ indicates the chiral center), and (b) azophenolic crown ether

\subsection{Experimental}

\subsubsection{Reagents}

The R-phenylglycinol (99\%) was purchased from Fluka (Buchs, Switzerland), while the S-phenylglycinol (98\%) was obtained from Lancaster (Eastgate, England). The racemic mixture of phenylglycinol was made by dissolving equal amounts of pure enantiomers in MilliQ-water (Millipore, Billerica, USA). The azophenolic crown ether was manufactured by Syncom BV (Groningen, the Netherlands) in a custom synthesis [25]. Toluene (99\%) and 1-phenyloctane (>98\%) were obtained from Merck (Darmstadt, Germany). NaOH was purchased from Aldrich. All chemicals were used as received. Macroporous polypropylene (MPP) particles were donated by Akzo Nobel, the Netherlands. They are white cylindrically shaped granules with a particle size of $0.8-1.18 \mathrm{~mm}$, and estimated pore size of $500-1000 \mathrm{~nm}$ and a porosity of 0.55 .

For analytical purpose o-phtalic aldehyde (OPA), methanol, absolute ethanol, mercapto-ethanol (MCE), perchloric acid and boric acid were purchased from Merck (Darmstadt, Germany), potassium hydroxide from Riedel-De Haën and L-norvaline from Sigma. All chemicals were of analytical grade. 


\section{4 || Chapter 6}

\subsubsection{Analytical method}

The aqueous enantiomer samples were analysed by HPLC. The HPLC set-up and the analytical method were described in detail in the paper of Steensma et al. [31], with the only difference that in this research the quantification of phenylglycinol was done with the internal standard L-norvaline. The accuracy of the applied analytical method was determined to hold within $3 \%$ which was sufficient for most of the experiments.

\subsubsection{Liquid-liquid equilibria}

All liquid-liquid experiments were carried out in a jacketed $50 \mathrm{ml}$ glass vessel connected to a Julabo F-32 thermostat bath to enable temperature control. In each experiment, $15 \mathrm{ml}$ of aqueous phase, containing the racemic mixture in a concentration of $2 \mathrm{mM}$, was mixed with a $15 \mathrm{ml}$ crown ether solution in 1-phenyloctane. The concentration of the crown ether in the organic solvent was varied throughout the experiments. Sufficient contact between the phases was achieved with a magnetic stirrer at a speed of approximately $400 \mathrm{rpm}$. After, typically 2 hours of stirring, when equilibrium is reached, the phases were allowed to settle. Then a sample was taken from the aqueous phase, $\mathrm{pH}$ was measured and the sample was analysed by HPLC. The concentration in the organic phase was calculated from the mass balance.

To determine the physical partitioning ratio the same experiment was carried out at a higher $\mathrm{pH}$ without the crown ether present. The $\mathrm{pH}$ was adjusted to 11.5 by adding $\mathrm{NaOH}$. The higher $\mathrm{pH}$ as well as the ratio of aqueous to organic phase of 1:10 was necessary because of the very low partitioning ratio, resulting in a very small difference between the initial and the end concentration of enantiomers in the aqueous phase. Since in that case the experimental error becomes substantial, the measurement was repeated 10 times and a value was given as a range of values obtained from these measurements.

\subsubsection{Determination of complexation constants}

Complexation constants between crown ether and R- and S-phenylglycinol in 1-phenyloctane were determined by UV-Vis titration [33]. The experimental procedure follows the one described by Steensma et al [31]. For each titration experiment a series of samples is prepared containing a constant initial concentration of crown ether of $0.015 \mathrm{mM}$. The concentration ranges for the R- and S- enantiomer were $0.019-0.080$ $\mathrm{mM}$ and $0.1-1.3 \mathrm{mM}$, respectively, in order to assure the complexation range span of $20 \%-80 \%$. Data treatment was done with both the Scott plot [34] and the Rose-Drago plot [35]. For the R enantiomer the Scott method could not be applied due to the high complexation constant and the minimum initial concentration of crown ether needed 
for detection by the UV/Vis spectrophotometer. For all the experimental data given, $\mathrm{K} \cdot[\mathrm{CE}]<1$, and therefore these results can be considered as reliable.

\subsubsection{Impregnation procedure}

Before impregnation MPP particles were first cleaned with acetone and n-hexane and then dried under vacuum at $60^{\circ} \mathrm{C}$. The dry resin was then contacted with a precalculated amount of the crown ether in 1-phenyloctane solution to assure full loading. The saturation point of the resin was previously determined by gradual adding of the solution until the point where the resin becomes adhesive. The exact loading of the resin with extractant was calculated from the increase of mass. Afterwards, EIRs were left typically overnight to assure complete adsorption of the extractant solution. It is assumed that the solution is completely adsorbed when no resin sticks to the glass wall anymore. EIRs were also characterised by density, measured with a helium pycnometer (AccuPyc 1330, Micromeritics).

\subsubsection{Sorption equilibria}

Batch adsorption experiments were used to determine the equilibrium isotherms. In each experiment EIRs and an aqueous solution of racemic phenylglycinol $(7 \mathrm{ml})$ were placed in a $50 \mathrm{ml}$ glass-stoppered flask and shaken at $200 \mathrm{rpm}$ and $25^{\circ} \mathrm{C}$ for at least $6 \mathrm{~h}$ using the thermostated shaking bath (Julabo Shake Temp SW23). Independent experiments showed that 6 hours was sufficient to reach equilibrium. The amounts of EIRs (range $0.1-0.75 \mathrm{~g}$ ) and the concentration of racemic phenylglycinol in water (range $0.5-7 \mathrm{mM}$ ) were varied throughout the experiments. Finally, a sample of the aqueous phase was removed using a 10-ml syringe fitted with a filter (Schleicher\&Schuel, Spartan 30/0,45 RC), and transferred to a 10-ml amber vial. $\mathrm{pH}$ was measured and the concentration of both R- and S-phenylglycinol were determined by HPLC. Preparation and analysis of the samples were the same as for the liquid-liquid experiments. The amount of R- and S-phenylglycinol in the EIR particles was calculated from the mass balance for each enantiomer.

\subsubsection{Column experiments}

Continuous experiments were performed on a column with a length of $30 \mathrm{~cm}$ and internal diameter of $1.595 \mathrm{~cm}$ (Superformance 300-16, G”tec, Muehtal, Germany). It was equipped with a water jacket connected to a circulating water bath at $25^{\circ} \mathrm{C}$. Besides the column, the set-up consisted of a solvent organizer (K-1500, Knauer, Berlin, Germany), degasser (K-5020, Knauer, Berlin, Germany) and a pump (K-1001, Knauer, Berlin, Germany). UV/Vis spectrophotometer (K-2600, WellChrom, Germany) was 


\section{$106 \|$ Chapter 6}

used to monitor the column effluents. The detector acquired data at $254 \mathrm{~nm}$ where phenylglycinol shows an absorption maximum. Since the UV detector can not make a difference between $\mathrm{R}$ and $\mathrm{S}$ enantiomer, samples were taken at regular intervals and analyzed with HPLC. For the breakthrough experiments column was packed with $24.29 \mathrm{~g}$ of fresh EIRs. A $0.5 \mathrm{mM}$ racemic phenylglycinol solution in water was pumped through the column with linear flow rates in range of $75.12-225 \mathrm{cmh}^{-1}$. Regeneration of the EIRs was done by pumping the MilliQ water with dissolved atmospheric carbon dioxide through the column until the UV signal was zero.

\subsection{Results and discussion}

\subsubsection{Liquid-liquid equilibria}

\section{Model description}

A schematic representation of the reactive liquid-liquid system studied is given in Figure 6.3. As follows from this scheme the reactive system can be described by a set of physical and chemical equilibrium equations and mass balances.

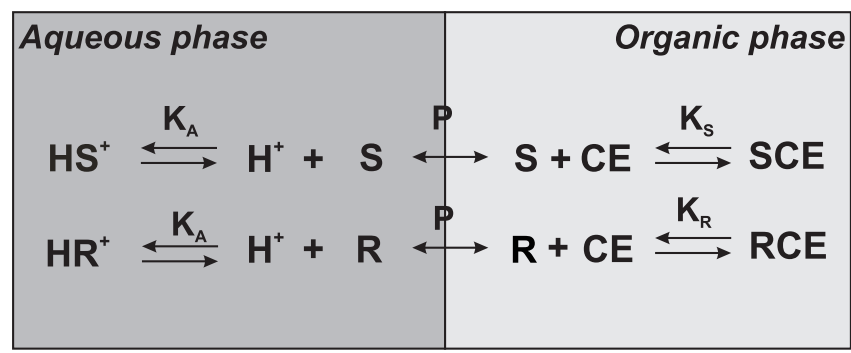

Figure 6.3: Schematic representation of the equilibrium reactions in the system

Physical partitioning of the neutral form of both enantiomers between the phases is the same. It is characterised by the partitioning ratio $P$ defined as

$$
P=\frac{C_{R}^{\text {org }}}{C_{R}^{\text {org }}}=\frac{C_{S}^{\text {org }}}{C_{S}^{\text {org }}}
$$

where $C$ stands for concentration in mol/l, while superscripts $a q$ and $\operatorname{org}$ denote aqueous and organic phase respectively. Subscripts $R$ and $S$ indicate the enantiomer. The acid-base equilibrium in the aqueous phase is characterised by the dissociation constant $K_{A}$ which is also the same for both enantiomers. 


$$
K_{A}=\frac{C_{R}^{a q} \cdot C_{H^{+}}^{a q}}{C_{H R^{+}}^{a q}}=\frac{C_{S}^{a q} \cdot C_{H^{+}}^{a q}}{C_{H S^{+}}^{a q}}
$$

The subscripts $\mathrm{H}^{+}, \mathrm{HR}^{+}$and $\mathrm{HS}^{+}$refer to the corresponding species. Reversible complexation in the organic phase between crown ether and the neutral amine form of the enantiomers is described by equilibrium complexation constants, $K_{R}$ and $K_{S}$ for the $\mathrm{R}$ and the $\mathrm{S}$ enantiomer respectively.

$$
\begin{aligned}
& K_{R}=\frac{C_{R C E}^{\text {org }}}{C_{R}^{\text {org }} \cdot C_{C E}^{\text {org }}} \\
& K_{S}=\frac{C_{S C E}^{\text {org }}}{C_{S}^{\text {org }} \cdot C_{C E}^{\text {org }}}
\end{aligned}
$$

$C E$ stands for the crown ether and $R C E$ and $S C E$ represent the corresponding complexes. Mass balances for all species present can be written as follows

$$
\begin{gathered}
\left(C_{S, 0}^{a q}-\left(C_{S}^{a q}+C_{H S^{+}}^{a q}\right)\right) \cdot V^{a q}=\left(C_{S}^{o r g}+C_{S C E}^{\text {org }}\right) \cdot V^{\text {org }} \\
\left(C_{R, 0}^{a q}-\left(C_{R}^{a q}+C_{H R^{+}}^{a q}\right)\right) \cdot V^{a q}=\left(C_{R}^{o r g}+C_{R C E}^{\text {org }}\right) \cdot V^{\text {org }} \\
C_{C E, 0}^{\text {org }}=C_{C E}^{\text {org }}+C_{S C E}^{\text {org }}+C_{R C E}^{\text {org }}
\end{gathered}
$$

With subscript 0 refers to the initial concentration of $\mathrm{S}$ and $\mathrm{R}$. The overall distribution ratios $D_{R}$ and $D_{S}$ are defined as the ratio of enantiomer concentration in the organic phase in all its forms over its concentration in the aqueous phase in all its forms at equilibrium.

$$
\begin{gathered}
D_{R}=\frac{C_{\text {totalR }}^{\text {org }}}{C_{\text {totalR }}^{a q}}=\frac{C_{R}^{\text {org }}+C_{R C E}^{\text {org }}}{C_{R}^{a q}+C_{H R^{+}}^{a q}} \\
D_{S}=\frac{C_{\text {total }}^{\text {org }}}{C_{\text {totals }}^{\text {aq }}}=\frac{C_{S}^{\text {org }}+C_{S C E}^{\text {org }}}{C_{S}^{a q}+C_{H S^{+}}^{a q}}
\end{gathered}
$$

The operational selectivity $\alpha_{o p}$ is defined as the ratio of distribution ratios (eq. $6.10)$.

$$
\alpha_{o p}=\frac{D_{R}}{D_{S}}
$$




\section{8 || Chapter 6}

The selectivity reaches an asymptotic value for high extractant concentrations. This asymptotic value is called the intrinsic selectivity $\alpha_{i n t}$ and represents the ratio of complexation constants.

$$
\alpha_{\text {int }}=\frac{K_{R}}{K_{S}}
$$

It was already shown by Steensma et al. [31] that this model predicts the extraction equilibria of phenylglycinol with crown ether dissolved in toluene satisfactorily. The model is especially successful if the uptake of $\mathrm{CO}_{2}$ from the air and the subsequent lowering of the $\mathrm{pH}$ is taken into account. To calculate the solubility of $\mathrm{CO}_{2}$ in water Henry's law can be applied

$$
C_{\mathrm{CO}_{2}}^{a q}=\frac{p_{\mathrm{CO}_{2}} \cdot \rho_{w}}{\mathrm{He}_{\mathrm{CO}_{2}}}
$$

where $p_{\mathrm{CO}_{2}}$ denotes the partial pressure of $\mathrm{CO}_{2}, \mathrm{He}_{\mathrm{CO}_{2}}$ is Henry's coefficient and $\rho_{w}$ is the molar density of water. Dissociation equilibria of carbonic acid are characterised by dissociation constants $K_{A 1}, K_{A 2}$ and $K_{A 3}$ (eqs 6.13-6.15).

$$
\begin{gathered}
K_{A 1}=\frac{C_{\mathrm{H}_{2} \mathrm{CO}_{3}}^{a q}}{C_{\mathrm{CO}_{2}}^{a q}} \\
K_{A 2}=\frac{C_{\mathrm{HCO}_{3}^{-}}^{a q} \cdot C_{H^{+}}^{a q}}{C_{\mathrm{H}_{2} \mathrm{CO}_{3}}^{a q}} \\
K_{A 3}=\frac{C_{\mathrm{CO}_{3}^{2-}}^{a q} \cdot C_{H^{+}}^{a q}}{C_{H C O_{3}^{-}}^{a q}}
\end{gathered}
$$

Electroneutrality condition can now be written as

$$
C_{\mathrm{OH}^{-}}^{a q}+2 \cdot C_{\mathrm{CO}_{3}^{2-}}^{a q}+C_{\mathrm{HCO}_{3}^{-}}^{a q}=C_{\mathrm{H}^{+}}^{a q}+C_{\mathrm{HS}^{+}}^{a q}+C_{\mathrm{HR}^{+}}^{a q}
$$

All the parameters of the model can be determined from independent measurements or obtained from literature. Complexation equilibrium constants $K_{R}$ and $K_{S}$ were determined by UV/Vis titration, the physical partitioning ratio was determined by equilibrium experiment without crown ether present, while dissociation constant of phenylglycinol $\left(\mathrm{pK}_{A}\right.$ of 8.5 [36]) and $\mathrm{CO}_{2}$ absorption parameters [37, 38] were taken from literature. 
Partitioning ratio. The partitioning ratio of phenylglycinol between the aqueous and organic phase strongly depends on the $\mathrm{pH}$ of the system. At low $\mathrm{pH}$, phenylglycinol is protonated and as such not soluble in the organic phase. Therefore the physical partitioning ratio can only be measured at high $\mathrm{pH}$. Since the overall partitioning effect is a result of partitioning of phenylglycinol in neutral form $\left(P_{a m}\right)$ and charged ammonium form $\left(P_{a m m o}\right)$, it can be represented as a linear combination of mentioned effects

$$
P_{\text {exp }}=x_{a m m o} \cdot P_{a m m o}+x_{a m} \cdot P_{a m}
$$

where mole fractions $x$ depend on the $\mathrm{pH}$ of the system and the $\mathrm{p} K_{A}$ of phenylglycinol. The partitioning of the ammonium form can be neglected and therefore the Henderson-Hasselbach equation [39] for amines can be used to describe the resulting effective partitioning $P_{\text {eff }}$ as a function of $\mathrm{pH}$.

$$
P_{\text {exp }}=x_{a m} \cdot P_{a m} \equiv x_{a m} \cdot P=P \cdot\left(1-\frac{1}{1+10^{p H-p K_{A}}}\right)
$$

In this research $P$ was measured at a $\mathrm{pH}$ of 11.5 and an aqueous to organic volume ratio of $1: 10$. The value of $P$ was found to be in the range of 0.02 to 0.04 . More accurate determination was not possible due to inaccuracy of the applied analytical method. For the modelling of the liquid - liquid equilibrium the average value of 0.03 was used.

Complexation constants. The typical UV/Vis titration experiment for determination of complexation constants between crown ether and phenylglycinol is shown in Figure 6.4. As the concentration of phenylglycinol increases, the peak at $550 \mathrm{~nm}$, which represents the complex, gets higher, while the peak at $400 \mathrm{~nm}$, characteristic for uncomplexed crown ether, gets lower. The same procedure was repeated for both enantiomers. The calculated complexation constants are $3.3 \pm 0.2 \times 10^{3}$ and $38.1 \pm$ $2.5 \times 10^{3}$ for the $\mathrm{S}$ and $\mathrm{R}$ enantiomer, respectively, which gives an intrinsic selectivity of 11.5 .

\section{Influence of the extractant concentration - Experimental results and model evaluation}

The influence of the crown ether concentration on the extraction performance has been studied at $25^{\circ} \mathrm{C}$ with no $\mathrm{pH}$ adjustment. The calculated distribution ratios $\mathrm{D}$ and operational selectivity $\alpha_{o p}$ are presented in Figure 6.5. It also shows that the model given by equations 6.1-6.18 predicts the experimental results quite good. A very good operational selectivity is already reached at a relatively low excess (2-3) in extractant 


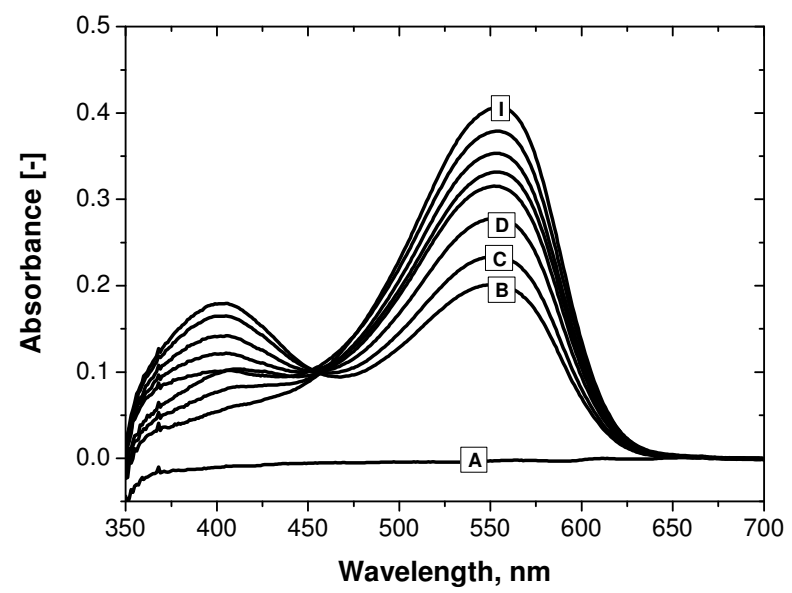

Figure 6.4: $U V$-Vis titration experiment for determination of the complexation constants between the crown ether and the $S$-enantiomer in 1-phenyloctane at $25^{\circ} \mathrm{C}$; for all samples: $0.015 \mathrm{mM} C E$, variable concentration of $S$-enantiomer. (A) baseline (pure water), (B) $0.10 \mathrm{mM}$, (C) $0.17 \mathrm{mM}$, (D) $0.31 \mathrm{mM}$, (E) $0.42 \mathrm{mM}$, (F) $0.53 \mathrm{mM},(G) 0.71 \mathrm{mM},(H) 0.90 \mathrm{mM}$, (I) $1.32 \mathrm{mM}$

concentration. Increasing its concentration results in a plateau value for the operational selectivity approaching the intrinsic selectivity $\alpha_{\text {int }}$. On the other hand, distribution ratios increase steadily with increasing crown ether concentration.

Compared to the results obtained by Steensma et al. [31] it can be concluded that the values of the complexation constants of the crown ether with the phenylglycinol enantiomers in 1-phenyloctane are higher and also show a higher intrinsic enantioselectivity compared to the results in the solvents dichloromethane and toluene ( $\alpha_{\text {int }}$ is 10 for both solvents [31]). However, due to the poor partitioning $(P=0.03)$ of phenylglycinol into 1-phenyloctane (dichloromethane: $P=0.6$; toluene $P=0.1$ [31]), the overall distribution ratio is somewhat lower.

\subsubsection{EIR equilibrium performance}

MPP particles were fully impregnated with a $10 \mathrm{mM}$ solution of crown ether in 1phenyloctane. The saturation capacity of MPP resins was determined to be $1.33 \mathrm{~cm}^{3}$ of 1-phenyloctane solution per gram of MPP; leading to the chiral selector's loading of $6.65 \mathrm{mmol} / \mathrm{kgEIR}$. A concentration of $10 \mathrm{mM}$ was selected to assure a sufficient sorption capacity for the impregnated resins. Competitive sorption isotherms of R- and S-phenylglycinol were determined and the results are presented in Figure 6.6. 


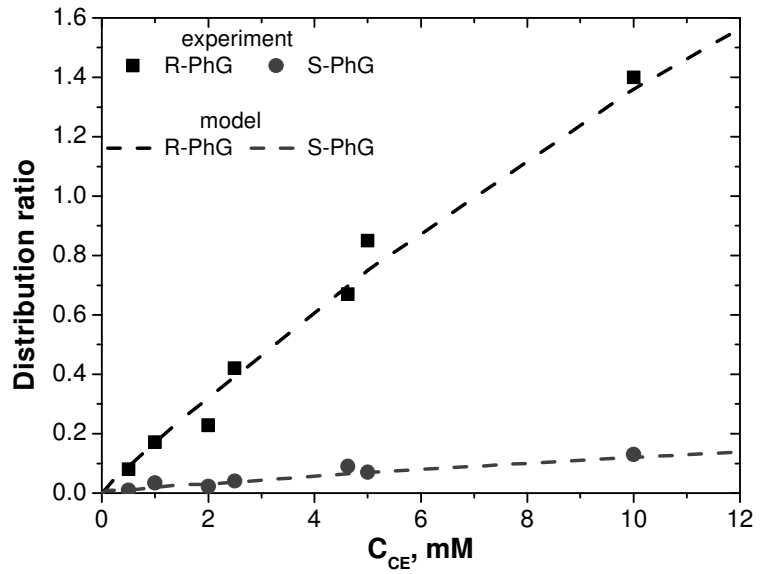

(a)

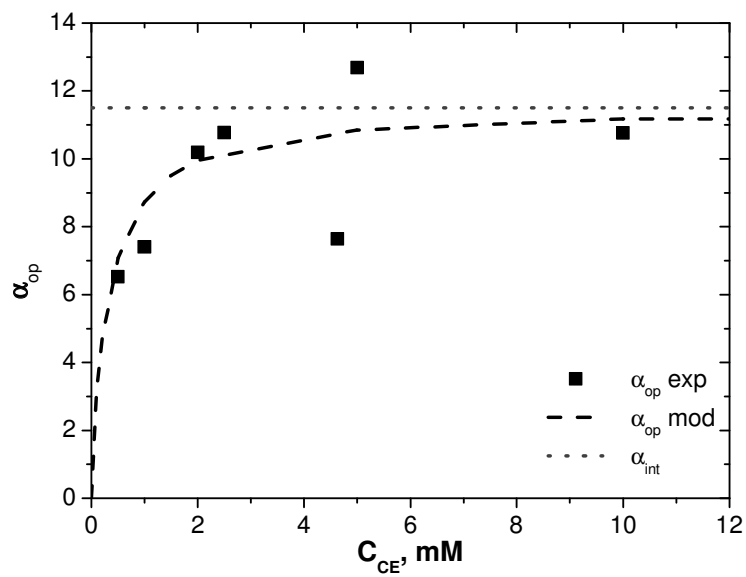

(b)

Figure 6.5: Influence of the crown ether concentration in 1-phenyloctane on the extraction of phenylglycinol, $[\mathrm{PhG}]_{\mathrm{rac}}=2 \mathrm{mM}, \mathrm{T}=25^{\circ} \mathrm{C}$. (a) distribution ratios, (b) operational selectivity 


\section{$112 \|$ Chapter 6}

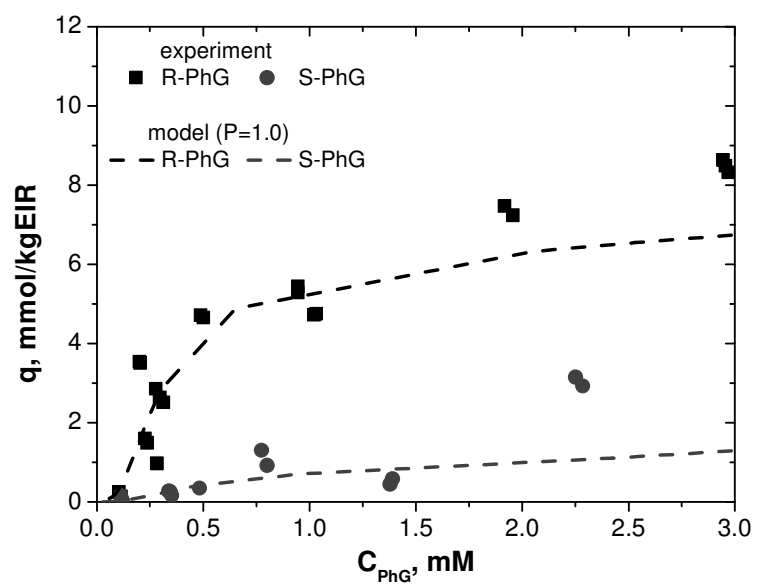

(a)

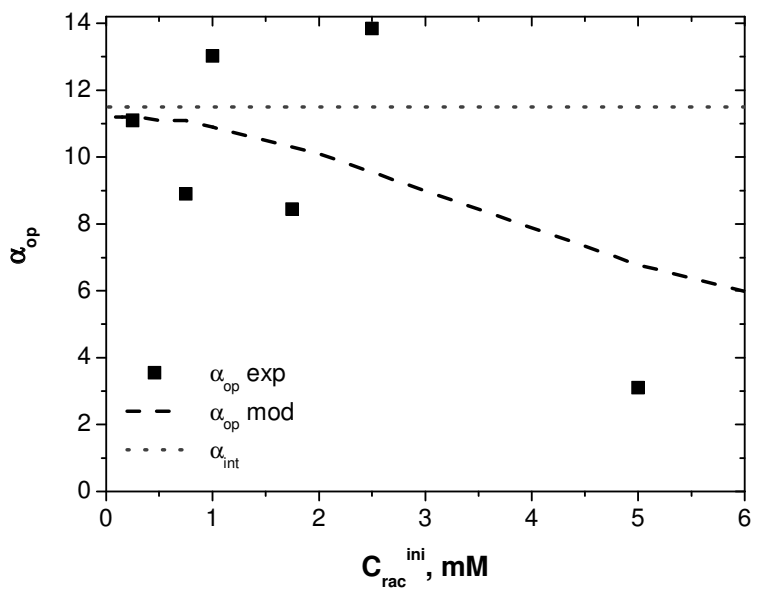

(b)

Figure 6.6: (a) Competitive sorption isotherms for $R$ and $S$ phenylglycinol, experimental results and model (with $P=1.0$ ) predictions; (b) Operational selectivity as a function of initial concentration of racemic mixture for a given amount of EIR particles $(0.5 \mathrm{~g})$ 
It shows the sorption capacity $q$, defined as the total amount of enantiomer, both free and complexed, retained in the particle per unit mass of EIR (eqs. 6.19 and 6.20) as a function of each enantiomer concentration in the water phase.

$$
\begin{gathered}
q_{R}=\frac{n_{\text {totalR }}^{\text {EIR }}}{m_{E I R}} \\
q_{S}=\frac{n_{\text {totalS }}^{\text {EIR }}}{m_{E I R}}
\end{gathered}
$$

The variable $n$ is the amount of enantiomer in mol and $m$ is the mass of EIR in kilogram.

From the presented results, it is clear that the sorption capacity of the R-enantiomer is much higher than for the S-enantiomer. In conclusion, this means that the crown ether inside the pores still remains enantioselective. To explain the obtained results, the model based on equilibria presented in Figure 6.3 was used. We assumed that the actual complexation happens in the liquid inside the pores and that we can consider the particle backbone as a "dead volume". Therefore the amount of enantiomer in the organic phase is equal to the amount of enantiomer in the EIR phase (eqs. 6.21 and $6.22)$.

$$
\begin{aligned}
& n_{\text {totalR }}^{\text {EIR }}=n_{\text {totalR }}^{\text {org }}=\left(C_{R}^{\text {org }}+C_{R C E}^{\text {org }}\right) \cdot V^{\text {org }} \\
& n_{\text {totals }}^{\text {EIR }}=n_{\text {totals }}^{\text {org }}=\left(C_{S}^{\text {org }}+C_{S C E}^{\text {org }}\right) \cdot V^{\text {org }}
\end{aligned}
$$

It follows that the model previously described (eqs. 6.1-6.16) can then be used to calculate the unknown equilibrium concentrations.

However, since first model calculations showed that the assumption of an inert particle backbone for the sorption is not realistic, the actual physical partitioning between aqueous and impregnated resin phase had to be determined separately. Therefore, the actual physical sorption was measured with particles impregnated with only 1-phenyloctane. The measurement was performed with two different initial concentrations of phenylglycinol in water, $0.3 \mathrm{mM}$ and $1.2 \mathrm{mM}$ and different particle to aqueous phase ratios at a $\mathrm{pH}$ of 12 by adding $\mathrm{NaOH}$. It was found that the physical partitioning ratio (parameter $\mathrm{P}$ of the model) is $1.0 \pm 0.2$, regardless of the initial concentration or phase (aqueous to organic) ratio, in the concentration range studied. Compared to pure liquid partitioning, this is an increase of about 30 times. It is possible that this effect is caused by the adsorption of phenylglycinol on the polymer surface. Therefore experiments were conducted with the empty resin to investigate adsorption capacity. However, due to the very low capacity and hence insufficient accuracy of the 


\section{$114 \|$ Chapter 6}

applied analytical method to determine small differences between the initial and the equilibrium concentration, that adsorption effect can not be measured with acceptable accuracy. Figure 6.6 shows that the EIR-model with a P value of 1.0 can predict the actual sorption isotherm rather well. The prediction of the model is especially good in the lower concentration region ( $<2 \mathrm{mM}$ phenylglycinol), while in the higher region the prediction is somewhat conservative. It might be that the solubility limit of the complex is exceeded and therefore precipitates i.e. it is "removed" from the system, which shifts the equilibrium towards the complex formation. However, the higher concentration region was not of interest for our further research and was not investigated in more detail.

Regarding selectivity, Figure 6.6 shows that the difference in the slope of the initial part of the two isotherms is rather high resulting in a high selectivity. According to the model, for a given amount of particles the selectivity (defined by eq. 6.10) approaches the value of the intrinsic selectivity in the initial concentration region. With the increase of the concentration of enantiomers in the aqueous phase the selectivity decreases. This can also be deducted from the shape of the isotherms.

\subsubsection{Column experiments}

The results of the column experiments are presented in Figure 6.7. The dimensionless outlet concentration is given as a function of bed volumes defined as volume of the solution fed to the unit volume of EIR particles. It is evident that the breakthrough curve for R enantiomer is not so sharp as the one of the $\mathrm{S}$ enantiomer (it is more gentle). This means that under the same conditions EIR has a stronger affinity towards R-phenylglycinol [40,41]. This agrees with the results of liquid-liquid and sorption equilibrium experiments (Figures 6.5 and 6.6). From the shape of the breakthrough profiles it can clearly be noticed that the phenylglycinol enantiomers can be separated using column packed with crown ether immobilized MPP resins.

The influence of the flow rate can be seen in Figure 6.7. As the flow rate decreases, the breakthrough curve of R enantiomer becomes less steep. At lower flow rates the contact time between the liquid solution and the EIR beads is longer leading to the higher amount of R enantiomer sorbed. On the other hand, for high enough flow rates (higher than $150 \mathrm{~cm} / \mathrm{h}$ ) its influence on the breakthrough curve diminishes. Opposite to the R enantiomer, the flow rates have considerably less influence on the breakthrough curve of $S$ enantiomer. Therefore, it can be concluded that the separation is better at lower flow rates.

Column stability. An important feature of a chromatographic column is stability, which is crucial for any application, especially for large scale industrial production. The molecular structure of the crown ether might indicate that its solubility in water 
can not be neglected. This might lead to leaching of the extractant and thus gradual loss of capacity. It was already shown [10] that the most of the leaching occurs after the first cycle when extractant adsorbed on the particle outer surface is washed away. Moreover, it was also proven that immobilization decreases the solubility for at least an order of magnitude [14]. In Figure 6.8 breakthrough profiles are represented after three cycles. It is evident that the profiles remain unchanged. This means that in this case there was no noticeable leaching of the extractant, opposite to the findings of Traving et al.[10]. Therefore, it can be expected that these resins will be rather stable. Nevertheless more detailed investigation regarding stability is needed.

Column regeneration. The scheme of the system equilibria presented in Figure 6.3 suggests that the particles can be regenerated by lowering the $\mathrm{pH}$ of the aqueous phase which will lead to the back shift of the equilibrium. The $\mathrm{pH}$ does not have to be reduced much. In this research, for the regeneration of the column, water with only atmospheric carbon dioxide dissolved was used. Figure 6.9 shows the elution profiles. It is evident that the column can be regenerated with moderately acidic solution with acceptable solvent consumption. The shape of the elution curves, i.e. larger tailing of the $\mathrm{R}$ enantiomer, proves once more that it is strongly retained on the column.

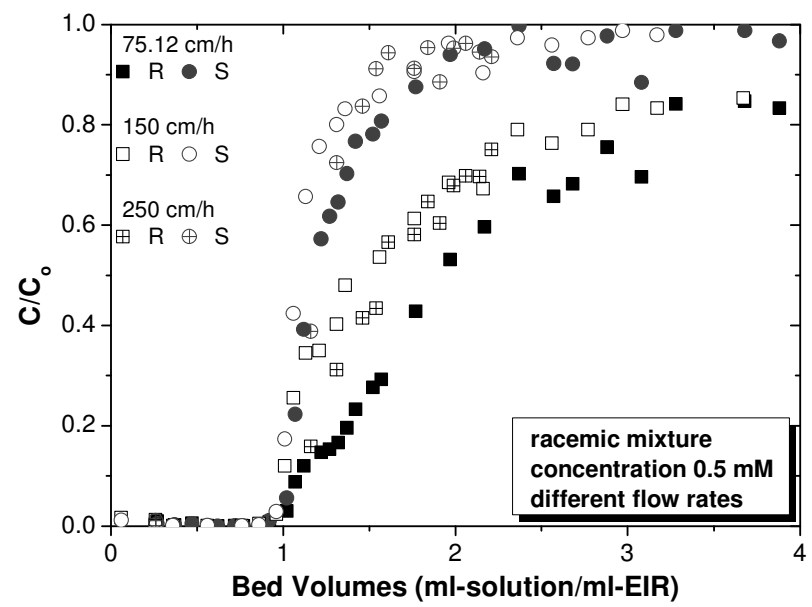

Figure 6.7: The influence of the flow rate on breakthrough profiles 


\section{$116 \|$ Chapter 6}

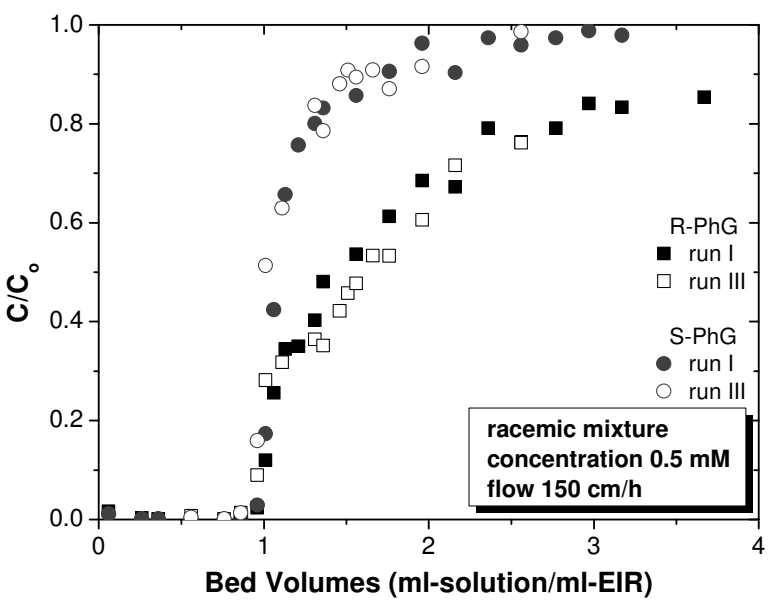

Figure 6.8: Column stability

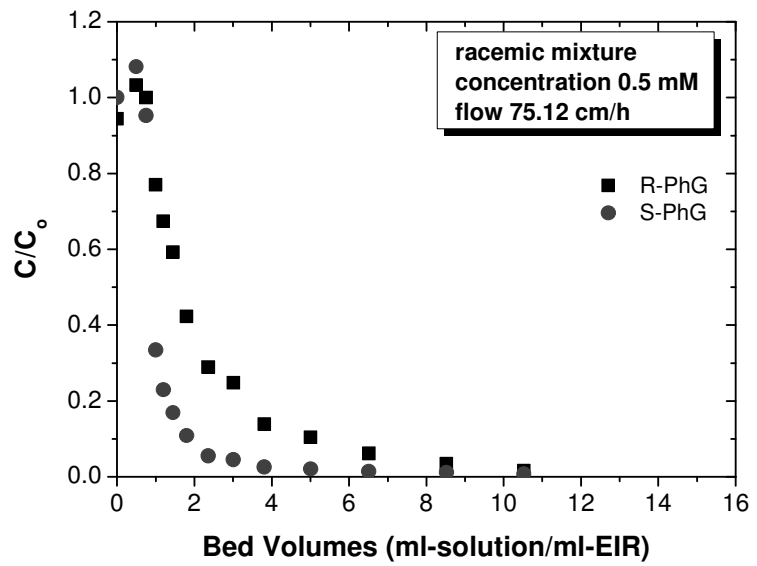

Figure 6.9: Elution profiles 


\title{
6.4 Conclusions
}

Extractant Impregnated Resins are a new, reduced cost technique for chiral separations. It was proven that enantiomers of phenylglycinol can be successfully separated using resins impregnated with a solution of azophenolic crown ether in 1-phenyloctane.

1-phenyloctane is a suitable solvent for this application because of its very low solubility in water. Moreover, crown ether remains enantioselective when dissolved in 1 -phenyloctane, with intrinsic selectivity of 11.5. However, due to very low solubility of phenylglycinol in 1-phenyloctane, the overall capacity of the crown ether solution in 1-phenyloctane is limited.

When immobilized in macroporous polypropylene particles this solution keeps its enantioselective complexation properties. The equilibrium selectivity of these EIRs approaches the intrinsic selectivity for low phenylglycinol concentrations. Competitive sorption equilibrium isotherms of $\mathrm{R}$ and $\mathrm{S}$ phenylglycinol can be successfully predicted by knowing the complexation constants and physical partitioning ratios, which can all be obtained from independent experiments.

Breakthrough profiles as well as the elution curves of the R enantiomer are much less sharp than those of the S enantiomer proving that the R enantiomer is strongly retained on the column. Separation of phenylglycinol enantiomers is favoured by using lower feed flow rates. The water with only atmospheric carbon dioxide dissolved proved to be sufficient for regeneration of the column. After several cycles breakthrough profiles remain unchanged meaning that there was no leaching of the chiral selector and thus can be expected that these EIRs will be sufficiently stable.

\section{Nomenclature}

\author{
Symbols \\ C concentration, $\mathrm{mol} / \mathrm{l}$ \\ $D \quad$ distribution ratio, defined by eqs. 6.8 and 6.9 \\ $\mathrm{He}_{\mathrm{CO}_{2}} \quad$ Henry's coefficient \\ $K_{R}, K_{S} \quad$ reaction equilibrium constant for the $\mathrm{R}$ and $\mathrm{S}$ enantiomer, $1 / \mathrm{mol}$ \\ $K_{A} \quad$ dissociation constant of phenylglycinol, mol/l \\ $K_{A 1}, K_{A 2}, K_{A 3}$ dissociation constants of carbonic acid \\ $n \quad$ amount of substance, mol \\ $p_{\mathrm{CO}_{2}} \quad$ partial pressure of carbon dioxide
}




\section{$118 \|$ Chapter 6}

$q \quad$ loading of the particle with enantiomer, defined by eqs. 6.19 and 6.20

V volume, 1

$x \quad$ molar fraction

$\alpha_{o p} \quad$ operational selectivity, defined by eq. 6.10

$\alpha_{\text {int }} \quad$ intrinsic selectivity, defined by eq. 6.11

$\rho_{w} \quad$ molar density of water

\section{Subscripts and superscripts}

aq aqueous

org organic

am amine form

ammo ammonium form

CE crown ether

eff effective

$\exp \quad$ experimental

$H R^{+}, H S^{+} \quad$ protonated enantiomers

mod model

$0 \quad$ initial

$P h G \quad$ phenylglycinol

$R, S \quad$ enantiomers

RCE, SCE complex between R or S enantiomer and crown ether

\section{References}

[1] N. Maier, P. Franco and W. Lindner. Separation of enantiomers: needs, challenges, perspectives. Journal of Chromatography A, 906, 3-33 (2001). 6.1

[2] E. Francotte. Enantioselective chromatography as a powerful alternative for the preparation of drug enantiomers. Journal of Chromatography A, 906, 379-397 (2001). 6.1

[3] A. Warshawsky. Extraction with Solvent-Impregnated Resins, volume 8 of Ion Exchange and Solvent Extraction, pages 229-310. Marcel-Dekker, New York (1981). 6.1

[4] J. L. Cortina and A. Warshawsky. Ion Exchange and Solvent Extraction, volume 13 of Ion Exchange and Solvent Extraction, chapter Developments in solid-liquid extraction by Solvent Impregnated Resins, pages 195-293. Dekker, New York (1997). 6.1

[5] R.-S. Juang. Preparation, properties and sorption behavior of impregnated resins 
containing acidic organophosphorus extractants. Proceedings of the National Science Council, Republic Of China, Part A: Physical Science and Engineering, 23(3), 353-364 (1999). 6.1

[6] H. Gao and Y. Su. Solvent extraction and adsorption by extracting resins of phenol. Huadong Huagong Xueyuan Xuebao, 17(3), 249-254 (1991). 6.1

[7] H. Kitazaki, M. Ishimaru, K. Inone, K. Yoshida and S. Nakamura. Separation and recovery of flavonoids by means of solvent extraction and adsorption on solventimpregnated resin. In Proceedings of the International Solvent Extraction Conference, ISEC'96, Melbourne, Australia, pages 1667-1672 (1996). 6.1

[8] R.-S. Juang and H.-L. Chang. Distribution equilibrium of citric acid between aqueous solutions and tri-n-octylamine-impregnated macroporous resins. Industrial and Engineering Chemistry Research, 34, 1294-1301 (1995). 6.1

[9] R.-S. Juang and T.-C. Chou. Sorption of citric acid from aqueous solutions by macroporous esins containing a tertiary amine - Equilibria. Separation Science and Technology, 31(10), 1409-1425 (1996). 6.1

[10] M. Traving and H.-J. Bart. Recovery of organic acids using ion-exchangerimpregnated resins. Chemical Engineering Technology, 5(10), 997-1003 (2002). $6.1,6.3 .3$

[11] M. O. Ruiz, J. L. Cabezas, I. Escudero, J. R. Alvarez and J. Coca. Valeric acid extraction with tri-N-butyl phosphate impregnated in a macroporous resin. I. Equilibrium and mass transfer rates. Separation Science and Technology, 39(1), 77-95 (2004). 6.1

[12] M. O. Ruiz, J. L. Cabezas, I. Escudero, J. R. Alvarez and J. Coca. $\alpha$-Phenylglycine extraction with a trialkylmethylammonium chloride-impregnated macroporous resin. 1. Equilibrium. Trans IChemE, 40(A), 529-536 (2002). 6.1

[13] A. Kostova and H.-J. Bart. Reactive sorption of L-phenylalanine by polymers impregnated with cation exchangers (Equilibria). Chemie-Ingenieur-Technik, 76(11), 1743-1748 (2004). 6.1

[14] K. Babić, L. van der Ham and A. de Haan. Recovery of benzaldehyde from aqueous streams using extractant impregnated resins. Reactive and Functional Polymers, 66(12), 1494-1505 (2006). 6.1, 6.3.3

[15] Y. Guan, X. Wu and G. Wu. The preparation of solvent impregnated resins and their application to the isolation of spiramycin. Chinese Journal of Antibiotics, 15(2), 90-96 (1990). 6.1

[16] L. Sousa, G. Sogah, D. Hoffman and D. Cram. Host-guest complexation. 12. Total optical resolution of amine and amino ester salt by chromatography. Journal of American Chemical Society, 100(14), 4569-4576 (1978). 6.1 
[17] G. Sogah and D. Cram. Host-guest complexation. 14. Host covalently bound to polystyrene resin for chromatographic resolution of enantiomers of amino acid and ester salt. Journal of American Chemical Society, 101(11), 3035-3042 (1979). 6.1

[18] Y. Machida, H. Nishi, K. Nakamura, H. Nakai and T. Sato. Enantiomer separation of amino compounds by a novel chiral stationary phase derived from crown ether. Journal of Chromatography A, 805, 85-92 (1998). 6.1

[19] M. Hyun, S. Han, B. Lipschutz, Y.-J. Shin and C. Welch. Liquid chromatographic resolution of racemic amines, amino-alcohols and related compounds on a chiral crown ether stationary phase. Journal of Chromatography A, 959, 75-83 (2002). 6.1

[20] M. Hyun, J. Jin, H. Koo and W. Lee. Liquid chromatographic resolution of racemic amines and amino alcohols on a chiral stationary phase derived from crown ether. Journal of Chromatography A, 837, 75-82 (1999). 6.1

[21] K. Hirose, K. Ogasahara, K. Nishioka, Y. Tobe and K. Naemura. Enantioselective complexation of phenolic crown ethers with chiral aminoethanol derivatives: effect of substituents of aromatic rings of hosts and guests on complexation. Journal of Chemical Society, Perkin Transactions, 2, 1984-1993 (2000). 6.1

[22] K. Hirose, J. Yongzhu, T. Nakamura, R. Nishioka, T. Ueshige and Y. Tobe. Chiral stationary phase covalently bound with a chiral pseudo-18-crown-6 ether for enantiomer separation of amino compounds using a normal mobile phase. Chirality, 17, 142-148 (2005). 6.1

[23] K. Hirose, J. Yongzhu, T. Nakamura, R. Nishioka, T. Ueshige and Y. Tobe. Preparation and evaluation of a chiral stationary phase covalently bound with chiral pseudo-18-crown-6 ether having 1-phenyl-1,2-cyclohexanediol as a chiral unit. Journal of Chromatography A, 1078, 35-41 (2005). 6.1

[24] K. Hirose, T. Nakamura, R. Nishioka, T. Ueshige and Y. Tobe. Preparation and evaluation of novel chiral stationary phases covalently bonded with chiral pseudo-18-crown-6 ethers. Tetrahedron Letters, 44, 1549-1551 (2003). 6.1

[25] K. Naemura, K. Nishioka, K. Ogasahara, Y. Nishikawa, K. Hirose and Y. Tobe. Preparation and temperature-dependent enantioselectivities of homochiral phenolic crown ethers having aryl chiral barriers: Thermodynamic parameters for enantoselective complexation with chiral amines. Tetrahedron: Asymmetry, 9, 563-574 (1998). 6.1, 6.2.1

[26] T. Shinbo, T. Yamaguchi, H. Yanagishita, K. Sakaki, D. Kitamoto and M. Sugiura. Supported liquid membranes for enantioselective transport of amino acid mediated by chiral crown ether - Effect of membrane solvent on transport rate and membrane stability. Journal of Membrane Science, 84, 241-248 (1993). 6.1 
[27] M. Pietraszkiewicz, M. Kozbial and O. Pietraszkiewicz. Chiral discrimination of amino acids and their potassium or sodium salts by optically active crown ether derived from D-mannose. Journal of Membrane Science, 138, 109-113 (1998). 6.1

[28] M. Kozbial, M. Pietraszkiewicz and O. Pietraszkiewicz. Chiral discrimination of amino acids by an optically active crown ether studied by HPLC, extraction and liquid membrane transport experiments. Journal of Inclusion Phenomena and Molecular Recognition in Chemistry, 30, 69-77 (1998). 6.1

[29] J. Clark, B. Han, A. Bhown and S. Wickramasinghe. Amino acid resolution using supported liquid membranes. Separation and Purification Technology, 42, 201-211 (2005). 6.1

[30] M. Steensma, N. J. M. Kuipers, A. B. de Haan and G. Kwant. Identification of enantioselective extractants for chiral separation of amines and aminoalcohols. Chirality, 18, 314-328 (2006). 6.1

[31] M. Steensma, N. J. M. Kuipers, A. B. de Haan and G. Kwant. Influence of process parameters on extraction equilibria for the chiral separation of amines and amino-alcohols with chiral crown ether. Journal of Chemical Technology and Biotechnology, 81, 588-597 (2006). 6.1, 6.2.2, 6.2.4, 6.3.1, 6.3.1

[32] V. Davankov. Chiral selectors with chelating properties in liquid chromatography: fundamental reflections and selective review of recent developments. Journal of Chromatography A, 666, 55-76 (1994). 6.1

[33] K. Hirose. A practical guide for the determination of binding constants. Journal of Inclusion Phenomena and Macrocyclic Chemistry, 39, 193-209 (2001). 6.2 .4

[34] R. Scott. Some comments on the Benesi-Hildebrand equation. Recueil des Travaux Chimiques des Pays-Bas, 75, 787-789 (1956). 6.2 .4

[35] N. Rose and R. Drago. Molecular addition compounds of iodine. I. An absolute method for the spectroscopic determination of equilibrium constants. Journal of American Chemical Society, 81, 6138-6141 (1959). 6.2.4

[36] F. Hein and F. Meier. Zur Kenntnis der Isomeren C-phenyl-äthanolamine und ihrer N,N-diäthyl-Derivate. Zeitschrift für anorganische und allgemeine Chemie, 376(3), 296 - 302 (1970). 6.3.1

[37] A. Saha and S. Bandyopadhyay. Solubility and diffusivity of $\mathrm{N}_{2} \mathrm{O}$ and $\mathrm{CO}_{2}$ in aqueous solutions of 2-amino-2-methyl-1-propanol. Journal of Chemical Engineering Data, 38, 78-82 (1993). 6.3.1

[38] D. Skoog, D. West, F. Holler and S. Crouch. Analytical chemistry-an introduction. Harcourt Inc., Orlando, 7th edition edition (2000). 6.3.1

[39] E. Schlichting, W. Halwachs and K. Schügerl. Reactive extraction of salicylic acid and D,L-phenylalanine in a stirred cell. Chemical Engineering Communications, 51, 193-205 (1987). 6.3.1 


\section{$122 \| \quad$ Chapter 6}

[40] R. Juang and S. Lee. Column separation of divalent metals from sulfate solutions using impregnated resins containing di(2-ethylhexyl)phosphoric acid. Reactive and Functional Polymers, 29, 175-183 (1996). 6.3.3

[41] R. Juang and S. Lee. Column sorption of divalent metals from sulfate solutions by extractant-impregnated macroporous resins. Journal of Chemical Technology and Biotechnology, 66, 153-159 (1996). 6.3 .3 


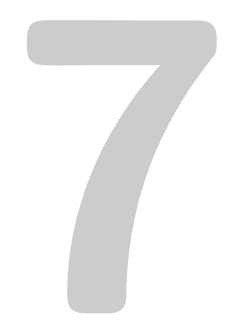

\section{Conclusions and recommendations}

The goal of this research was to explore the possibilities for the application of Extractant Impregnated Resins (EIRs) for the separation of polar organic substances from aqueous streams. The research focused on the separation of aldehydes and on the chiral resolution of amino-alcohols. In both cases, the application of Extractant Impregnated Resins appeared very promising. 



\subsection{Conclusions}

\subsubsection{Recovery of aldehydes}

$\mathrm{E}$

XTRACTANT IMPEGNATED RESINS are a viable technology for recovery of aldehydes from aqueous solutions. The applicability was first proven for benzaldehyde and subsequently successfully extended to various other aldehydes of different molecular structure.

Branched aliphatic primary amines are proven to be high capacity extractants for aldehydes and being liquid at room conditions, suitable for application in EIR technology. A commercially available C18-20 branched aliphatic primary amine, Primene JM-T, was identified in liquid-liquid extraction experiments, as a suitable extractant. The overall extraction performance of the Primene ${ }^{\circledast} \mathrm{JM}-\mathrm{T}$ depends highly on the molecular structure of the aldehyde. A higher initial concentration of the amine results in a higher overall distribution ratio, while for a higher initial concentration of aldehyde, the distribution ratio is lower. Both effects are observed for all the temperatures studied. The influence of the temperature on the reactive equilibrium is highly dependent on the system studied. This means that regeneration by temperature shift seems most likely only possible for linear aldehydes and that other means of regeneration need to be found for other aldehydes.

Addition of an extractant significantly increases adsorption capacity of otherwise very poor adsorbents, as shown for the case of MPP and Stamypor particles. Particles with the highest porosity (Amberlite XAD-16) can retain the highest amount of extractant, resulting in the highest capacity for the solute's recovery. The molecular structure of the aldehyde displayed a large influence on the overall sorption capacity. The influence of the temperature on the overall sorption capacity corresponds to what was observed for the reactive liquid-liquid system.

Sorption kinetics is controlled by both diffusion inside the particle and chemical reaction. Particle morphology and the support material do influence the sorption rate. The effective diffusivity of aldehydes is faster in less hydrophobic particles i.e. faster in XAD-16 than in MPP impregnated particles. For both EIRs the same value of the reaction rate constant was obtained, suggesting that the immobilized reactant behaves as in bulk liquid. The effect of particle size effect on the kinetics is dominated by the diffusion time constant which is inversely proportional to the square of the radius of the particle $\left(R^{2}\right)$.

The sorption process (both equilibrium and kinetics) was modelled based on the analogy with the liquid-liquid extraction. Based on the known liquid-liquid behaviour, the equilibrium sorption isotherms of extractant impregnated resins could be successfully predicted for most of the aldehydes. The sorption kinetics in the EIR could be modelled by using the analogy with diffusion and reaction in a stagnant liquid 
sphere when correcting for the porosity and particle properties influencing the diffusion. The effect of initial aldehyde concentration, extractant loading and particle size on the sorption rate is well described. The developed model performs best in the low aldehyde concentration region.

The reduction of the extractant solubility in water indicates that immobilization increases the stability of EIRs with regard to extractant loss due to the leakage in water significantly. It is not clear yet whether this is sufficient for long term operation or if additional measures need to be taken.

\subsubsection{Chiral separation of amino-alcohols}

It was demonstrated that resins impregnated with a solution of azophenolic crown ether in 1-phenyloctane (intrinsic selectivity of 11.5) are promising materials for the separation of the enantiomers of phenylglycinol. Due to the very low solubility of phenylglycinol in 1-phenyloctane, the overall capacity of the crown ether solution in 1-phenyloctane is limited. When immobilized in macroporous polypropylene particles the crown ether solution keeps its enantioselective complexation properties. The equilibrium selectivity of these EIRs approaches the intrinsic selectivity for low phenylglycinol concentrations. Breakthrough profiles as well as the elution curves of both enantiomers demonstrated that the $\mathrm{R}$ enantiomer is more strongly retained on the column. Water containing only atmospheric carbon dioxide proved to be sufficient for column regeneration. After several cycles breakthrough profiles remain unchanged indicating that these EIRs will be sufficiently stable for industrial application.

\subsection{Recommendations for future work}

\subsubsection{Recovery of aldehydes}

The applicability of EIRs for the recovery of aldehydes was successfully proven. However, for successful industrial application several key issues need further attention:

- EIR regeneration

- EIR stability

- multicomponent sorption behaviour

- effect of porous support

Regeneration of the EIR particles is essential. In this thesis a temperature shift was explored as a potential regeneration method, but with limited success. Therefore, 
other regeneration options should be tested, like for example a $\mathrm{pH}$ shift. It is known that the reaction between amines and aldehydes is $\mathrm{pH}$ dependent [1-3]. However, attention should be paid to the stability of EIRs in this case and it should be prevented that the extractant is washed away at extreme $\mathrm{pH}$ conditions. Once a suitable regeneration method is identified, the dynamic behaviour of EIRs should be investigated in column experiments, in fixed or fluidized bed.

In this research it was proven that the resins impregnated with bulky extractants are relatively stable, especially having in mind that the impregnation reduces the solubility in water. However, the operational stability should be investigated in more detail. Multiple sorption and washing steps should be repeated to determine the stability of the system over longer time. In case proven that the stability is not sufficient for successful application, the optimal stabilization technique should be identified and the performance of stabilized EIRs evaluated. There are several techniques described in literature to achieve this [4-6].

In the present research only single solute isotherms were determined. In future research, more complex mixtures should be investigated, either containing various aldehydes or various other organic components. It is possible that in mixtures containing more acidic components the selectivity of resins impregnated with primary amines towards aldehydes will not be favourable.

In this research resin beads were used as a solid support. Some other types of supports like monoliths or porous fibers can also be evaluated. Furthermore the influence of the polymeric support material is proven to be significant for the sorption of benzaldehyde. This interaction should be investigated in more detail in order to gain more insight on how to tune the support to increase the capacity and selectivity of EIRs. Better understanding of this effect will allow development of a more accurate predictive model.

\subsubsection{Chiral separations}

The potential feasibility of Extractant Impregnated Resins for the separation of phenylglycinol enantiomers has been demonstrated. To be of sufficient economical interest however, the capacity of the resins impregnated with a solution of azophenolic crown ether in 1-phenyloctane for the separation should be improved. This can be achieved by introducing more crown ether in the particle which is however limited by its solubility in 1-phenyloctane. Therefore, an alternative solvent that can dissolve more crown ether but still preserve its chiral selectivity should be identified and tested. It is possible that reducing the number of carbon atoms on the side chain of the solvent can have a desirable effect. However, the optimum should be achieved between the solubility of crown ether in the solvent and the solvent's solubility in water. Additionally, the structure of crown ether might be adapted to allow better solubility in 


\section{8 || Chapter 7}

1-phenyloctane and lower its solubility in water.

The stability of the EIRs was investigated in the column experiments with only a limited number of runs. For industrial application it is necessary to investigate the longer term stability of these EIRs more extensively. Finally, these stable EIRs should be tested in larger scale production equipment. In that respect, simulated moving bed [7] or similar multicolumn [8] techniques should be evaluated.

To achieve a baseline resolution of enantiomers the process should be optimized to minimise the column effects. In order to do so, a predictive model of the dynamic operation should be developed. The model can be constructed based on the data presented in this research as well as the data obtained from the literature regarding kinetics [9] and column correlations [10]. The model should be used to identify the optimal process conditions for both analytical resolution of the enantiomers and the preparative chromatographic operation.

\section{References}

[1] R. Martin. Reactions of carbonyl compounds with amines and derivatives. Journal of Physical Chemistry, 68(6), 1369-1377 (1964). 7.2.1

[2] E. Cordes and W. Jencks. On the mechanism of Schiff base formation and hydrolysis. Journal of American Chemical Society, 84(5), 832-837 (1962). 7.2.1

[3] E. Cordes and W. Jencks. The mechanism of hydrolisis of Schiff bases derived from aliphatic amines. Journal of American Chemical Society, 85(18), 2843-2848 (1963). 7.2.1

[4] D. Muraviev, L. Ghantous and M. Valiente. Stabilization of solvent-impregnated resin capacities by different techniques. Reactive and Functional Polymers, 38, 259-268 (1998). 7.2.1

[5] S. Alexandratos and K. Ripperger. Synthesis and characterization of high-stability solvent-impregnated resins. Industrial and Engineering Chemistry Research, 37, 4756-4760 (1998). 7.2.1

[6] A. Trochimczuk, N. Kabay, M. Arda and M. Streat. Stabilization of solvent impregnated resins (SIRs) by coating with water soluble polymers and chemical crosslinking. Reactive and Functional Polymers, 59, 1-7 (2004). 7.2.1

[7] A. Rodrigues and L. Pais. Chiral Separation Techniques, chapter Modeling and simulation in SMB for chiral purification, pages 219-251. Wiley-VCH Verlag $\mathrm{GmbH}$, second edition (2001). 7.2.2

[8] L. Aumann and M. Morbidelli. A continuous Multicolumn Countercurrent Solvent Gradient Purification (MCSGP) process. Biotechnology and Bioengineering, 98(5), 1043-1055 (2007). 7.2.2 
[9] M. Steensma, N. J. M. Kuipers, A. B. de Haan and G. Kwant. Modelling and experimental evaluation of reaction kinetics in reactive extraction for chiral separation of amines, amino acids and amino-alcohols. Chemical Engineeing Science, 62(5), 1395-1407 (2007). 7.2.2

[10] G. Guiochon, A. Felinger, D. Shirazi and A. Katti. Fundamentals of preparative and nonlinear chromatography. Elsevier Inc., second edition (2006). 7.2.2 



\section{List of publications and conference contributions resulted from this thesis}

Journal publications

1. K. Babić, L. van der Ham, and A. de Haan. Recovery of benzaldehyde from aqueous streams using extractant impregnated resins. Reactive and Functional Polymers, 66(12), 1494-1505 (2006).

2. K. Babić, A. G. J. van der Ham, and A. B. de Haan. Reactive extraction of aldehydes from aqueous solutions with Primene ${ }^{\circledR}$ JM-T. Submitted to Separation and Purification Technology.

3. K. Babić, A. G. J. van der Ham, and A. B. de Haan. Sorption equilibrium for the removal of aldehydes from aqueous streams with Primene ${ }^{\circledast}$ JM-T impregnated resins. Manuscript in preparation.

4. K. Babić, A. G. J. van der Ham, and A. B. de Haan. Sorption kinetics for the removal of aldehydes from aqueous streams with extractant impregnated resins. Adsorption, accepted for publication.

5. K. Babić, G. H. M. Driessen, A. G. J. van der Ham, and A. B. de Haan. Chiral separation of amino-alcohols using extractant impregnated resins. Journal of Chromatography A, 1142,84-92 (2007).

\section{Reviewed conference proceedings}

1. K. Babić, A. G. J. van der Ham, and A. B. de Haan. Functionalised solvent impregnated resins for the removal of aldehydes from aqueous streams. In Proceedings of ISEC 2005, Beijing, China, pages 1517-1522 (2005).

2. K. Babić, A. G. J. van der Ham, and A. B. de Haan. Extractant impregnated resin technology for the recovery of aldehydes from aqueous streams. In Proceedings of ISEC 2008, Tucson, Arizona, USA (2008). 
132 List of publications and conference contributions

\section{Conference presentations}

- 2007

- Oral presentation titled "Sorption kinetics for the removal of aldehydes from aqueous streams with extractant impregnated resins" at Fundamentals of Adsorption 9 (FOA9), Giardini Naxos, Italy

- 2006

- Oral presentation titled "Evaluation of extractant impregnated resin technology for chiral separation of amino-alcohols" at Nederlands Procestechnologie Symposium NPS 6, Eindhoven, the Netherlands

- Poster presentation titled "Chiral separation of amino-alcohols using extractant impregnated resins" at Symposium on Preparative and Industrial Chromatography and Allied Techiques (SPICA 2006), Innsbruck, Austria

- Oral presentation titled "Chiral separation of amino-alcohols using extractant impregnated resins" at Preparative Chromatography Conference PREP 2006, Baltimore, USA

- 2005

- Oral presentation titled "Functionalized solvent impregnated resins for the removal of aldehydes from aqueous streams" at the International Solvent Extraction Conference (ISEC) 2005, Beijing, China

- 2004

- Oral presentation titled "Solvent impregnated resin technology for the removal of aldehydes from aqueous solutions" at PRO3 Symposium, Kaiserslautern, Germany 


\section{About the author}

Katarina Babić was born on May 17th 1979 in Belgrade, Serbia. After completing her secondary education in the Gymnasium with a general orientation where she graduated in both humanistic and natural sciences, she enrolled in chemical engineering studies at the Faculty of Technology and Metallurgy at Belgrade University. During the studies she also volunteered in an IAESTE (the International Association for the Exchange of Students for Technical Experience) subcommittee, helping foreign students during their internship.

In April 2002 she came to the Separation Technology group of the University of Twente in the Netherlands to do a master project titled "Recovery of benzoic acid extracted from organic solution into water by carbon dioxide under pressure". The research involved an equilibrium study of the benzoic acid extraction in a pressurized autoclave.

In April 2003, she started a PhD project in the same group, titled "Extractant Impregnated Resins for the recovery of aldehydes and chiral separation". This research focused on the development of a hybrid separation technique, a synergistic combination of extraction and adsorption, and its application for the separation of polar organics from aqueous solutions. Key issues like equilibrium, kinetics and stability of impregnated resins were addressed. This research was presented in a number of recognized international conferences and resulted in several publications in journals highly recognized within the research community.

Since July 2007, she is working in SABIC, a petrochemical company, whose European branch is situated in Sittard, the Netherlands. She is a member of a Process Technology group in the Research and Development department. At present she is responsible for a number of process development and optimization projects. 